University of Louisville ThinkIR: The University of Louisville's Institutional Repository

Electronic Theses and Dissertations

$12-2015$

\title{
The effect of the patient protection and Affordable Care Act on the Medicare Part D coverage gap as reflected in diabetes medication adherence.
}

Jennifer A. Forristal

University of Louisville

Follow this and additional works at: https://ir.library.louisville.edu/etd

Part of the Other Public Health Commons

\section{Recommended Citation}

Forristal, Jennifer A., "The effect of the patient protection and Affordable Care Act on the Medicare Part D coverage gap as reflected in diabetes medication adherence." (2015). Electronic Theses and Dissertations. Paper 2315.

https://doi.org/10.18297/etd/2315

This Doctoral Dissertation is brought to you for free and open access by ThinkIR: The University of Louisville's Institutional Repository. It has been accepted for inclusion in Electronic Theses and Dissertations by an authorized administrator of ThinkIR: The University of Louisville's Institutional Repository. This title appears here courtesy of the author, who has retained all other copyrights. For more information, please contact thinkir@louisville.edu. 


\title{
THE EFFECT OF THE PATIENT PROTECTION AND
}

\author{
AFFORDABLE CARE ACT ON THE MEDICARE PART D \\ COVERAGE GAP AS REFLECTED IN DIABETES \\ MEDICATION ADHERENCE
}

\author{
By \\ Jennifer A Forristal

\begin{abstract}
A Dissertation
Submitted to the Faculty of the

School of Public Health and Information Sciences of the

University of Louisville in Partial Fulfillment of the

Requirements for the Degree of

Doctor of Philosophy in Public Health Sciences
\end{abstract} \\ Department of Health Management and Systems Sciences \\ University of Louisville \\ Louisville, Kentucky
}

December 2015 



\section{THE EFFECT OF THE PATIENT PROTECTION AND AFFORDABLE CARE ACT ON THE MEDICARE PART D COVERAGE GAP AS REFLECTED IN DIABETES MEDICATION ADHERENCE}

By

Jennifer A Forristal

A Dissertation Approved on

November 18, 2015

By the following Dissertation Committee

Dissertation Director

Barry Wainscott, M.D., MPH

Robert Esterhay, M.D.

Christian Furman, M.D., MSPH

LaQuandra Nesbitt, M.D., MPH 


\section{DEDICATION}

This is dedicated to my parents who instilled in me a love of learning and the importance of education. 


\section{ACKNOWLEDGEMENTS}

I would like to thank my committee for their support, insight and constructive criticism throughout this process. I am very grateful to Humana for the use of their data. I want to acknowledge William Fleming for his advice, Fred Brownfield for his support and Yihau $\mathrm{Xu}$ for her guidance.

I would like to thank my family for their love and support during this process especially my husband, Jamieson and kids, Tyler and Addison, who sacrificed many nights and weekends so I could focus on this work. My parents, Dave and Kathy Dively and siblings, Daniel and Julie have always been a source of strength and encouragement.

I would like to thank my friends who have supported me in every endeavor, especially Cyndi, Charlotte, Christine and Megan. I would like to thank all my fellow

public health students who suffered right along with me: Robin, Robyn, Katie, Christine, Susan and Leslie, you are truly some of the smartest women I know.

I am blessed.

Ecclesiastes 12:12 


\begin{abstract}
THE EFFECT OF THE PATIENT PROTECTION AND

AFFORDABLE CARE ACT ON THE

MEDICARE PART D COVERAGE GAP AS REFLECTED IN

DIABETES MEDICATION ADHERENCE
\end{abstract}

Jennifer Forristal

November 18, 2015

Background: This dissertation involves an evaluation of the effect of the Patient

Protection and Affordable Care Act (ACA) on diabetic medication adherence as the Medicare Part D coverage gap begins to close.

Purpose: The dissertation's primary research question: will medication adherence for Humana Medicare Part D health plan members filling diabetic medications at Humana's mail order pharmacy improve as the coverage gap is incrementally closed due to the ACA? The study had 3 objectives: 1) to evaluate diabetes medication adherence of health plan members before they reach the coverage gap and then while they are in the coverage gap, 2) to compare diabetes medication adherence between two similar groups with differing benefit structures, one group with a gap in coverage as opposed to a group with no benefit changes within the year and 3) to examine diabetes medication adherence trend over multiple years as the coverage gap is closed.

Methods: A retrospective, pre-post cohort analysis with control group study design was used to assess the study objectives. The control group consisted of low- 
income subsidy (LIS) members with no gap in coverage and the treatment group reached the coverage gap.

Results: Brand and generic medication users exhibited decreases in adherence once they entered the coverage gap although significant differences were seen for all years in the brand cohort only. The control group exhibited better adherence than the treatment group. The control group also exhibited stable adherence year over year while the treatment group realized a decline.

Conclusions: The results of this study indicate that being in the coverage gap was a significant indicator of a decrease in adherence for health plan members on brand diabetic medications. While the study findings showed a decrease rather than an increase in the treatment group medication adherence year over year, the results did indicate no significant changes in the control group. The expectation would be that once the coverage gap is fully closed in 2020, the treatment group would exhibit similar behavior. Both groups exhibited high adherence overall suggesting the mail order dispensing channel could have an effect on adherence. 


\section{TABLE OF CONTENTS}

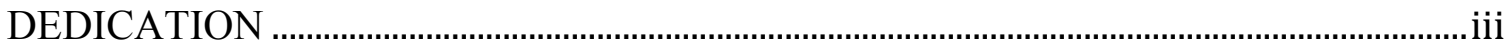

ACKNOWLEDGEMENTS ........................................................................................................ iv

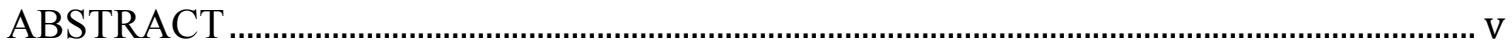

LIST OF TABLES ……………………………………………………………………... ix

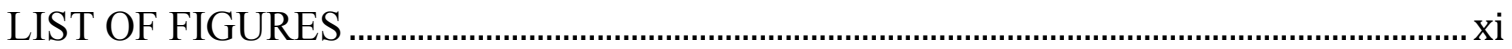

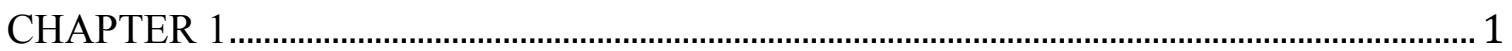

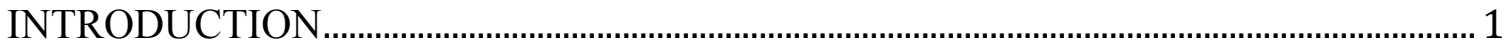

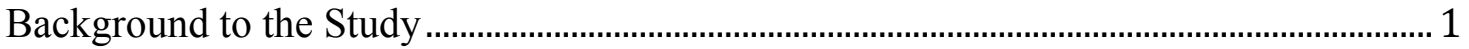

The Importance of Adherence in Public Health ..................................................................... 2

The Importance of Adherence in Diabetes......................................................................... 5

The Medicare Modernization Act of 2003 ......................................................................... 10

The Patient Protection and Affordable Care Act ............................................................... 11

The Effect of Cost-Sharing and Copayments on Adherence ............................................. 12

Proposed Reform Effects ............................................................................................... 15

Statement of the Problem................................................................................................... 16

Purpose of the Study ........................................................................................................ 17

Research Question and Hypotheses................................................................................ 18

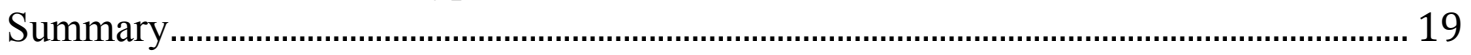

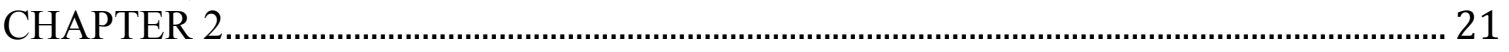

LITERATURE REVIEW ……………………………………………………………... 21

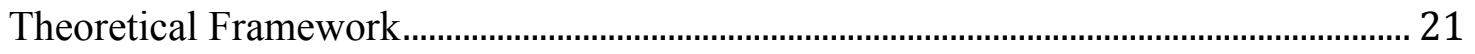

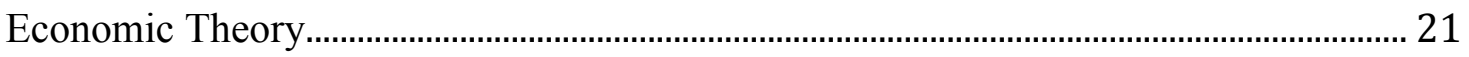

Andersen's Behavioral Model of Health Services Use...................................................... 23

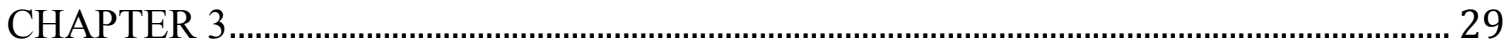

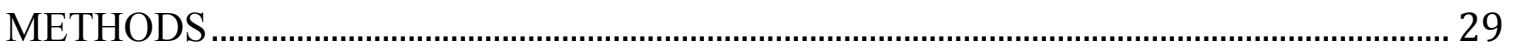

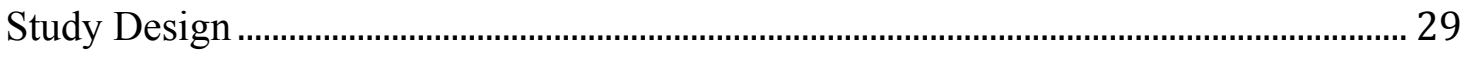

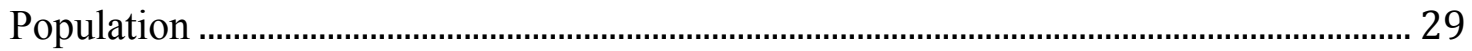

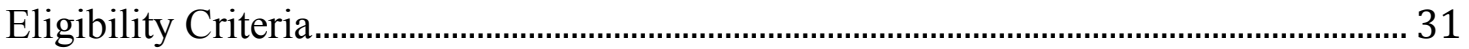

Description of study variables .............................................................................................. 33

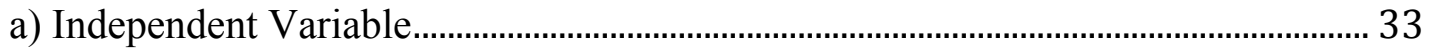

b) Dependent Variable or Outcome Measure................................................................... 36

Propensity Score Matching.................................................................................................. 39

Data analyses required to address objectives: ............................................................. 41

Confidentiality ................................................................................................................... 43

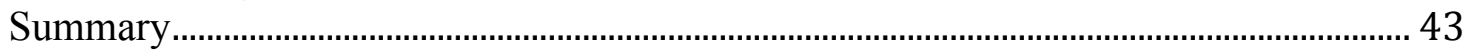

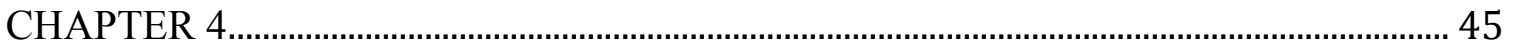

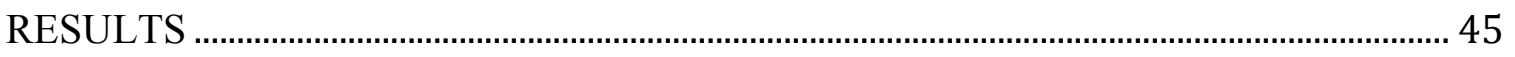

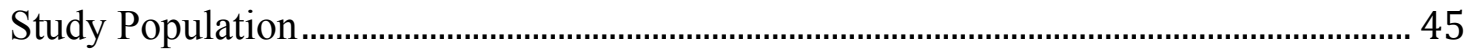

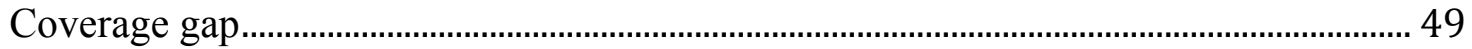

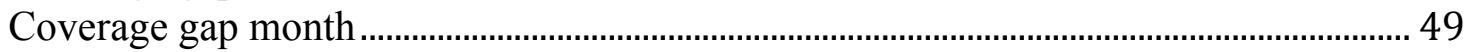

Descriptive analyses of pre-coverage gap and within coverage gap medication

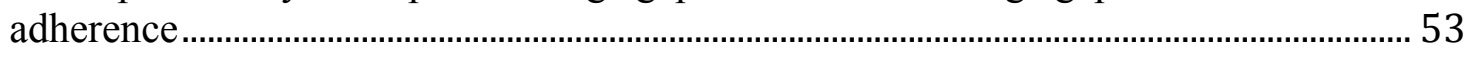

Propensity score matching.............................................................................................. 56

Descriptive analyses of propensity score matched control and treatment groups.......... 63 


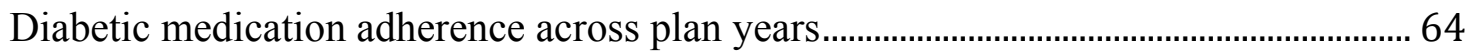

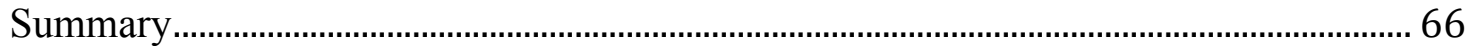

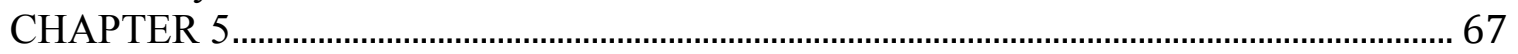

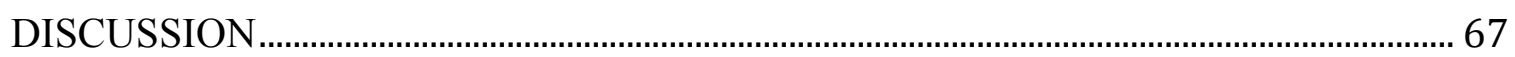

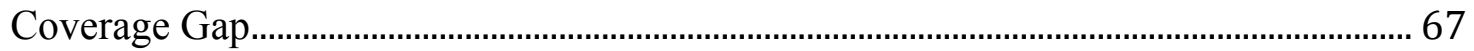

Pre-coverage gap and within coverage gap medication adherence................................... 72

Demographics for propensity score matched groups......................................................... 75

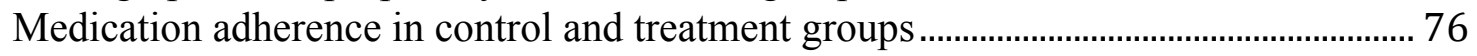

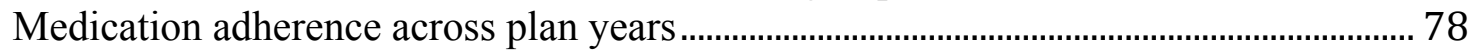

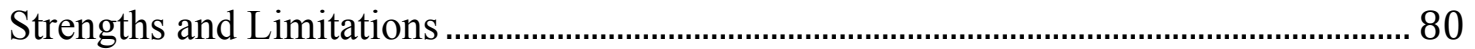

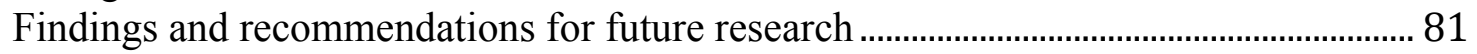

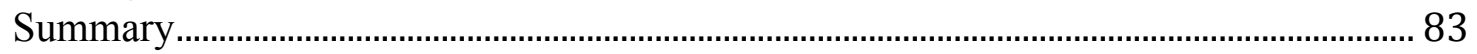

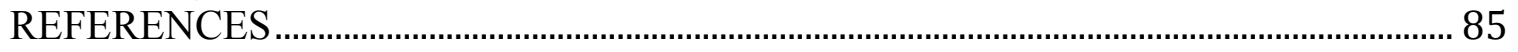

APPENDIX I

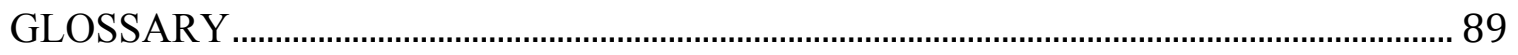

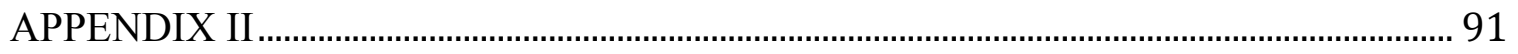

UNIVERSITY OF LOUISVILLE INSTITUTIONAL REVIEW BOARD

DETERMINATION

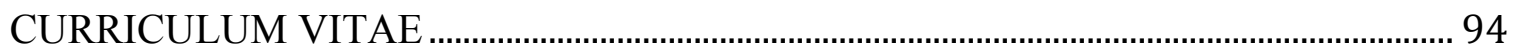




\section{LIST OF TABLES}

Table 1: WHO categories of non-adherence................................. 5

Table 2: Drugs for Type 2 Diabetes...................................... 7

Table 3: 2009-2014 Medicare Part D Standard Benefit Model Plan Parameters.... 12

Table 4: 2009-2014 Medicare Part D Standard Benefit Model Plan Parameters, including True Out-Of-Pocket (TrOOP) amounts........................... 35

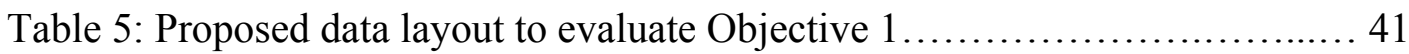

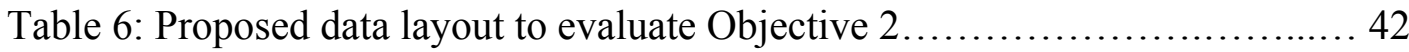

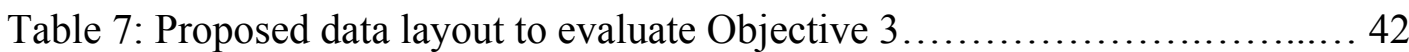

Table 8: Percent of total health plan members utilizing brand only, generic only or both............................................................... 51

Table 9: Univariate analysis comparing medication adherence pre-coverage gap and within the coverage gap for the brand cohort........................... 53

Table 10: Univariate analysis comparing medication adherence pre-coverage gap and within the coverage gap for the generic cohort........................... 53

Table 11: Index fill cost share, days spent in pre-coverage gap and coverage gap for health plan members using brand diabetic medications..................... 55

Table 12: Index fill cost share, days spent in pre-coverage gap and coverage gap for health plan members using generic diabetic medications.................... 55

Table 13: Comparison of baseline statistics for unmatched and matched health plan members for brand diabetic medication cohort, $2009 \ldots \ldots \ldots \ldots \ldots \ldots \ldots \ldots . \ldots 58$

Table 14: Comparison of baseline statistics for unmatched and matched health plan members for generic diabetic medication cohort, $2009 \ldots \ldots \ldots \ldots \ldots \ldots \ldots . \ldots 5$

Table 15: Comparison of baseline statistics for unmatched and matched health plan members for brand diabetic medication cohort, 2010 
Table 16: Comparison of baseline statistics for unmatched and matched health plan members for generic diabetic medication cohort, $2010 \ldots \ldots \ldots \ldots \ldots \ldots \ldots . \ldots . \ldots 59$

Table 17: Comparison of baseline statistics for unmatched and matched health plan members for brand diabetic medication cohort, $2011 \ldots \ldots \ldots \ldots \ldots \ldots \ldots \ldots . . . \ldots 59$

Table 18: Comparison of baseline statistics for unmatched and matched health plan members for generic diabetic medication cohort, $2011 \ldots \ldots \ldots \ldots \ldots \ldots \ldots . \ldots 0$

Table 19: Comparison of baseline statistics for unmatched and matched health

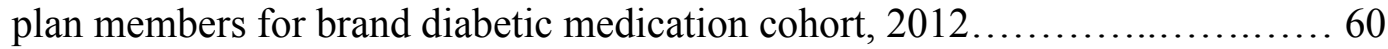

Table 20: Comparison of baseline statistics for unmatched and matched health plan members for generic diabetic medication cohort, $2012 \ldots \ldots \ldots \ldots \ldots \ldots \ldots \ldots \ldots$

Table 21: Comparison of baseline statistics for unmatched and matched health plan members for brand diabetic medication cohort, 2013 ..................... 61

Table 22: Comparison of baseline statistics for unmatched and matched health plan members for generic diabetic medication cohort, 2013 ..................... 61

Table 23: Comparison of baseline statistics for unmatched and matched health plan members for brand diabetic medication cohort, $2014 \ldots \ldots \ldots \ldots \ldots \ldots \ldots \ldots 61$

Table 24: Comparison of baseline statistics for unmatched and matched health plan members for generic diabetic medication cohort, $2014 \ldots \ldots \ldots \ldots \ldots \ldots \ldots \ldots . \ldots 2$

Table 25: C-statistics for logistic regression models by year, medication cohort.. 62

Table 26: Univariate analysis comparing medication adherence of the control and treatment groups for the brand cohort...................................... 63

Table 27: Univariate analysis comparing medication adherence of the control and treatment groups for the generic cohort............................... 63

Table 28: Medicare Part D Plan Enrollment Trends, 2007 - 2014_.............. 68

Table 29: Insulin and diabetic medications approved between $2009-2014 \ldots \ldots . . .70$

Table 30: Demographics across plan years for treatment group using brand medications ............................................................. 75

Table 31: Demographics across plan years for treatment group using generic medications.............................................................. 75 


\section{LIST OF FIGURES}

Figure 1: Relationship between Adherence and Hospitalization in Diabetes............. 9

Figure 2: Medicare Part D Benefit Phases..................................... 11

Figure 3: Andersen's Behavioral Model of Health Service Use...................... 23

Figure 4: Andersen's Behavioral Model of Health Service Use (with variables used in

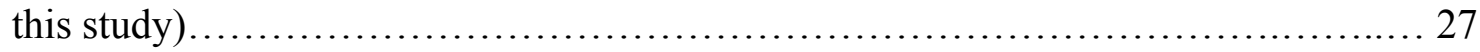

Figure 5: Enrollment by plan sponsor..................................... 31

Figure 6: Study sample and number of health plan members using brand diabetic

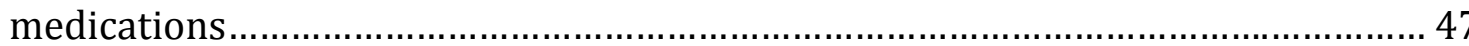

Figure 7: Study sample and number of health plan members using generic diabetic

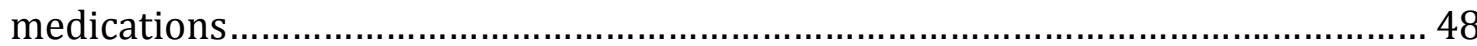

Figure 8: Percent of eligible study participants who reach the coverage gap by cohort

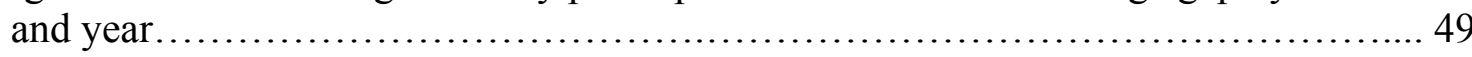

Figure 9: Percent of health plan members utilizing brand diabetic medications who reach the coverage gap between April and September, by month................... 50

Figure 10: Percent of health plan members utilizing generic diabetic medications who reach the coverage gap between April and September, by month.................... 50

Figure 11: Percent of health plan members utilizing only brand diabetic medications who reach the coverage gap between April and September, by month....

Figure 12: Percent of health plan members utilizing only generic diabetic medications who reach the coverage gap between April and September, by month............... 52

Figure 13: Percent of health plan members utilizing both brand and generic diabetic medications who reach the coverage gap between April and September, by month.... 52

Figure 14. Percent of health plan members utilizing brand diabetic medications that were adherent with a PDC $>80 \%$ 
Figure 15. Percent of health plan members utilizing generic diabetic medications that were adherent with a PDC $>80 \%$

Figure 16: Control group medication adherence across plan years for the brand cohort

Figure 17: Control group medication adherence across plan years for the generic cohort.

Figure 18: Treatment group medication adherence across plan years for the brand cohort. 65

Figure 19: Treatment group medication adherence across plan years for the generic cohort.

Figure 20: Percent of non-LIS Part D enrollees who entered the coverage gap, 2009-2012. 68

Figure 21: Percent of health plan members who reached the gap with brand launches and patent losses.

Figure 22: The Express Scripts Prescription Price Index.

Figure 23: Medication adherence pre-coverage gap and while in the coverage gap for the brand cohort

Figure 24: Medication adherence pre-coverage gap and while in the coverage gap for the generic cohort

Figure 25: Medication adherence of the control and treatment groups for the brand cohort

Figure 26: Medication adherence of the control and treatment groups for the generic cohort 


\section{CHAPTER 1}

\section{INTRODUCTION}

\section{Background to the Study}

Former Attorney General C. Everett Koop said, “Drugs don’t work in patients who don't take them (P. Ho, Bryson, \& Rumsfeld, 2009).” Compliance, adherence and persistence are terms commonly used to describe the patient's reaction to medical advice or instruction (Bailey \& Kodack, 2011). Compliance describes a patient's willingness to follow a prescribed treatment regimen. Adherence, however, is the extent to which the patient achieves an agreed upon treatment regimen without close supervision. Persistence is the duration of time from initiation to discontinuation of therapy. Poor medication adherence accounts for substantial deterioration of disease, death and increased health care costs in the United States. Of all medication-related hospital admissions in the United States, 33 to 69 percent result from poor medication adherence, with an estimated cost of $\$ 100$ billion a year (Osterberg \& Blaschke, 2005).

Adherence to medication regimens has been observed since the time of Hippocrates, when the effects of various potions were recorded with notations of whether the patient had taken them or not (Osterberg \& Blaschke, 2005). There are many ways to measure medication adherence that involve both direct and indirect methods. Direct methods include directly observed medication administration and detection of medication levels in the blood while methods with indirect measurement are patient questionnaires, pill counts and rate of refills (Osterberg \& Blaschke, 2005). 
Medication non-adherence is a multifaceted issue that relates to both behavioral and system barriers (Touchette \& Shapiro, 2008). Behavioral barriers include social support, cognition and personal health beliefs. System barriers include treatment complexity (multiple medications/dosing schedule), system complexity (multiple providers) and cost.

\section{The Importance of Adherence in Public Health}

The impact of poor medication adherence has an impact to the population in terms of both health and cost. In 2009, a research brief by the New England Healthcare Institute estimated that medication non-adherence, in addition to suboptimal prescribing, drug administration and diagnosis could result in as much as $\$ 290$ billion per year in avoidable medical spending, equivalent to 13 percent of total U.S. health care expenditures (New England Healthcare Institute, 2009). While a report released by Express Scripts in 2014 estimated the cost at $\$ 337$ billion, which equates to about one of every nine healthcare dollars spent wasted due to non-adherence (Sundar, 2015). In fact, non-adherence to prescribed medication regimens has been shown to result in $\$ 100$ billion in costs related to excess hospitalizations alone (New England Healthcare Institute, 2009) and accounts for as many as 40 percent of nursing home admissions (Case Management Society of America, 2006). Clearly, poor adherence can lead to an increase in acute healthcare resource utilization and result in the need for specialized and costly long-term care.

In addition to the cost burden that medication non-adherence places on the healthcare system, it can also be a cause of mortality. An analysis conducted in England 
attributed medication non-adherence to be a contributing factor in at least 25 percent of suicides and homicides by people with mental illness (Priebe et al., 2010). It also is estimated that a lack of adherence to regimens for heart disease is responsible for 125,000 deaths annually (McCarthy, 1998).

The adverse effects of poor adherence are both individual and societal (Giuffrida $\&$ Torgerson, 1997). Non-adherence reduces the benefit of the preventive or curative services of the therapy to the individual. The lack of adherence may cause unnecessary diagnostic and treatment procedures, adding cost to the system and for the patient. Nonadherence to treatment for infectious disease can result in drug resistance and spread of infection to others. This is especially relevant in the treatment of tuberculosis, a serious public health concern. Poor adherence leads to more expensive treatment for the individual patient as the disease progresses and increases the possibility of drug resistance and threat of infection to the population at large. Another public health example would be adherence to anti-rejection medications following organ transplantation. Organs are a scare resource and when protocols are not followed, those resources are wasted. In fact, a study in the 1980's showed 18 percent of post-transplant patients were non-adherent (Burns \& Shaw, 2007). Of those 18 percent a majority (91 percent) lost the transplanted organ or died compared to 18 percent of patients in the adherent group. Finally, non-adherence by individuals in clinical trials can result in overestimations of therapeutic dosing, causing drug toxicity in adherent patients.

Although medication adherence has clear benefits to society and the individual, the choice to be adherent lies primarily with the individual. Some reasons a person might choose to be non-adherent to therapy include a decision to avoid potential serious side 
effects or on the basis that the patient disagrees with the treatment or even the diagnosis itself (Priebe et al., 2010). There are potential benefits to non-adherence because it can sometimes reduce the cost of treatment and adverse effects, especially if the treatment is inappropriate (Giuffrida \& Torgerson, 1997).

There are numerous barriers to adherence, many of which the patient may have no control over. The World Health Organization (WHO) defines five categories of medication related non-adherence (P. Ho et al., 2009). The first category is the health system, which could include a lack of access to providers, poor communication between the patient and provider or even a language barrier. The type of condition the patient has is often a barrier to adherence. Patients who have diseases with no symptoms or physical cues may have a difficult time remembering to take their medication. Patients who suffer from mental illness may take their medications, start to feel better and stop taking it, cycling through phases of adherence and non-adherence. The patient themself can be a barrier to adherence. Studies have shown that adherence is lower in younger patients and those of nonwhite race. Older patients may have mental impairments that hinder their ability to be adherent or dexterity issues that would prohibit them from something as simple as opening a child-protective bottle. The fourth category is therapy. For example, patients on multiple drugs or drugs that require multiple doses a day are less likely to be fully- adherent. Finally, a patient's socioeconomic status can act as a barrier to adherence. Low health literacy can result in an inability to understand directions on how or when to take the medication and higher medication costs can hinder the patient's ability to even obtain the medication on a regular basis. 
Table 1. WHO categories of non-adherence (P. Ho et al., 2009)

\begin{tabular}{|l|l|}
\hline $\begin{array}{l}\text { Categories of } \\
\text { non-adherence }\end{array}$ & Examples \\
\hline Health System & $\begin{array}{l}\text { Poor quality of provider-patient relationship; poor communication; } \\
\text { lack of access to healthcare; lack of continuity of care }\end{array}$ \\
\hline Condition & $\begin{array}{l}\text { Asymptomatic chronic disease (lack of physical cues); mental } \\
\text { health disorders (e.g. depression) }\end{array}$ \\
\hline Patient & $\begin{array}{l}\text { Physical impairments (e.g. vision problems or impaired dexterity); } \\
\text { cognitive impairment; psychological/behavioral; younger age; } \\
\text { nonwhite race }\end{array}$ \\
\hline Therapy & Complexity of regimen; side effects \\
\hline Socioeconomic & Low literacy; higher medication costs; poor social support \\
\hline
\end{tabular}

\section{The Importance of Adherence in Diabetes}

Medication adherence is especially important for chronic diseases like diabetes, where medication can prevent or delay the onset of complications, reduce hospitalization risks and costs and improves quality of life for patients (Sacks, Burgess, Cabral, Pizer, \& McDonnell, 2013). Diabetes is increasingly common among seniors, with prevalence rates estimated at 26.7 percent and roughly 390,000 cases diagnosed annually (Sacks et al., 2013). Generic medications are used as first-line and second-line therapies, with a 30day supply of metformin, a biguanide, and sulfonylureas (glimepiride, glipizide, glyburide) readily available as inexpensive $\$ 4$ cash generics. Higher priced branded products like sitagliptin (marketed only as Januvia and not yet generically available), with average 30 -day cash prescription prices exceeding $\$ 300$, are recommended for more complex or advanced disease.

The long-term complications of diabetes, particularly type 2 diabetes, present a difficult challenge that requires comprehensive management of glycemia and a myriad of cardiovascular (CV) risk factors and comorbidities (Bailey \& Kodack, 2011). 
Hemoglobin A1c (HbA1c) levels reflect the glucose concentration in the blood. A high glucose concentration equates to a higher $\mathrm{HbAlc}$. Levels of $\mathrm{HbAlc}$ are not influenced by daily fluctuations in the blood glucose concentration rather reflect the average glucose levels over the prior six to eight weeks. Therefore, HbAlc is a useful indicator of how well the blood glucose level has been controlled in the recent past and may be used to monitor the effects of diet, exercise and drug therapy on blood glucose in diabetic patients. In healthy, non-diabetic patients the HbA1c level is less than 7 percent of total hemoglobin. It has been demonstrated that the complications of diabetes can be delayed or prevented if the HbAlc level can be kept close to 7 percent (American Diabetes Association, 2015). In general, values should be kept below 8 percent.

Although an extensive and effective range of medications options exist to address these issues, only slightly more than half of patients achieve a HbAlc target of less than 7.0 percent and about two-thirds of patients die of CV disease (Bailey \& Kodack, 2011). There are established protocols, guidelines and algorithms to accommodate the needs of most patients under a majority of circumstances. However, medication adherence is often a neglected issue in this patient population. Table 2 outlines the available therapies used to manage Type 2 diabetes, the initial dose and the approximate cash price for a 30 -day supply as of June 2015 . 
Table 2. Drugs for Type 2 Diabetes (Pharmacist's Letter/Prescriber's Letter, June 2015)

\begin{tabular}{|c|c|c|}
\hline Class & Specific Agents & $\begin{array}{l}\text { Initial Dose (Approximate cost for 30-day } \\
\text { supply) }\end{array}$ \\
\hline $\begin{array}{l}\text { Alpha-glucosidase } \\
\text { inhibitor }\end{array}$ & $\begin{array}{l}\text { Acarbose (Precose, others) } \\
\text { Miglitol (Glyset) }\end{array}$ & $\begin{array}{l}\text { Acarbose: } 25 \mathrm{mg} \text { PO TID (\$45) } \\
\text { Miglitol: } 25 \mathrm{mg} \text { PO TID (\$145) }\end{array}$ \\
\hline Amylin analog & Pramlintide (Symlin) & $\begin{array}{l}\text { Pramlintide: } 60 \mathrm{mcg} \text { SC prior to major meals } \\
(\$ 590)\end{array}$ \\
\hline Biguanide & $\begin{array}{l}\text { Metformin (Glucophage, } \\
\text { Glucophage XR) }\end{array}$ & $\begin{array}{l}\text { Metformin: } 500 \mathrm{mg} \text { PO BID or } 850 \mathrm{mg} \text { PO once } \\
\text { daily (less than } \$ 20 / \text { month) }\end{array}$ \\
\hline $\begin{array}{l}\text { Dipeptidyl } \\
\text { peptidase-4 (DPP- } \\
\text { 4) inhibitor or } \\
\text { incretin enhancer }\end{array}$ & $\begin{array}{l}\text { Alogliptin (Nesina) } \\
\text { With metformin (Kazano) } \\
\text { With pioglitazone (Oseni) } \\
\text { Linagliptin (Tradjenta) } \\
\text { With metformin (Jentaduetno) } \\
\text { With empagliflozin } \\
\text { (Glyxambi) } \\
\text { Saxagliptin (Onglyza) } \\
\text { With metformin (Kombiglyze } \\
\text { XR) } \\
\text { Sitagliptin (Januvia) } \\
\text { With metformin (Janumet, } \\
\text { Janumet XR) } \\
\text { With simvastatin (Juvisync) }\end{array}$ & $\begin{array}{l}\text { Alogliptin: 25mg PO once daily (\$310) } \\
\text { Linagliptin: } 5 \mathrm{mg} \text { PO once daily ( } \$ 330) \\
\text { Saxagliptin: } 2.5 \text { or } 5 \mathrm{mg} \text { PO once daily ( } \$ 325) \\
\text { Sitagliptin: } 100 \mathrm{mg} \text { PO once daily }(\$ 330)\end{array}$ \\
\hline $\begin{array}{l}\text { Glucagon-like, } \\
\text { peptide-1 (GLP-1) } \\
\text { agonist or incretin } \\
\text { mimetic }\end{array}$ & $\begin{array}{l}\text { Albiglutide (Tanzeum) } \\
\text { Dulaglutide (Trulicity) } \\
\text { Exenatide (Byetta) } \\
\text { Exenatide extended-release } \\
\text { (Bydureon) } \\
\text { Liraglutide (Victoza) }\end{array}$ & $\begin{array}{l}\text { Albiglutide: } 30 \mathrm{mg} \text { SC once weekly }(\$ 325) \\
\text { Dulaglutide: } 0.75 \mathrm{mg} \text { SC once weekly }(\$ 490) \\
\text { Exenatide: } 5 \mathrm{mg} \text { SC BID }(\$ 480) \\
\text { Exenatide extended-release: } 2 \mathrm{mg} \mathrm{SC} \text { once weekly } \\
\text { (\$475) } \\
\text { Liraglutide: } 0.6 \mathrm{mg} \mathrm{SC} \text { daily x } 1 \text { week then } 1.2 \mathrm{mg} \\
\text { SC once daily }(\$ 430)\end{array}$ \\
\hline Insulin & $\begin{array}{l}\text { Rapid-acting insulin: lispro } \\
\text { (Humalog), aspart (NovoLog), } \\
\text { glulisine (Apidra) } \\
\text { Regular short-acting insulin: } \\
\text { Humulin R, Novolin R } \\
\text { Intermediate-acting (basal) } \\
\text { insulin: NPH (Humulin N, } \\
\text { Novolin N) } \\
\text { Long-acting (basal) insulin: } \\
\text { glargine (Lantus), detemir } \\
\text { (Levemir) }\end{array}$ & Varies \\
\hline
\end{tabular}




\begin{tabular}{|c|c|c|}
\hline Class & Specific Agents & $\begin{array}{l}\text { Initial Dose (Approximate cost for 30-day } \\
\text { supply) }\end{array}$ \\
\hline $\begin{array}{l}\text { Insulin } \\
\text { (continued) }\end{array}$ & $\begin{array}{l}\text { Premixed insulin: } \\
\text { Rapid acting: NovoLog Mix } \\
\text { 70/30, Humalog Mix } 75 / 25 \text { or } \\
\text { 50/50 } \\
\text { Short-acting: Humulin 70/30, } \\
\text { Novolin 70/30 }\end{array}$ & Varies \\
\hline Meglitinide & $\begin{array}{l}\text { Nateglinide (Starlix) } \\
\text { Repaglinide (Prandin, others) } \\
\text { With metformin (PrandiMet) }\end{array}$ & $\begin{array}{l}\text { Nateglinide: } 60 \text { to } 120 \mathrm{mg} \text { PO TID (\$105) } \\
\text { Repaglinide: } 0.5,1 \text { or } 2 \mathrm{mg} \text { PO TID (\$50) }\end{array}$ \\
\hline $\begin{array}{l}\text { Sodium-glucose } \\
\text { cotransporter-2 } \\
\text { (SGLT2) inhibitor } \\
\text { or "flozins" }\end{array}$ & $\begin{array}{l}\text { Canagliflozin (Invokana) } \\
\text { With metformin (Invokamet) } \\
\text { Dapagliflozin (Farxiga) } \\
\text { Empaglifozin (Jardiance) } \\
\text { With linagliptin (Glyxambi) }\end{array}$ & $\begin{array}{l}\text { Canagliflozin: 100mg PO once daily }(\$ 340) \\
\text { Dapagliflozin: 5mg PO once daily }(\$ 340) \\
\text { Empaglifozin: } 10 \mathrm{mg} \text { PO once daily }(\$ 340)\end{array}$ \\
\hline $\begin{array}{l}\text { Sulfonylurea-first } \\
\text { generation }\end{array}$ & $\begin{array}{l}\text { Chlorpropamide (Diabinese, } \\
\text { others) } \\
\text { Tolazamide (Tolinase, others) } \\
\text { Tolbutamide (Orinase, others) }\end{array}$ & $\begin{array}{l}\text { Chlorpropamide: } 100 \text { to } 200 \mathrm{mp} \text { PO once daily } \\
\text { (less than } \$ 20 / \text { month) } \\
\text { Tolazamide: } 250 \mathrm{mg} \text { PO once daily }(\$ 48) \\
\text { Tolbutamide: } 1 \mathrm{~g} \text { PO once daily }(\$ 70)\end{array}$ \\
\hline $\begin{array}{l}\text { Sulfonylurea- } \\
\text { second generation }\end{array}$ & $\begin{array}{l}\text { Glyburide (Diabeta, Glynase, } \\
\text { Micronase, others) } \\
\text { With metformin (Glucovance) } \\
\text { Glipizide (Glucotrol, } \\
\text { Glucotrol XL, others) } \\
\text { Glimepiride (Amaryl, others) } \\
\text { With metformin (Amaryl M) } \\
\text { With pioglitazone (Duetact) } \\
\text { With rosiglitazone } \\
\text { (Avandaryl) }\end{array}$ & $\begin{array}{l}\text { Glyburide: } 2.5 \mathrm{mg} \text { PO once daily (less than } \\
\$ 10 / \text { month) } \\
\text { Glipizide: } 5 \mathrm{mg} \text { PO once daily (less than } \\
\$ 10 / \text { month) } \\
\text { Glimepiride: } 1 \mathrm{mg} \text { PO once daily (less than } \\
\text { \$10/month) }\end{array}$ \\
\hline $\begin{array}{l}\text { Thiazolidinedione } \\
\text { (TZD) }\end{array}$ & $\begin{array}{l}\text { Pioglitazone (Actos) } \\
\text { With metformin (ActosMet, } \\
\text { ActosMet XR) } \\
\text { With glimepiride (Duetact) } \\
\text { With alogliptin (Oseni) } \\
\text { Rosiglitazone (Avandia) } \\
\text { With metformin (Avandamet) } \\
\text { With glimiperide (Avandaryl) }\end{array}$ & $\begin{array}{l}\text { Pioglitazone: Initial } 15 \mathrm{mg} \text { PO once daily (less } \\
\text { than \$20) } \\
\text { Rosiglitazone: Initial } 4 \mathrm{mg} \text { PO once daily (\$115) }\end{array}$ \\
\hline
\end{tabular}


Extensive evidence indicates that rigorous control of blood glucose is associated with a reduction in long- term vascular complications in patients with type 2 diabetes (Bailey \& Kodack, 2011). Greater adherence to treatment regimens has shown to improve metabolic control outcomes. Indeed, non-adherent patients are at increased risk for the development of vascular complications, hospitalizations and death. Researchers conducting a study of adherence in a medically indigent population with type 2 diabetes noted that each 10 percent decrease in adherence was accompanied by a positive 0.14 percent increase in HbA1c (Bailey \& Kodack, 2011). In addition, the benefits of improved adherence have been linked to fewer emergency department visits and fewer inpatient admissions. Patients with diabetes who did not regularly take their diabetes medications as prescribed were 2.5 times more likely to be hospitalized than those who were adherent more than 80 percent of the time (Lau \& Nau, 2004).

Figure 1. Relationship between Adherence and Hospitalization in Diabetes (Lau \& Nau, 2004)

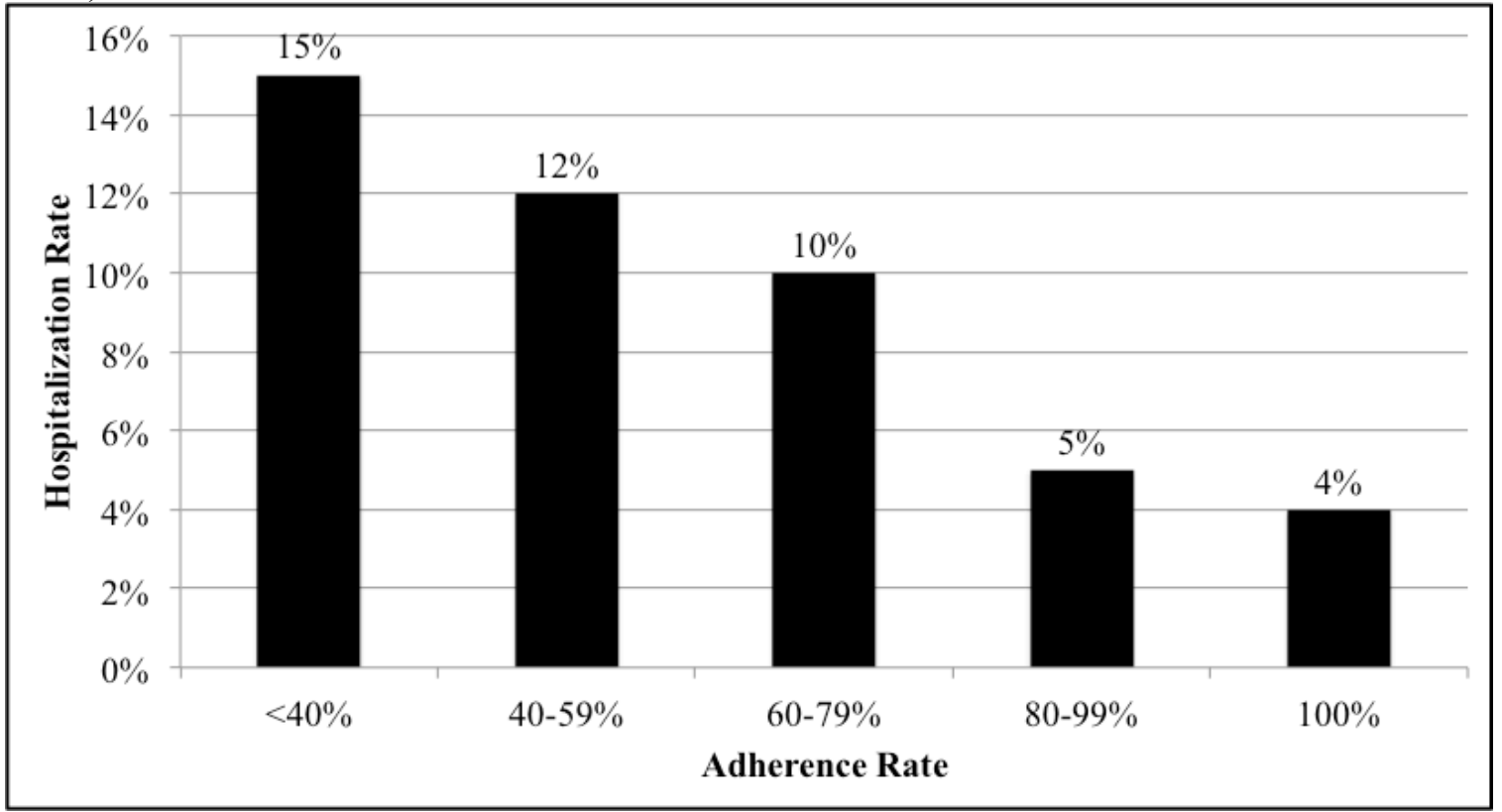




\section{The Medicare Modernization Act of 2003}

The Medicare Modernization Act (MMA) of 2003 allowed Medicare expansion in 2006 to offer voluntary outpatient prescription drug coverage ("The Medicare Prescription Drug Benefit Fact Sheet," 2014). All 54 million people on Medicare are eligible to enroll in this benefit offered through private plans approved by the federal government. The Medicare drug benefit is offered through stand-alone prescription drug plans (PDP) covering only outpatient medications and Medicare Advantage prescription drug (MAPD) plans covering all Medicare benefits including drugs.

Enrollment in Medicare drug plans is voluntary, with the exception of those who are dually eligible for both Medicare and Medicaid and certain other low-income health plan members who are automatically enrolled in a PDP if they do not choose a plan on their own ("The Medicare Prescription Drug Benefit Fact Sheet," 2014). In 2014, more than 37 million Medicare health plan members were enrolled in Medicare Part D plans, up from 26 million in 2009. Of this total, about two-thirds were enrolled in a stand-alone PDP and one-third enrolled in a Medicare Advantage drug plan.

A unique feature to the Medicare Part D benefit is the coverage gap, sometimes referred to as the "donut hole". The coverage gap was included because the cost of providing continuous coverage with no gap would have exceeded the budgetary limit imposed on the legislation when the Medicare drug benefit was established (Hoadley, Thompson, Hargrave, Cubanski, \& Neuman, 2008). The coverage gap is a benefit phase where the enrollee incurs all or most of the drug cost until they hit a certain dollar limit. The Medicare health plan members who are eligible for a low-income subsidy or dually eligible for both Medicare and Medicaid are not subject to the coverage gap. 
In 2013, most PDPs (69 percent) offered little or no gap coverage beyond that required by law (Hoadley, Summer, Hargrave, \& Cubanski, 2013). The plans offering extra gap coverage have premiums that are almost twice as expensive as those that offer no coverage and therefore fewer enrollees. In fact, enrollment in these plans has remained low since 2006 with only 5-6 percent of PDP enrollees choosing a plan that includes some type of coverage in the gap. In 2013, only 35 percent of MAPD enrollees were in a plan that had extra gap coverage, which was up from 27 percent in 2006.

\section{The Patient Protection and Affordable Care Act}

In 2010, the Patient Protection and Affordable Care Act (ACA) made significant changes to the coverage gap. Table 3 outlines the benefit phases, coverage limits and coverage gap changes from 2009 to 2014. Standard Part D Plans have a deductible phase, followed by an initial coverage phase where the enrollee pays 25 percent of the drug cost up to a set coverage limit. The enrollee then enters the coverage gap, where until 2010 the enrollee was responsible for 100 percent of the drug costs until they entered the catastrophic phase. The ACA mandates that the coverage gap will incrementally close until it is eliminated in 2020 .

Figure 2. Medicare Part D Benefit Phases

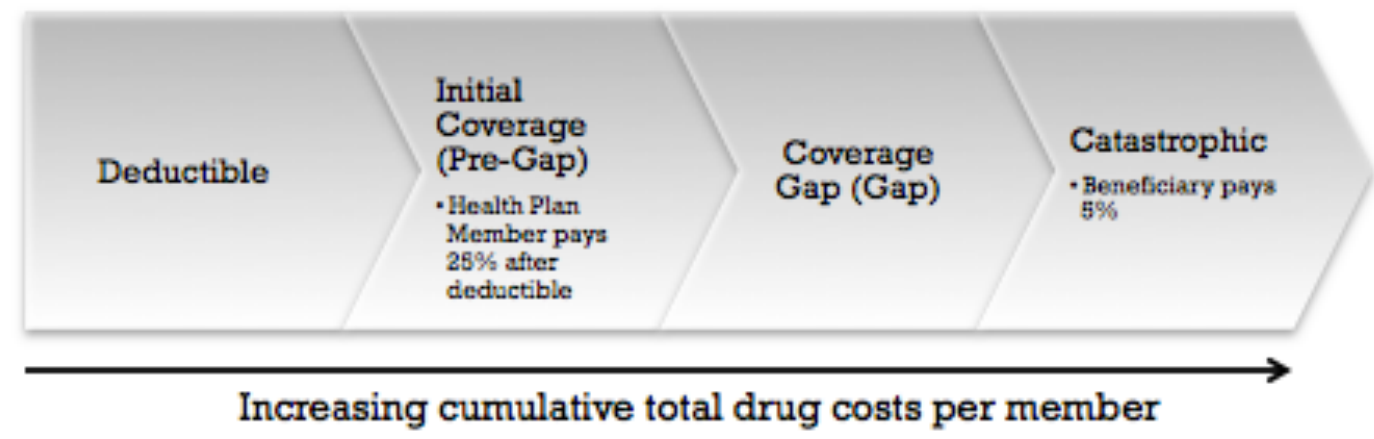


Among Part D enrollees who used prescription drugs in 2009 and did not receive a low-income subsidy, about one in five (19 percent) had spending high enough to reach the coverage gap (Hoadley, Summer, Hargrave, \& Cubanski, 2011). Overall, about 3.4 million health plan members (12 percent of the total population of Part D enrollees) reached the coverage gap and faced the full cost of their prescription drugs in 2009.

Table 3. 2009-2014 Medicare Part D Standard Benefit Model Plan Parameters (Q1Group)

\begin{tabular}{|c|c|c|c|c|c|c|c|}
\hline \multirow{2}{*}{$\begin{array}{c}\text { Medicare } \\
\text { Part D Phase } \\
\text { Benefits }\end{array}$} & \multirow[b]{2}{*}{ Responsibility } & \multicolumn{6}{|c|}{ Plan Year } \\
\hline & & 2009 & 2010 & 2011 & 2012 & 2013 & 2014 \\
\hline Deductible & Member Pays & $\$ 295$ & $\$ 310$ & $\$ 310$ & $\$ 320$ & $\$ 325$ & $\$ 310$ \\
\hline \multirow{3}{*}{$\begin{array}{c}\text { Initial } \\
\text { Coverage }\end{array}$} & Member Pays & $25 \%$ & $25 \%$ & $25 \%$ & $25 \%$ & $25 \%$ & $25 \%$ \\
\hline & Plan Pays & $75 \%$ & $75 \%$ & $75 \%$ & $75 \%$ & $75 \%$ & $75 \%$ \\
\hline & $\begin{array}{l}\text { Coverage } \\
\text { Limit }\end{array}$ & $\$ 2,700$ & $\$ 2,830$ & $\$ 2,840$ & $\$ 2,930$ & $\$ 2,970$ & $\$ 2,850$ \\
\hline \multirow{8}{*}{$\begin{array}{c}\text { Coverage } \\
\text { Gap }\end{array}$} & \multicolumn{7}{|c|}{ Brand Drugs } \\
\hline & Member Pays & $100 \%$ & $100 \%$ & $50 \%$ & $50 \%$ & $47.5 \%$ & $47.5 \%$ \\
\hline & Plan Plays & $0 \%$ & $0 \%$ & $0 \%$ & $0 \%$ & $2.5 \%$ & $2.5 \%$ \\
\hline & $\begin{array}{c}\text { Manufacturer } \\
\text { Pays }\end{array}$ & $0 \%$ & $\$ 250$ & $50 \%$ & $50 \%$ & $50 \%$ & $50 \%$ \\
\hline & \multicolumn{7}{|c|}{ Generic Drugs } \\
\hline & Member Pays & $100 \%$ & $100 \%$ & $93 \%$ & $86 \%$ & $79 \%$ & $72 \%$ \\
\hline & Plan Pays & $0 \%$ & $0 \%$ & $7 \%$ & $14 \%$ & $21 \%$ & $28 \%$ \\
\hline & $\begin{array}{l}\text { Coverage } \\
\text { Limit }\end{array}$ & $\$ 6,154$ & $\$ 6,440$ & $\$ 6,484$ & $\$ 6,730$ & $\$ 6,955$ & $\$ 6,691$ \\
\hline \multirow{3}{*}{$\begin{array}{c}\text { Catastrophic } \\
\text { Coverage }\end{array}$} & Member Pays & $5 \%$ & $5 \%$ & $5 \%$ & $5 \%$ & $5 \%$ & $5 \%$ \\
\hline & Plan Pays & $15 \%$ & $15 \%$ & $15 \%$ & $15 \%$ & $15 \%$ & $15 \%$ \\
\hline & $\begin{array}{c}\text { Medicare } \\
\text { Pays }\end{array}$ & $85 \%$ & $85 \%$ & $85 \%$ & $85 \%$ & $85 \%$ & $85 \%$ \\
\hline
\end{tabular}

\section{The Effect of Cost-Sharing and Copayments on Adherence}

Patterson, et al. examined the association of higher copayments to a greater risk of non-adherence specifically targeting beta blocker utilization in heart failure patients 50 years and older (Patterson, Blalock, Smith, \& Murray, 2011). From a database of 38 
million unique individuals, the researchers pared down the cohort to 2,359 relatively compliant heart failure patients.

The researchers found that patients with the highest copayment level (\$26-30) as compared with the lowest copayment level (under \$1) had on average a 7 percent less medication supply of beta-blockers over the course of a year. The researchers also found that patients with the higher copayment tier showed an increased risk of non-adherence. This study did have several limitations including a small sample size in the upper limit copayment tier and selection factors that could not be controlled.

Li, et al. and Zhang, et al. conducted studies that examined cost as a barrier to adherence when Medicare Part D patients reach the coverage gap and incur 100 percent cost share of their medications (Li, McElligott, Bergquist, Schwartz, \& Doshi, 2012; Zhang, Baik, \& Lave, 2013). Researchers in both studies utilized a pre-post design and a 5 percent sample of Medicare health plan members. Li, et al. looked specifically at patients with hypertension and hyperlipidemia. They utilized a control group of lowincome subsidy patients who would have no benefit changes in the gap phase. The other three groups consisted of patients with no coverage in the gap, those with generic only coverage and patients with brand and generic coverage in the gap.

While in the coverage gap, patients in the no-coverage group had higher average out-of-pocket costs per prescription (\$31 for anti-hypertensives and \$79 for lipidlowering drugs), as did those in the generic-only coverage group (\$29 for antihypertensives and \$58 for lipid-lowering drugs). The remaining groups had no substantial change in copayments. Compared to the control group, the no-coverage group had a statistically significant decrease in the number of brand and generic prescriptions, which 
would translate to a decrease in adherence. The generic-only coverage group had a statistically significant decrease in brand prescriptions but not adherence to generic prescriptions.

Zhang, et al. examined a population with heart failure and/or diabetes through the coverage gap. As in the prior study, a low-income subsidy group was utilized as a control but only 2 other groups were identified: no coverage through the gap and generic only coverage. Researchers utilized propensity score matching for age, sex, race and number of Elixhauser comorbidities. The Elixhauser comorbidity index is a measurement tool that defines 30 comorbid (i.e., co-existing) conditions using ICD-9 codes. This instrument was developed in order to be used with large administrative data sets (Elixhauser, Steiner, Harris, \& Coffey, 1998).

The study conducted by Zhang, et al. had three important findings. First, when matched to the comparison group, there were statistically significant reductions in all studied outcomes present in both study groups: probability of using a drug, mean number of monthly prescriptions filled and monthly pharmacy spending. However, the nocoverage group showed a greater decrease in medication adherence than those with generic drug coverage only in the gap. Second, the overall decrease in monthly medications amounts and spending was primarily due to a decrease in brand medication utilization. For example, those without drug coverage in the gap reduced their overall medication use by 0.85 medications per month ( 75 percent brand name $/ 25$ percent generic). This group decreased its monthly pharmacy spending by $\$ 73.15$ ( $\$ 66.65$ brand name $/ \$ 6.40$ generic). Third, those with generic only coverage in the gap reduced their use of brand-name drugs but did not compensate for the decrease by increasing their use of 
generic drugs. In fact, they also decreased their use of generic drugs slightly but negligibly.

These studies are significant because they establish a relationship between cost and medication adherence. In fact, researchers of a 2004 RAND study found that doubling copayments for medications reduced adherence by 25 to 45 percent (Goldman, 2004). As patients' use of medications declined due to increased copayments, emergency room visits increased 17 percent and hospital stays rose 10 percent among patients with chronic conditions such as diabetes, asthma or gastric acid disorder.

\section{Proposed Reform Effects}

In 2013, two studies were published with focus on what may happen to adherence for patients on anti-diabetic medication when the coverage gap closes (Sacks et al., 2013; Zeng, Patel, \& Brunetti, 2013). Researchers in both studies share the hypothesis that closing the coverage gap thereby decreasing costs for patients will result in better medication adherence. The Zeng, Patel \& Brunetti study analyzed 2 cohorts of patients: one group before any reform measures were enacted in 2010 and one group when brand drugs were covered at 50 percent through the gap in 2011. Pharmacy claims data was used for analysis and medication adherence was measured by portion of days covered (PDC).

Zeng, et al, found that the average copayment in the coverage gap decreased by 27 percent from 2010 to 2011 and patients with no coverage or partial coverage in the gap showed improved medication adherence in 2011 over 2010. However, patients with full coverage in the gap showed unchanged adherence year over year. 
Sacks, et al. utilized 2 cohorts consisting of low income and non-low income while logistic regression was used to model the likelihood of adherence to oral antidiabetic medications. The researchers concluded that the elimination of the coverage gap would not affect generic utilization but should increase adherence for those who utilize brand medications.

In 2012, a poster titled "Impact of the Affordable Care Act on Medication Adherence in a Population of Medicare Part D Beneficiaries" was presented at the Academy for Managed Care Pharmacy (AMCP) conference (Brown, Ward, \& Yihua, 2012). The objectives of the study were to assess the impact of changes in the Medicare Part D Coverage gap on adherence to brand and generic medications across plan years. The researchers looked at Humana Medicare Part D health plan member utilization of diabetic and anti-platelet medications between 2009 and 2012. They found the ACA is modestly improving adherence across plan years and during the Medicare coverage gap for brand medications while adherence to generic diabetes medications showed no significant improvement.

\section{Statement of the Problem}

Prior research has been conducted on associations between medication adherence and copayment levels in the Commercially insured population (Patterson et al., 2011). Researchers have also studied the effect of the Part D coverage gap on medication adherence (Li et al., 2012; Zhang et al., 2013) and how proposed coverage gap reform may influence adherence (Sacks et al., 2013; Zeng et al., 2013). However, little research 
has been published regarding the ACA's effect on medication adherence in the coverage gap utilizing actual claims data.

\section{Purpose of the Study}

The main goal of this study is to examine how a public policy can affect medication adherence in a subset of a population. In order to achieve this goal, the study has 3 objectives: 1) to evaluate diabetes medication adherence of health plan members before they reach the coverage gap and then while they are in the coverage gap, 2) to compare diabetes medication adherence between two similar groups with differing benefit structures, one group with a gap in coverage as opposed to a group with no benefit changes within the year and 3) to examine diabetes medication adherence trend over multiple years as the coverage gap is closed.

Medication adherence is the primary outcome measure of this study. Adherence will be calculated by examining pharmacy claims data and using portion of days covered (PDC), which is the method endorsed by the Pharmacy Quality Alliance (PQA) (Nau). If a health plan member has enough medication to cover 80 percent of the measurement period, that health plan member will be considered adherent. Based on numerous studies of the relationship of medication adherence and healthcare outcomes, PQA selected 0.8 (or 80 percent) as the threshold above which the patient can be considered to be adherent for most classes of chronic medications.

To the best of my knowledge, this is one of only a handful of studies to utilize real-world claims data to examine the affect of the ACA on medication adherence in the 
Medicare Part D coverage gap. The study also provides the opportunity to add to the wealth of literature around cost related non-adherence in the Medicare population.

\section{Research Question and Hypotheses}

Will medication adherence for Humana Medicare Part D health plan members filling diabetic medications at Humana's mail order pharmacy improve as the coverage gap is incrementally closed due to the Patient Protection and Affordable Care Act $(\mathrm{ACA}) ?$

Research Hypothesis 1: Diabetes medication adherence will decrease when health plan members are in the coverage gap.

Null Hypothesis 1: There will be no change to diabetes medication adherence when a health plan member enters the coverage gap.

Research Hypothesis 2: Diabetes medication adherence of the control group will be better than the study group.

Null Hypothesis 2: There will be no statistically significant difference in medication adherence between the groups.

Research Hypothesis 3: Diabetes medication adherence in the coverage gap will show significant improvement for brand drugs year over year as the coverage gap closes.

Null Hypothesis 3: Diabetes medication adherence will not show significant improvement for brand drugs.

Research Hypothesis 4: Diabetes medication adherence in the coverage gap will show slight improvement for generic drugs year over year as the coverage gap closes. 
Null Hypothesis 4: Diabetes medication adherence will not show slight improvement for generic drugs.

\section{Summary}

Medication adherence is an essential part of managing chronic disease. Poor medication adherence results in additional costs to the healthcare system, a decreased quality of life for the patient and can even result in death. For patients with diabetes, medication adherence plays a vital role in managing blood glucose levels. Specifically, it has been documented that each 10 percent decrease in adherence was accompanied by a positive 0.14 percent increase in HbA1c. Furthermore, diabetic patients who did not regularly take their diabetes medications were 2.5 times more likely to be hospitalized than those who followed their prescribed treatment regimens more than 80 percent of the time.

Medicare is a federal insurance program established in 1965 providing health insurance to Americans ages 65 and older and to individuals under age 65 with specific disabilities or end-stage renal disease. In order to increase Medicare health plan members' access to medications and help lower their prescription drug costs, the Medicare Prescription Drug, Improvement, and Modernization Act (MMA) of 2003 introduced a prescription drug benefit referred to as 'Medicare Part D'. Medicare Part D has been structured to include substantial cost sharing by way of deductibles, copayments and coinsurance.

A significant amount of research has been dedicated to understanding the impact of cost sharing on prescription drug utilization, medication adherence and health 
outcomes. A review of the literature indicates that cost sharing has also been associated with decreased medication adherence, increased costs and increased out-of-pocket expenses for health plan members. As the coverage gap closes, it provides a unique opportunity to examine the effect of lessening the cost burden on medication adherence. Details of the theoretical framework used to assess the study objectives are provided in Chapter 2. 


\section{CHAPTER 2}

\section{LITERATURE REVIEW}

\section{Theoretical Framework}

The objectives in this study will be analyzed using the framework provided by the economic theory and Andersen's Behavioral Model of Health Services Use. Both theories offer a framework by which to examine health services utilization with respect to cost and other variables. The economic theory points toward cost as a driver for behavior while Andersen's model includes a range of factors and feedback loops that ultimately affect health care use and subsequent outcomes.

\section{Economic Theory}

Economic theory postulates that, when a patient is charged the full price of a prescription medication and has adequate information to weigh the medication's benefits versus adverse effects, they will consume an optimal amount of the medication, given their priorities and income constraints (Gibson, Ozminkowski, \& Goetzel, 2005). The theory assumes that rational patients will evaluate both the costs and benefits of a medication compared with other methods of producing health and will utilize combinations of these that maximize their health with respect to their income limitations.

It is possible that a patient who obtains insurance coverage that includes a prescription benefit may be motivated to consume more medications than normal once the cost barrier is removed and the price to the patient is lower than full price (Gibson et 
al., 2005). Therefore, raising the price of the medication through higher levels of cost sharing can have various economic and behavioral effects.

Increasing cost to the patient can result in a change in consumption. As cost sharing shifts to the patient, the patient moves up the demand curve and closer to the economically optimal amount (Gibson et al., 2005). This ultimately results in a reduction in consumption of medication. In terms of this study, as patients move into the coverage gap and bear the full cost of the medication, it would be reasonable to expect some patients to change their utilization patterns. For example, a patient could change consumption from taking a medication twice daily as prescribed to once daily. In this study, medication adherence for the health plan members was calculated prior to reaching the coverage gap and then while in the coverage gap to look for a change in medication utilization and consumption.

Another economic effect as a result of higher costs is substitution. Patients are likely to search for less expensive substitutes as the prices of prescription medications rise (Gibson et al., 2005). Therefore, if they discover a suitable substitute, patients are likely to consume smaller quantities of prescription medications and larger quantities of the substitute. Patients who utilize brand name medications may consider switching to a generic alternative or over the counter product once they reach the coverage gap.

An increase in cost to the patient may cause them to consider the value of the medication. A price increase would decrease the likelihood that drugs of low value, for which the cost exceeds the perceived benefit to the patient, would be used (Gibson et al., 2005). Conversely, patients would be price insensitive for high-value drugs, such as those that are perceived as life sustaining, and would be expected to continue to fill 
prescriptions. However, this assumes that consumers have adequate information to evaluate both the benefits and costs of drugs, which this study will lack sufficient data to establish.

\section{Andersen's Behavioral Model of Health Services Use}

Andersen's Behavioral Model of Health Services Use was originally developed in 1968 and has since been modified multiple times (Andersen, 1995). The foundation of the model lies in the premise that outcomes are dependent on environment factors, population characteristics and health behavior factors. The 1995 modified model, as shown below, is most frequently used in studies assessing health services use.

Figure 3. Andersen's Behavioral Model of Health Service Use (Andersen, 1995)

$$
\begin{array}{llll}
\text { ENVIRONMENT POPULATION CHARACTERISTICS } & \begin{array}{l}
\text { HEALTH } \\
\text { BEHAVIOR OUTCOMES }
\end{array}
\end{array}
$$

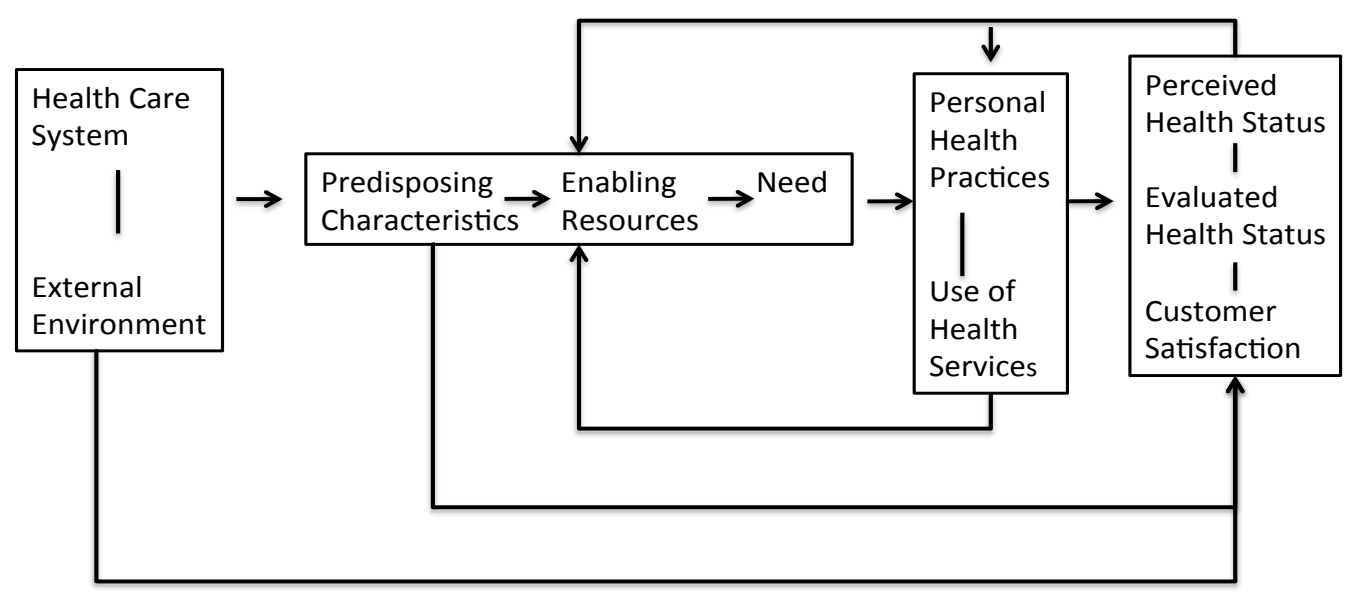


Environment factors, not present in the initial model, are an important input for understanding the use of health services and refer to a combined measure of health care system factors and external environment factors (Andersen, 1995). Health care system factors include dynamics related to accessible health care resources, their organization in the health care system that impact health services use and national health policy. External environment factors refer to physical, political and economic components in a health care system that impact use of health care services.

Population characteristics signify predisposing factors, enabling resources and need (Andersen, 1995). Predisposing factors involve demographic variables (age, gender) that represent biological imperatives suggesting the likelihood that people will need health services and social structure (education, marital status, race/ethnicity, occupation) that determine the status of a person in the community, ability to cope with health problems and capacity to control resources to deal with health issues. An individual's health beliefs are also a predisposing factor. Health beliefs are attitudes, values and knowledge that people have about health and health services that influence their perception of need and use of health services. Enabling resources include accessibility and availability of family and community resources such as income, health insurance, a regular source of care, travel to services and waiting times. Need factors refer to both perceived and evaluated need. Perceived need is an individual's judgments of their health status, how they experience symptoms of illness and whether or not they judge their problems to be of sufficient magnitude to seek professional help. Evaluated need represents professional judgment about that person's health status and the need for medical care. 
Health behavior factors represent a compound measure of personal health practices such as diet and exercise interacting with the use of formal health services including type, site, purpose and coordinated services in an episode of illness (Andersen, 1995).

Outcomes include perceived and evaluated health status and consumer satisfaction (Andersen, 1995). Perceived health status reflects the health status, as understood by the population itself while evaluated health status refers to the health status as evaluated by professionals. Consumer satisfaction is a clear outcome of health services including convenience, availability, financing, provider characteristics and quality of care. The feedback loops in the model reflect the dynamic and recurrent nature of a health services model.

A major contribution of Andersen's model is the proposed measures of access. Andersen presents four concepts within access that can be viewed through the conceptual framework (Andersen, 1995). Potential access is the presence of enabling resources or those means that allow the individual to seek care. Realized access is the actual use of care. Equitable access occurs when demographic characteristics and need regulate who obtains healthcare services. Whereas, inequitable access is a result of social structure (e.g. ethnicity), health beliefs and enabling resources (e.g. income) determining who receives medical care.

Andersen also introduces the concept of mutability of his factors (Andersen, 1995). To be considered useful for promoting equitable access, a variable must be mutable or point to policy that might bring about behavior changes. For example, 
demographic variables have low mutability since age cannot be altered to change utilization. Social structure is also low because ethnicity cannot be changed and occupational/educational status is not easily transformed. Health beliefs are assigned medium mutability because they can be altered and sometimes affect behavior change. The RAND corporation study (Goldman, 2004) changed a highly mutable factor by doubling copayments. This change resulted had a significant impact on health services utilization as medication adherence declined.

Andersen's model presents a broad framework of various factors that influence health services utilization. In theory, all variables described in the model would be measured to adequately assess health care utilization but this study utilizes pre-existing data from a database and data required to assess each variable is not readily available. For purposes of this study, the Andersen's model framework serves as a theoretical guide to assess the impact of the Medicare Part D coverage gap on Medicare health plan members' diabetic medication adherence, based upon the availability of the data. Figure 4 illustrates the model with variables included in this study.

Environment factors indicate a measure of external environment factors and health care system factors, such as national policy. In this study, the national policies of interest are the ACA and the Medicare Part D coverage gap limits set by the Center for Medicare and Medicaid Services (CMS). 
Figure 4. Andersen's Behavioral Model of Health Service Use (with variables used in this study) (Andersen, 1995)

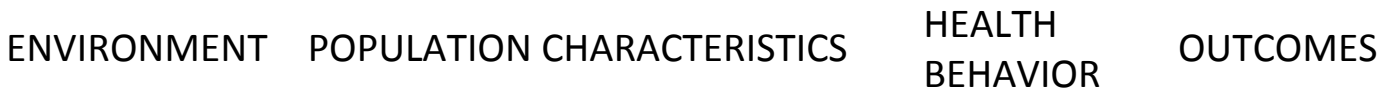

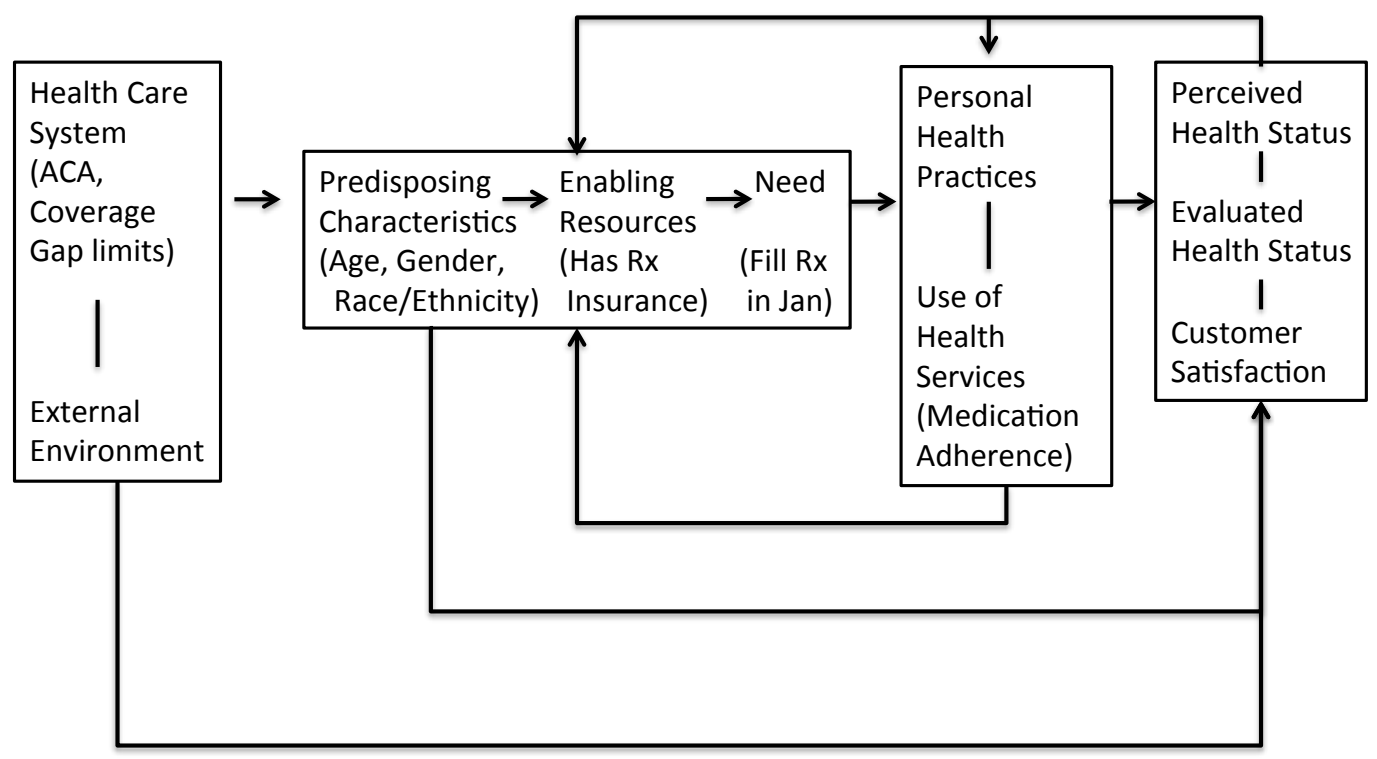

Predisposing factors, such as demographic variables were easily assessed in this study, including age, gender and race/ethnicity. Data representing social status, such as marital status, education, occupation, co-morbidities and an individual's health beliefs and attitudes, were not available. The enabling resource considered in this study was prescription drug insurance, as an individual's access to a prescription drug benefit might influence their medication utilization. Need factors refer to an individual's perceptions of their health status and their need for medical care. While the data does not provide a 
direct measurement of need factors, an individual's choice to fill their diabetic medication might be reflective of their perception of their health status and their need for medical care. Therefore, filling diabetic medication in January of the respective plan year was used as a need factor in this study.

Health behavior factors are a compound measure of an individual's personal health practices and health services use. Information related to the health plan member's personal health practices was not available in the data. However, the health behavior assessed in this study refers to an individual's prescription refill behavior and medication adherence before they reach the coverage gap and while in the coverage gap phase of their benefit. While health behavior assessment reflects the desired outcome to be measured in this study, the data available for this study did not allow for measurement of the outcomes listed in Andersen's health behavior model and were abridged at measurement of health services use, (i.e. medication adherence).

The aim of this study was to assess the impact of the Medicare Part D coverage gap on medication adherence by using a methodologically sound research design theoretically guided by the economic theory and Andersen's Behavioral Model of Health Services Use. The goal of the research was to accurately identify when a health plan member enters the coverage gap, incorporate health plan pharmacy data, include a control group, account for confounding variables, use a validated measure of adherence and apply statistically sound techniques for data analyses. Details of the methods used to assess the study objectives are provided in chapter 3 . 


\section{CHAPTER 3}

\section{METHODS}

\section{Study Design}

A retrospective, pre-post cohort analysis with control group study design was used to assess the study objectives. The study objectives examined medication adherence of health plan members enrolled in a health plan with no prescription drug coverage during the coverage gap (study group) compared with that of health plan members enrolled in a plan with no coverage gap (control group). The study objectives also examined medication adherence of the study group before they enter the coverage gap and while they are in the coverage gap. Pharmacy claims data from a large managed care organization with over 7 million lives and spanning 50 states was utilized. Data was extracted for the period January 1, 2009 to December 31, 2014. All analyses were conducted utilizing SAS Enterprise Guide version 5.1.

\section{Population}

The population of interest in this study consisted of Humana Medicare Part D health plan members who reached the coverage gap benefit phase and utilized Humana mail order pharmacy to fill diabetic medications between 2009 and 2014. It should be noted that Humana mail order does not offer auto-refill for Medicare members but does outreach to members to encourage a refill when eligible. The comparison group consisted 
of Humana Medicare Part D health plan members who did not face a gap in coverage at any period during the study years and utilized Humana mail order pharmacy to fill diabetic medications.

Study participants included Medicare health plan members enrolled in a Medicare Advantage prescription drug (MAPD) or Medicare Part D prescription drug (PDP) plan offered by Humana, Inc. In order to qualify for the study group, health plan members must have been enrolled in a plan that offered no coverage in the gap. In order to be considered for inclusion in the control group, health plan members must have been enrolled in a plan with no lapse in benefit (i.e., the coverage gap), such as Low Income Subsidy (LIS) Medicare Part D plans.

Humana, Inc. is the second largest national insurer of Medicare Part D health plan members. Total Medicare Part D enrollment as reported by CMS for years 2007 and 2014 is presented in Figure 5 (Medicare Payment Advisory Commission, 2015). During that time, Humana retained a significant amount of market share at 18 and 17 percent, respectively. 
Figure 5. Enrollment by plan sponsor (Medicare Payment Advisory Commission, 2015)

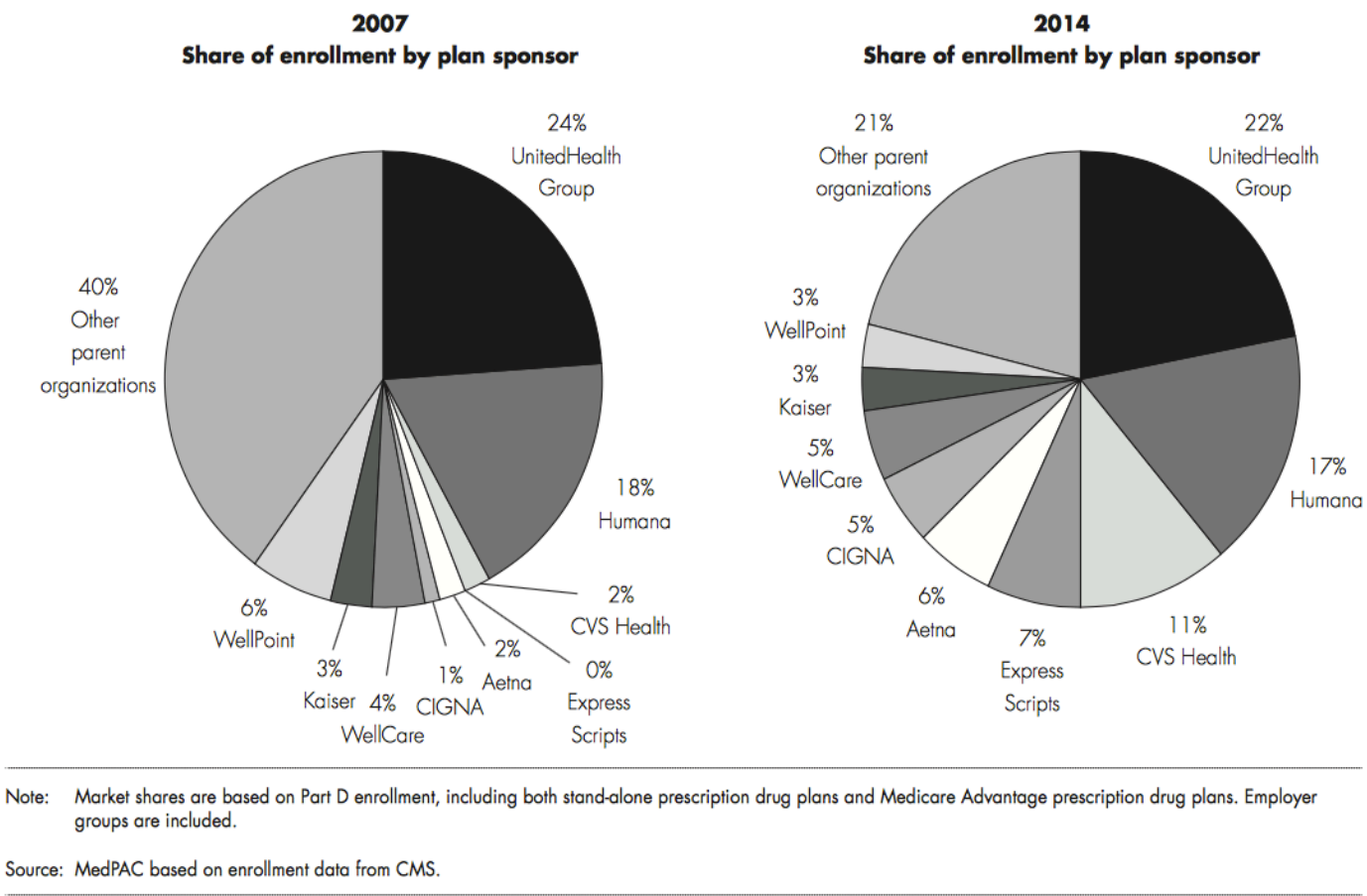

\section{Eligibility Criteria}

Health plan members were eligible for inclusion in the analysis if they had at least one prescription claim for a medication of interest at Humana's mail order pharmacy during the month of January in plan years 2009, 2010, 2011, 2012, 2013 or 2014. The date of the first fill of a study medication during the intake period was defined as the index fill.

Health plan members in the study group were Medicare Part D prescription drug plan (PDP) or Medicare Advantage (MAPD) health plan members aged 18 to 89 years at the beginning of the plan year with 12 months continuous enrollment in a plan year. Eligible health plan members must have reached the Medicare coverage gap between 
April 1st and September 30th during the respective plan year. The April to September time period is used in order to measure medication adherence both pre-coverage gap and within the coverage gap. Eligible health plan members for the comparison group must have been enrolled in a low-income subsidy (LIS) PDP or MAPD plan that offered continuous benefits with no deductible or coverage gap phases.

Adherence to generic and brand medications was calculated separately. Generic formulations of the study drugs were identified using a generic product indicator (GPI) variable for each drug in each year of the database. Eligible health plan members had a fill of one or more of the study medications. The diabetes medications of interest include all medications listed in Table 2 with the exception of insulin. Adherence was calculated using the days supply field found on the pharmacy claim. Pharmacy claims data for insulin does not have a quantifiable days supply. Moreover, it is not possible to calculate a PDC for any medication taken on an as needed basis or with a variable dosage unit per day (McKenzie, Lenz, Gillespie, \& Skradski, 2012). Injectable medications with a fixed unit dose were included.

The disease of interest in this study was Type 2 diabetes but medical data was not available for all health plan members to confirm a diagnosis by way of medical claims. Daily management of Type 1 diabetes is managed by balancing insulin, diet and exercise (Mehta et al., 2015). Therefore, it was assumed that excluding insulin from the study medications limited the population to those diagnosed with Type 2 diabetes. 


\section{Description of study variables}

\section{a) Independent Variable}

The independent variable in this study was the coverage gap status of individuals. The coverage gap status was evaluated at two levels: pre- gap and gap. Pre-coverage gap refers to the period before an individual hits the coverage gap and gap refers to the period during the coverage gap.

\section{Determination of benefit phases}

In order to assess whether a Medicare health plan member enters the coverage gap, total costs and true out-of-pocket (TrOOP) costs must be calculated. Total costs represent those associated with filling a prescription drug and include the amount the health plan pays and the amount a health plan member pays (co-pay or member responsibility amount) after filling a prescription drug.

True out-of-pocket costs, on the other hand, include only costs incurred by the health plan member. TrOOP costs are the prescription drug costs that count toward the annual out- of-pocket threshold that health plan members must reach before the catastrophic drug benefit phase begins (Center for Medicaid and Medicare Services, 2014). Payment that counts toward TrOOP includes the amount a person pays for covered prescriptions before the plan begins to pay (the deductible phase), the amount a person pays for each covered prescription after the plan begins to pay (copayments or coinsurance during initial coverage period) and payments made for a covered prescription while in the coverage gap. 
Payments for TrOOP eligible costs can be made by any of the following (Center for Medicaid and Medicare Services, 2014):

- The person enrolled in a Medicare drug plan (including payments from his or her Medical Savings Account [MSA], Health Savings Account [HSA], or Flexible Spending Account [FSA])

- Family of the health plan member or friends

- Qualified State Pharmacy Assistance Programs (SPAPs)

- Medicare's Extra Help (low-income subsidy)

- Most charities (unless they're established, run, or controlled by the person's current or former employer or union or by a drug manufacturer's Patient Assistance Program operating outside Part D)

- Drug manufacturers providing discounts under the Medicare coverage gap discount program

- Indian Health Service (IHS)

- AIDS Drug Assistance Programs (ADAPs)

The drugs must be on the plan's formulary or treated as "on formulary" due to a coverage determination, exceptions process or appeal. The drugs must be purchased at an innetwork pharmacy or in accordance with the health plan's out of network policy.

Payments that do not count toward TrOOP costs include the drug cost share paid by the plan, monthly plan premiums paid by the health plan member, drugs purchased outside the U.S and its territories, drugs not covered by the plan, drugs that are excluded from the definition of Part D drug (even in cases where the plan chooses to cover them) 
and over-the-counter (OTC) drugs (even in cases where the plan requires them for step therapy) (Center for Medicaid and Medicare Services, 2014).

Payments do not count toward TrOOP if made by the following (Center for Medicaid and Medicare Services, 2014):

- Group health plans such as the Federal Employees Health Benefit Program (FEHBP) or employer or union retiree coverage

- Government-funded health programs such as Medicaid, TRICARE, Workers' Compensation, the Department of Veterans Affairs (VA), Federally Qualified Health Centers (FQHCs), Rural Health Clinics (RHCs), the Children's Health Insurance Program (CHIP), and black lung benefits

- Other third-party groups with a legal obligation to pay for the person's drug costs

- Patient Assistance Programs (PAPs) operating outside the Part D benefit

- Other types of insurance

For health plan members enrolled in standard Part D plans, the table below was used to determine benefit phases for the respective plan year.

Table 4. 2009-2014 Medicare Part D Standard Benefit Model Plan Parameters, including True Out-Of-Pocket (TrOOP) amounts (Q1Group)

\begin{tabular}{|l|l|l|l|}
\hline Year & $\begin{array}{l}\text { Initial } \\
\text { Deductible }\end{array}$ & $\begin{array}{l}\text { Total Drug Cost for } \\
\text { Coverage Gap } \\
\text { Entry }\end{array}$ & $\begin{array}{l}\text { TrOOP for } \\
\text { Catastrophic } \\
\text { Coverage }\end{array}$ \\
\hline $\mathbf{2 0 0 9}$ & $\$ 295$ & $\$ 2,700$ & $\$ 4,350$ \\
\hline $\mathbf{2 0 1 0}$ & $\$ 310$ & $\$ 2,830$ & $\$ 4,550$ \\
\hline $\mathbf{2 0 1 1}$ & $\$ 310$ & $\$ 2,840$ & $\$ 4,550$ \\
\hline $\mathbf{2 0 1 2}$ & $\$ 320$ & $\$ 2,930$ & $\$ 4,700$ \\
\hline $\mathbf{2 0 1 3}$ & $\$ 325$ & $\$ 2,970$ & $\$ 4,750$ \\
\hline $\mathbf{2 0 1 4}$ & $\$ 310$ & $\$ 2,850$ & $\$ 4,550$ \\
\hline
\end{tabular}


The following methodology was used to assess whether a health plan member hit the coverage gap or moved on to catastrophic coverage:

1) Total drug costs (drug cost + dispensing fee) were calculated for each health plan member. The next step involved determining health plan members who had total costs less than the total drug cost for coverage gap entry for the plan year and plan members who had total costs less than the threshold. For 2009 , this amount was $\$ 2,700$. Health plan members who had total costs less than $\$ 2,700$ represented those who remained in the initial coverage limit. Health plan members who had total costs greater than $\$ 2,700$ were those who hit the coverage gap.

2) For health plan members with total drug costs greater than $\$ 2,700$, their TrOOP costs were calculated. For plan year 2009, health plan members who incurred TrOOP costs less than or equal to $\$ 4,350$ and health plan members who incurred TrOOP costs greater than $\$ 4,350$ were identified. Health plan members with TrOOP costs less than or equal to $\$ 4,350$ represented those who remained in the coverage gap through the entire year. Health plan members with TrOOP costs greater than $\$ 4,350$ represented those who were covered under the catastrophic coverage limit.

\section{b) Dependent Variable or Outcome Measure}

Medication adherence is the primary outcome measure of this study. Adherence was calculated using portion of days covered (PDC), which is the method endorsed by the Pharmacy Quality Alliance (PQA) (Nau). PDC is also the medication adherence measure used by CMS to assign stars to health plans from which quality bonus payments are calculated (Green, 2013). Based on numerous studies of the relationship of 
medication adherence and healthcare outcomes, PQA selected 0.8 (or 80 percent) as the threshold above which the patient can be considered to be adherent for most classes of chronic medications, including diabetic medications.

\section{Steps and Assumptions considered for medication adherence calculation}

The following steps and assumptions were considered to calculate medication adherence:

1) An adherence value was calculated for each Medicare health plan member. The pregap PDC reflects adherence before a health plan member hits the coverage gap and the gap-PDC reflects adherence during the coverage gap.

2) The day a health plan member's total costs are equal to the coverage gap limit for that year, was considered as the day a health plan member hits the coverage gap. All prescriptions filled on the day a health plan member hits the coverage gap were considered as prescriptions filled after hitting the coverage gap.

3) Medication adherence was calculated by using the health plan member's January index fill as the start date and December 31 st as the end date.

4) If a health plan member's days supply for their last fill was greater than the number of days in the calendar year, then the days supply was truncated to reflect the number of days left in the calendar year.

5) The variable days supply associated with dosage forms such as an injectable (e.g. insulin) may result in incorrect estimates. Thus, as is frequently done in studies assessing medication adherence, only oral dosage and fixed dose injectable forms were considered for the purposes of medication adherence calculations. 
6) Medication adherence was calculated per drug class and not for specific drugs. As long as a health plan member filled any medication within a drug class, the health plan member was considered adherent.

7) It is assumed that a health plan member is prescribed only one medication per drug class.

\section{Portion of Days Covered (PDC) Calculation}

The PDC measures the quantity of days a health plan member has a drug available during the study interval by assigning a simple binary measure indicating the presence or absence of the study drug for each day in the study period. Therefore, drug oversupplies from early refills are not included in PDC calculations. The PDC is a ratio with a range of $0-1$, with a higher number indicating higher adherence. A ratio of greater than 1.0 is not possible, as the PDC is capped at 1.0 (Martin et al., 2009).

$$
\text { PDC }=\frac{\text { Total Days Medication is Available }}{\text { Total Number of Days Evaluated }} \times 100
$$

The numerator in the PDC was calculated by utilizing claims data to determine if a health plan member had medication coverage for each day in the study period. Dummy variables with values of 0 or 1 were assigned to each day in the period. If a health plan member had prescription drug coverage for a particular day they were assigned a value of 1. If they did not have prescription drug coverage for a particular day they were assigned a value of 0 . The sum of all days that a health plan member had medication coverage provided the numerator for the PDC calculation. This approach is common when measuring PDC for a therapeutic class, where health plan members are concurrently prescribed more than one medication from within the same therapeutic class. It is also 
useful to account for drug switches, addition of drugs within a class and early refills. Counting medications per day prevents over-estimation of adherence values.

\section{Propensity Score Matching}

Propensity score matching (PSM), first published by Paul Rosenbaum and Donald Rubin in 1983, is a statistical matching technique that attempts to estimate the effect of a treatment, policy or other intervention by accounting for the covariates that predict receiving the treatment (Rosenbaum \& Rubin, 1983). PSM involves forming matched sets of treated and untreated subjects that share a similar value of the propensity score (Austin, 2014). PSM attempts to reduce the bias due to confounding variables that could be found in an estimate of the treatment effect obtained from simply comparing outcomes among health plan members that received the treatment versus those that did not. Matching attempts to mimic randomization by creating a sample of health plan members that received the treatment that is comparable on all observed covariates to a sample of health plan members that did not receive the treatment.

Propensity score matching utilized the traditional framework of matching two groups to make them comparable but rather than match individually on multiple variables, it matches them on a single indicator, the propensity score (Rosenbaum \& Rubin, 1983). When matching, controls from the low-income subsidy group were selected who had similar propensity scores to those in the treatment group (those with a coverage gap). The goal was a dataset of treatments and controls with similar characteristics on all key variables that were used to define the propensity scores. The propensity score is defined as the probability of being in the treatment group given the 
individual's level on the covariates included in the model (Rosenbaum \& Rubin, 1983). The propensity score was estimated using a logistic regression model. Logistic regression makes no assumptions about the distributions of the covariates on the dichotomous outcome (D'Agostino 1998). A single propensity score was estimated for every individual in the study, both treatments and controls. This propensity score was then used to adjust for the differences between the two groups on the observed covariates in the study. Thus, the propensity score allows researchers to control for a large number of background covariates simultaneously based on a single number (Rosenbaum \& Rubin, 1983).

Based on Andersen's Behavioral Model of Health Services Use as described in depth in chapter 2 and a review of the literature citing factors affecting medication adherence, the following variables were used as covariates: age, gender and race (Andersen, 1995; Zhang et al., 2013). Data on age, gender and race were readily available from the data set.

A random id variable was introduced to allow a different ordering of data for the match in order to approximate a randomized control trial. The matching method used was the Nearest Neighbor Without Replacement Caliper Match. "Nearest Neighbor" signifies treatments are being assigned to controls based on the first pairing that meets the matching criteria. "Without Replacement" denotes controls are removed once matched to a case so the controls cannot be matched to more than one case. "Caliper" refers to the number of decimals used in matching and acts as a constraint to allow the matching algorithm to be more or less restrictive. Medical literature recommends that, in most situations, nearest neighbor caliper matching without replacement (random order or closest distance) be used when forming pairs of treated and untreated subjects with 
similar values of the propensity score (Austin, 2014). This approach tended to result in estimates with minimal bias compared with other algorithms across a wide range of scenarios.

\section{Data analyses required to address objectives:}

1) To evaluate diabetes medication adherence of health plan members before they reach the coverage gap and then while they are in the coverage gap.

Data: Pharmacy claims data for Medicare health plan members with no prescription drug coverage during the coverage gap.

Analysis: Statistical significance was assessed at $\alpha=0.05$ using a paired t-test to compare the pre-coverage and coverage gap mean PDC

Table 5. Proposed data layout to evaluate Objective 1

\begin{tabular}{|l|l|l|l|}
\hline Year & $\begin{array}{c}\text { Pre Coverage Gap } \\
\text { mean PDC }\end{array}$ & $\begin{array}{c}\text { Coverage Gap } \\
\text { mean PDC }\end{array}$ & $\begin{array}{c}\text { Statistical } \\
\text { Significance }\end{array}$ \\
\hline 2009 & & & \\
\hline 2010 & & & \\
\hline 2011 & & & \\
\hline 2012 & & & \\
\hline 2013 & & & \\
\hline 2014 & & & \\
\hline
\end{tabular}

2) To compare diabetes medication adherence between two similar groups with differing benefit structures, one group with a gap in coverage as opposed to a group with no benefit changes within the year.

Data: Pharmacy claims data for Medicare health plan members enrolled in plans with no gap in coverage and Medicare health plan members without any prescription drug coverage during the coverage gap. 
Analysis: Statistical significance was assessed at $\alpha=0.05$ using a paired t-test to compare the control and treatment mean PDC by year.

Table 6. Proposed data layout to evaluate Objective 2

\begin{tabular}{|l|c|c|c|}
\hline Year & $\begin{array}{c}\text { Control Group } \\
\text { mean PDC }\end{array}$ & $\begin{array}{c}\text { Treatment Group } \\
\text { mean PDC }\end{array}$ & $\begin{array}{c}\text { Statistical } \\
\text { Significance }\end{array}$ \\
\hline 2009 & & & \\
\hline 2010 & & & \\
\hline 2011 & & & \\
\hline 2012 & & & \\
\hline 2013 & & & \\
\hline 2014 & & & \\
\hline
\end{tabular}

3) To examine diabetes medication adherence trend over multiple years as the coverage gap is closed.

Data: Pharmacy claims data for Medicare health plan members enrolled in plans with no gap in coverage and Medicare health plan members without any prescription drug coverage during the coverage gap.

Analysis: Statistical significance was assessed at $\alpha=0.05$ using a paired t-test to compare 2009 mean PDC to each subsequent year for both control and treatment groups.

Table 7. Proposed data layout to evaluate Objective 3

\begin{tabular}{|l|l|l|}
\hline & $\begin{array}{c}\text { Control Group } \\
\text { Statistical } \\
\text { Significance }\end{array}$ & $\begin{array}{c}\text { Treatment } \\
\text { Group } \\
\text { Statistical } \\
\text { Significance }\end{array}$ \\
\hline 2009 vs 2010 & & \\
\hline 2009 vs 2011 & & \\
\hline 2009 vs 2012 & & \\
\hline 2009 vs 2013 & & \\
\hline 2009 vs 2014 & & \\
\hline
\end{tabular}




\section{Confidentiality}

The University of Louisville Institutional Review Board (IRB) evaluated and granted approval for this study after an expedited review. A copy of the approval letter is included in Appendix A.

\section{Summary}

This study focuses on Medicare health plan members utilizing diabetic medications from a mail order pharmacy. A retrospective, pre-post cohort analysis with control group study design was used to determine the effect of the Medicare Part D coverage gap on diabetic medication adherence. Medicare health plan members who met the study inclusion criteria were selected from the health plan's covered 7 million lives. For members in the study group, total costs and TrOOP were calculated to determine whether they entered the coverage gap. Members of the comparison group had no gap in coverage during the respective plan year.

Pre-coverage gap and within coverage gap analysis was conducted for the study group. Medication adherence was calculated using PDC, which is the method endorsed by the PQA and used by CMS to assign health plan star ratings. Propensity score matching was used to obtain balanced control and treatment groups based on covariates of age, race and gender. The PSM models were analyzed for goodness of fit. Mean adherence was analyzed between the groups along with the mean medication adherence 
trend over multiple years as the coverage gap is closed due to the ACA. The results obtained from the data analyses are presented in Chapter 4. 


\section{CHAPTER 4}

\section{RESULTS}

This chapter begins with a discussion of the study population and specifics regarding the inclusion/exclusion process. Next, details of those reaching the coverage gap are presented. In the following section, results of the descriptive analyses of precoverage gap and within coverage gap diabetic medication adherence are provided. Then, propensity score matching models are delivered and goodness of fit test results presented. Finally, diabetic medication adherence results from the propensity score matched groups are offered and compared.

\section{Study Population}

The study sample was selected from Humana Medicare health plan members enrolled in a Medicare Advantage (MAPD) prescription drug plan or Part D plan (PDP) during the study years of interest. The health plan members were divided into two cohorts by brand or generic diabetic medication utilization. Generic formulations of the study drugs were identified using a generic product indicator (GPI) variable for each drug in each year of the database.

The following criteria were utilized to determine inclusion/exclusion of the treatment group: 
1) At least one prescription claim for a medication of interest at Humana's mail order pharmacy during the month of January in plan years 2009, 2010, 2011, 2012,2013 or 2014

2) Aged 18 to 89 years at the beginning of the plan year

3) Exclusion of members eligible for Low Income Subsidy (LIS) benefit (these members were utilized for the control group if they met eligibility criteria in the next step)

4) 12 months continuous enrollment in a plan year

5) Reached the Medicare coverage gap spending limits between April 1st and September 30th during the respective plan year

Figure 6 presents the study sample and health plan members using brand diabetic medications that reached the coverage gap. Figure 7 presents the study sample and health plan members using generic diabetic medications that reached the coverage gap. There is a significant decrease in study population during the last step because a relatively small percent (12-14 percent) of overall Part D health plan members have spending to reach the coverage gap. 


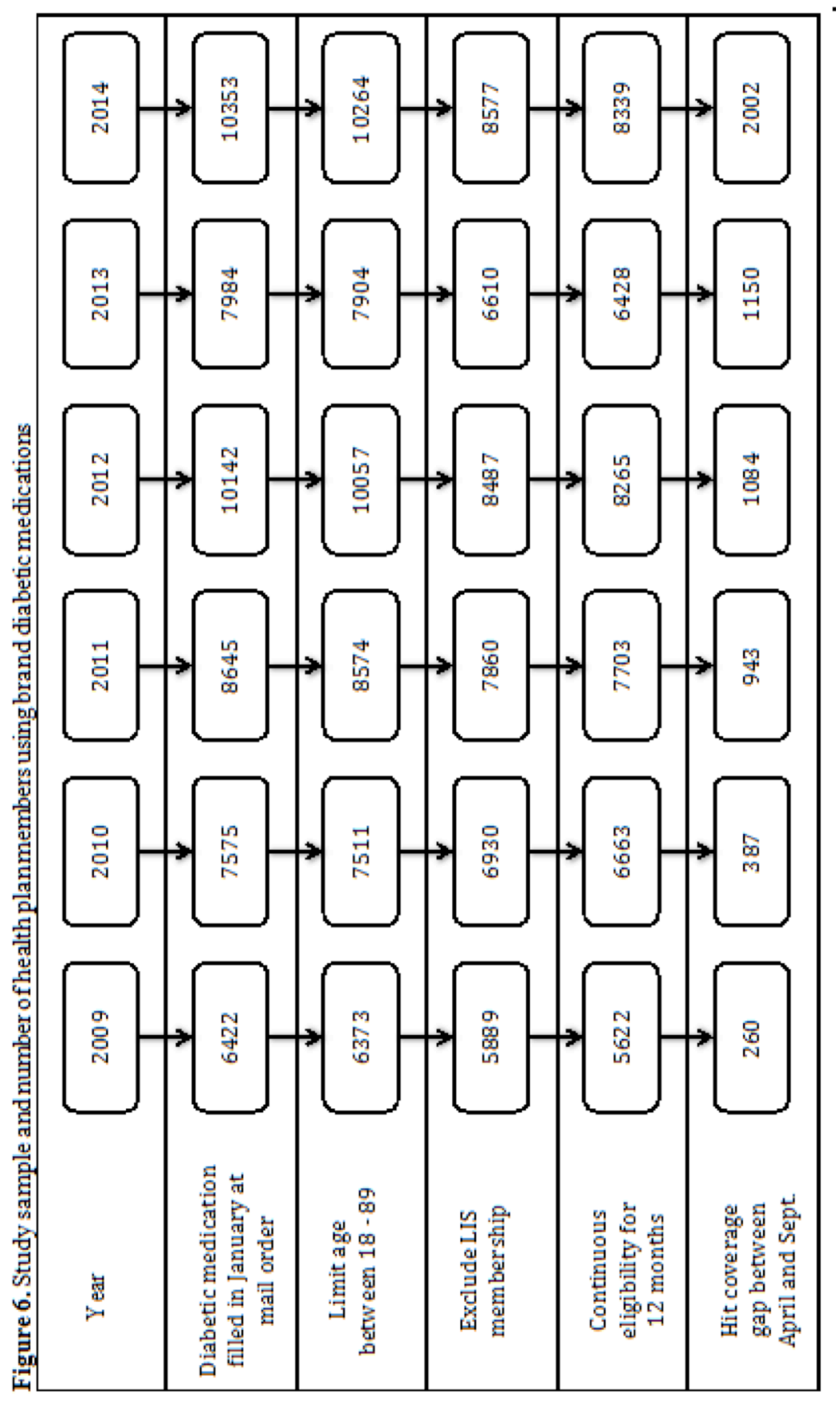




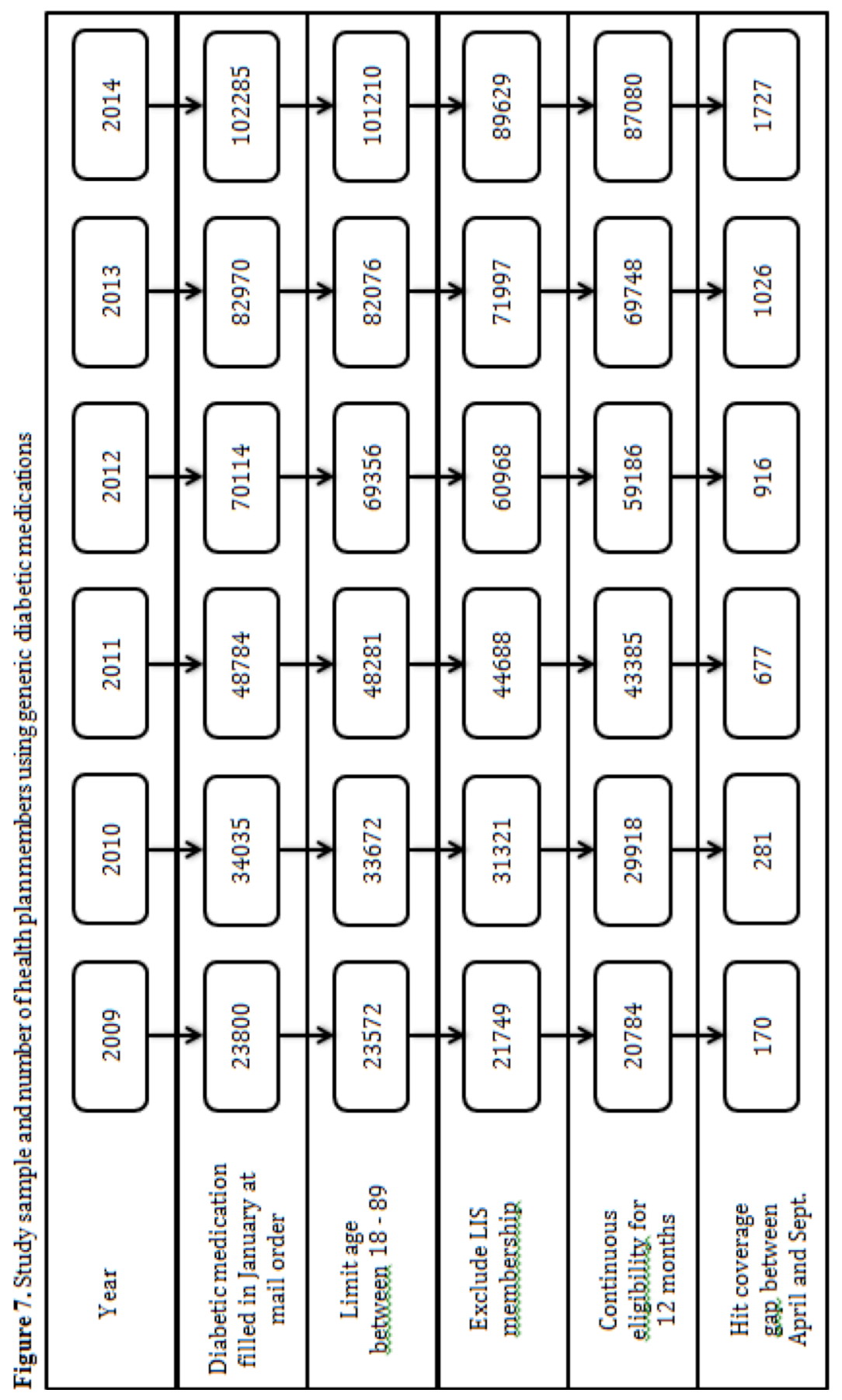




\section{Coverage gap}

Of the health plan members who met the study inclusion and exclusion criteria, a greater percentage of brand diabetic medication utilizers entered the coverage gap as compared with those utilizing generic medication. As shown in Figure 8, the percentage of health plan members reaching the coverage gap increased steadily each year for the brand cohort. The generic cohort exhibited a slight increase year over year with the exception of years 2012-2013.

Figure 8. Percent of eligible study participants who reach the coverage gap by cohort and year

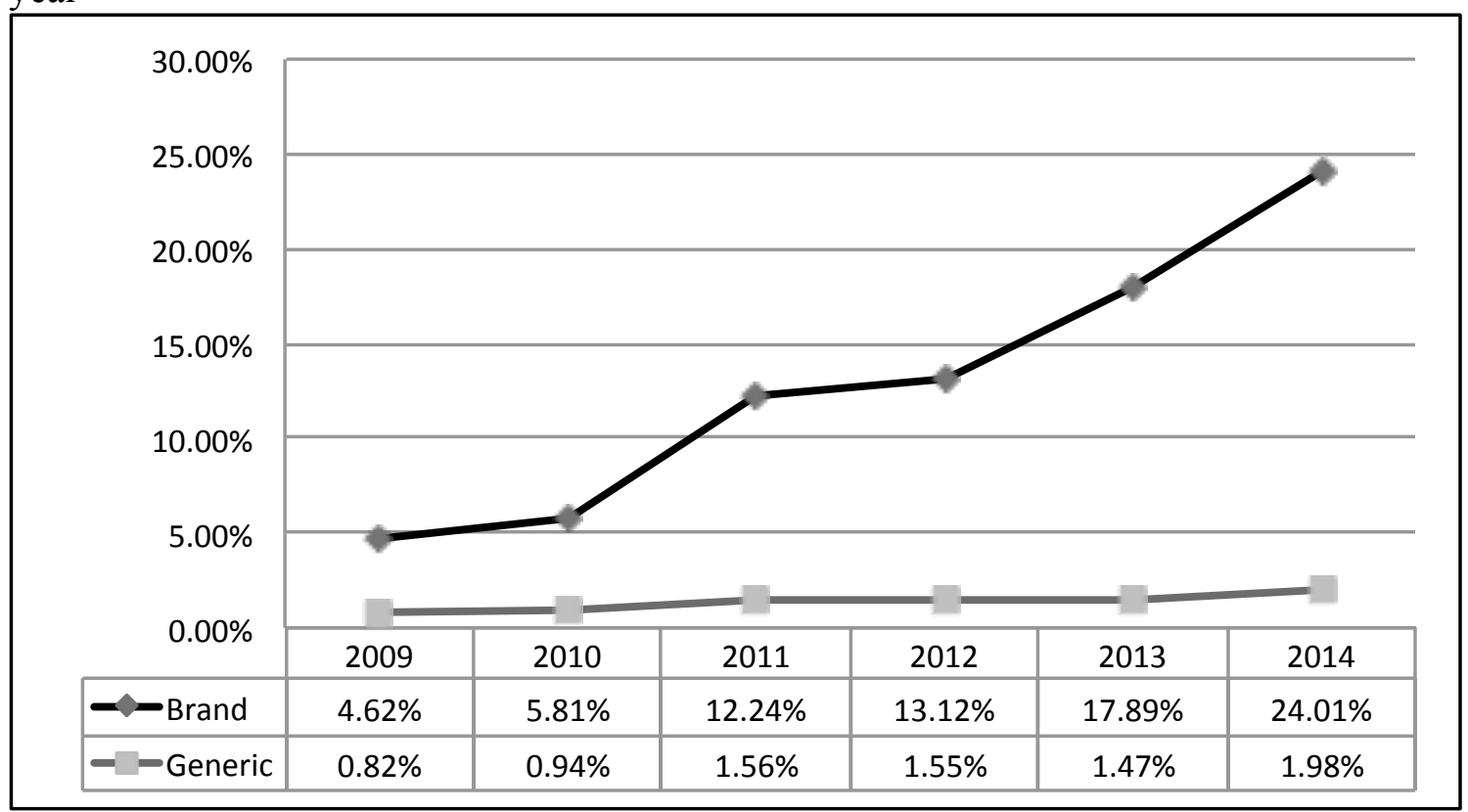

\section{Coverage gap month}

The percent of health plan members who entered the coverage gap between April and September, by cohort are shown in Figures 9 and 10. Of those members who entered the coverage gap in this study, the largest percentage moved into the coverage gap in September, regardless of cohort. 
Figure 9. Percent of health plan members utilizing brand diabetic medications who reach the coverage gap between April and September, by month

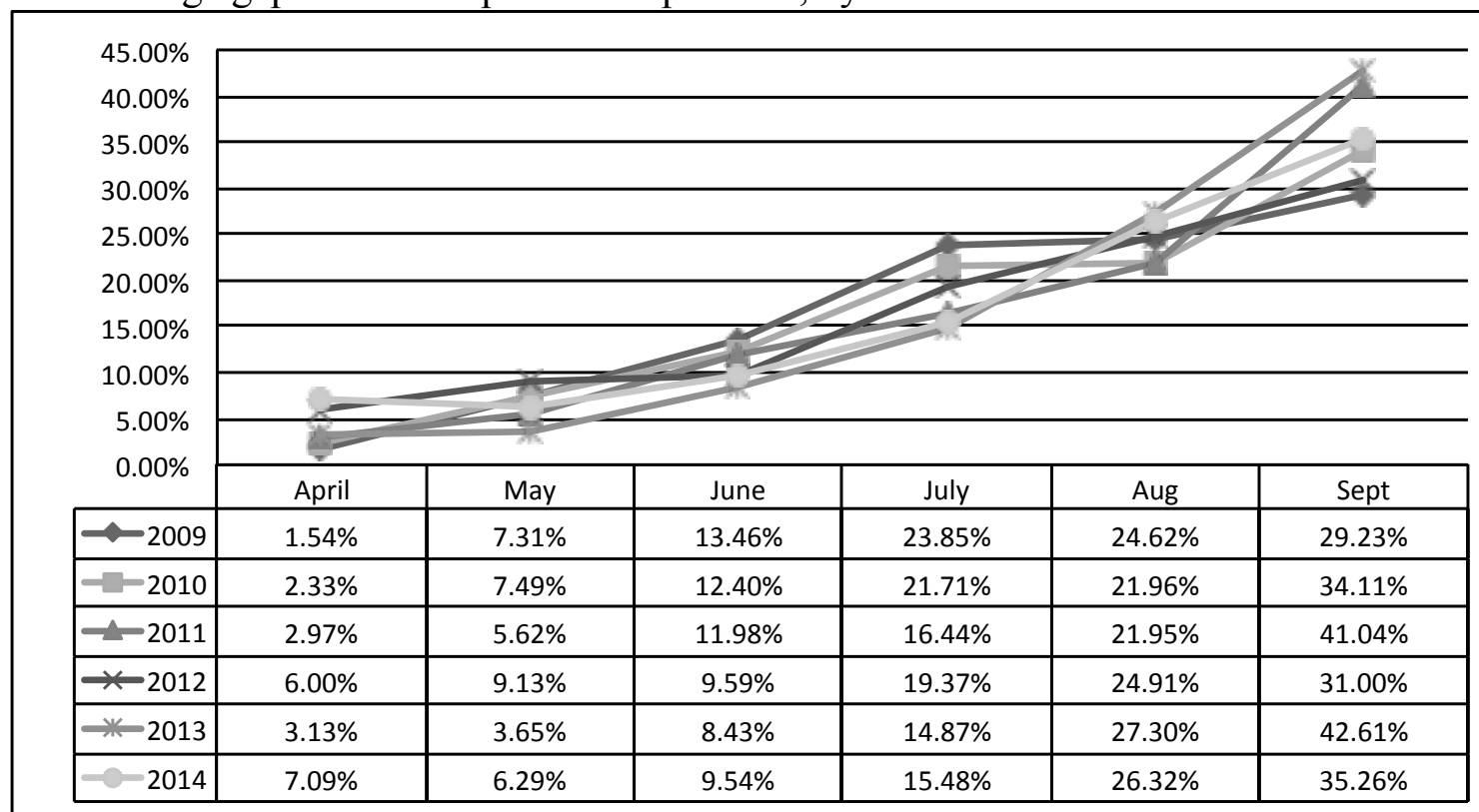

Figure 10. Percent of health plan members utilizing generic diabetic medications who reach the coverage gap between April and September, by month

\begin{tabular}{|c|c|c|c|c|c|c|}
\hline \multicolumn{7}{|l|}{$50.00 \%$} \\
\hline \multicolumn{7}{|l|}{$45.00 \%$} \\
\hline \multicolumn{7}{|l|}{$\begin{array}{l}40.00 \% \\
35.00 \%\end{array}$} \\
\hline \multicolumn{7}{|l|}{$\begin{array}{l}30.00 \% \\
25.00 \%\end{array}$} \\
\hline \multicolumn{7}{|l|}{$20.00 \%$} \\
\hline \multirow{4}{*}{$\begin{array}{r}15.00 \% \\
10.00 \% \\
5.00 \% \\
0.00 \%\end{array}$} & & & & 2 & & \\
\hline & \multicolumn{6}{|c|}{$=2=$} \\
\hline & \multicolumn{6}{|c|}{2} \\
\hline & April & May & June & July & Aug & Sept \\
\hline-2009 & $1.18 \%$ & $7.06 \%$ & $12.35 \%$ & $18.24 \%$ & $28.82 \%$ & $32.35 \%$ \\
\hline-2010 & $1.07 \%$ & $6.41 \%$ & $11.74 \%$ & $21.71 \%$ & $21.71 \%$ & $37.37 \%$ \\
\hline-2011 & $2.36 \%$ & $5.32 \%$ & $10.49 \%$ & $16.99 \%$ & $21.71 \%$ & $43.13 \%$ \\
\hline$\times 2012$ & $6.77 \%$ & $10.26 \%$ & $10.59 \%$ & $19.21 \%$ & $23.80 \%$ & $29.37 \%$ \\
\hline$-*-2013$ & $4.39 \%$ & $5.46 \%$ & $9.16 \%$ & $17.74 \%$ & $26.90 \%$ & $36.35 \%$ \\
\hline-2014 & $5.73 \%$ & $5.73 \%$ & $10.42 \%$ & $18.07 \%$ & $25.88 \%$ & $34.16 \%$ \\
\hline
\end{tabular}


It is possible for health plan members to fall into both cohorts if they are using both brand and generic medications. A breakout of these groups is provided in Table 8 . The percentage of health plan members using only generic medications increased while the groups using only brand medications and both medications declined over the study period.

Table 8. Percent of total health plan members utilizing brand only, generic only or both

\begin{tabular}{|l|c|c|c|c|c|c|}
\hline & $\mathbf{2 0 0 9}$ & $\mathbf{2 0 1 0}$ & $\mathbf{2 0 1 1}$ & $\mathbf{2 0 1 2}$ & $\mathbf{2 0 1 3}$ & $\mathbf{2 0 1 4}$ \\
\hline Brand only & $41 \%$ & $34 \%$ & $35 \%$ & $33 \%$ & $35 \%$ & $36 \%$ \\
\hline Generic only & $9 \%$ & $8 \%$ & $11 \%$ & $21 \%$ & $27 \%$ & $26 \%$ \\
\hline $\begin{array}{l}\text { Both generic } \\
\text { and brand }\end{array}$ & $50 \%$ & $57 \%$ & $53 \%$ & $46 \%$ & $38 \%$ & $39 \%$ \\
\hline
\end{tabular}

Figures 11-13 present the percent of health plan members who hit the gap by month based on whether they used brand, generic or both medications.

Figure 11. Percent of health plan members utilizing only brand diabetic medications who reach the coverage gap between April and September, by month

\begin{tabular}{|c|c|c|c|c|c|c|}
\hline \multirow{2}{*}{$\begin{array}{l}50.00 \% \\
45.00 \%\end{array}$} & & & & & & \\
\hline \multirow{2}{*}{\multicolumn{7}{|c|}{$40.00 \%$}} \\
\hline & & & & & & \\
\hline \multicolumn{7}{|l|}{$35.00 \%$} \\
\hline \multicolumn{7}{|l|}{$25.00 \%$} \\
\hline \multicolumn{7}{|l|}{$20.00 \%$} \\
\hline \multicolumn{7}{|l|}{$15.00 \%$} \\
\hline \multirow{3}{*}{$\begin{array}{r}10.00 \% \\
5.00 \% \\
0.00 \%\end{array}$} & \multicolumn{6}{|c|}{$\mathrm{C}, \mathrm{Z}=$} \\
\hline & \multicolumn{6}{|c|}{$=2$} \\
\hline & April & May & June & July & Aug & Sept \\
\hline-2009 & $1.75 \%$ & $6.14 \%$ & $12.28 \%$ & $28.95 \%$ & $21.05 \%$ & $29.82 \%$ \\
\hline-2010 & $4.29 \%$ & $8.57 \%$ & $13.57 \%$ & $21.43 \%$ & $25.71 \%$ & $26.43 \%$ \\
\hline-2011 & $3.17 \%$ & $6.33 \%$ & $13.72 \%$ & $15.83 \%$ & $23.22 \%$ & $37.73 \%$ \\
\hline$\rightarrow-2012$ & $4.97 \%$ & $9.94 \%$ & $10.37 \%$ & $18.14 \%$ & $25.27 \%$ & $31.32 \%$ \\
\hline-2013 & $1.65 \%$ & $3.30 \%$ & $8.07 \%$ & $12.66 \%$ & $28.62 \%$ & $45.69 \%$ \\
\hline-2014 & $7.98 \%$ & $6.06 \%$ & $8.62 \%$ & $14.47 \%$ & $26.38 \%$ & $36.49 \%$ \\
\hline
\end{tabular}


Figure 12. Percent of health plan members utilizing only generic diabetic medications who reach the coverage gap between April and September, by month

\begin{tabular}{|c|c|c|c|c|c|c|}
\hline \multirow{2}{*}{$\begin{array}{l}60.00 \% \\
50.00 \%\end{array}$} & & & & & & \multirow{2}{*}{$\Leftrightarrow$} \\
\hline & & & & & & \\
\hline $40.00 \%$ & & & & & & \\
\hline $30.00 \%$ & & & & & & \\
\hline $20.00 \%$ & & & & & & \\
\hline $10.00 \%$ & \multicolumn{4}{|c|}{$x^{2}=0$} & & \\
\hline $0.00 \%$ & April & May & June & July & Aug & Sept \\
\hline-2009 & $0.00 \%$ & $0.00 \%$ & $0.00 \%$ & $8.33 \%$ & $37.50 \%$ & $54.17 \%$ \\
\hline$-=2010$ & $0.00 \%$ & $2.94 \%$ & $11.76 \%$ & $20.59 \%$ & $35.29 \%$ & $29.41 \%$ \\
\hline-2011 & $0.00 \%$ & $6.19 \%$ & $8.85 \%$ & $17.70 \%$ & $24.78 \%$ & $42.48 \%$ \\
\hline$\rightarrow 2012$ & $6.78 \%$ & $13.90 \%$ & $13.90 \%$ & $16.95 \%$ & $22.03 \%$ & $26.44 \%$ \\
\hline$m-2013$ & $4.28 \%$ & $7.60 \%$ & $9.74 \%$ & $19.00 \%$ & $28.03 \%$ & $31.35 \%$ \\
\hline$-0-2014$ & $1.65 \%$ & $3.30 \%$ & $8.07 \%$ & $12.66 \%$ & $28.62 \%$ & $45.69 \%$ \\
\hline
\end{tabular}

Figure 13. Percent of health plan members utilizing both brand and generic diabetic medications who reach the coverage gap between April and September, by month

\begin{tabular}{|c|c|c|c|c|c|c|}
\hline \multicolumn{7}{|l|}{$50.00 \%$} \\
\hline \multicolumn{7}{|l|}{$45.00 \%$} \\
\hline \multicolumn{7}{|l|}{$40.00 \%$} \\
\hline \multicolumn{7}{|l|}{$35.00 \%$} \\
\hline \multicolumn{7}{|l|}{$30.00 \%$} \\
\hline \multicolumn{7}{|l|}{$25.00 \%$} \\
\hline \multicolumn{3}{|l|}{$20.00 \%$} & & & & \\
\hline \multirow{3}{*}{$\begin{array}{r}15.00 \% \\
10.00 \% \\
5.00 \% \\
0.00 \%\end{array}$} & \multicolumn{6}{|c|}{ 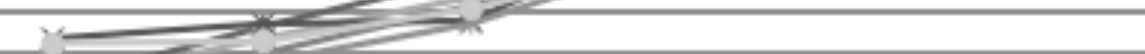 } \\
\hline & \multicolumn{6}{|c|}{2} \\
\hline & April & May & June & July & Aug & Sept \\
\hline-2009 & $1.37 \%$ & $8.22 \%$ & $14.38 \%$ & $19.86 \%$ & $27.40 \%$ & $28.77 \%$ \\
\hline$-2-2010$ & $1.21 \%$ & $6.88 \%$ & $11.74 \%$ & $21.86 \%$ & $19.84 \%$ & $38.46 \%$ \\
\hline-2011 & $2.84 \%$ & $5.14 \%$ & $10.82 \%$ & $16.84 \%$ & $21.10 \%$ & $43.26 \%$ \\
\hline-2012 & $6.76 \%$ & $8.53 \%$ & $9.02 \%$ & $20.29 \%$ & $24.64 \%$ & $30.76 \%$ \\
\hline-2013 & $4.46 \%$ & $3.97 \%$ & $8.76 \%$ & $16.86 \%$ & $26.12 \%$ & $39.83 \%$ \\
\hline-2014 & $6.31 \%$ & $6.50 \%$ & $10.36 \%$ & $16.38 \%$ & $26.27 \%$ & $34.18 \%$ \\
\hline
\end{tabular}




\section{Descriptive analyses of pre-coverage gap and within coverage gap medication}

adherence

Mean medication adherence by cohort for health plan members before they

reached the coverage gap and then while they were in the coverage gap is displayed in

Tables 9 and 10. As shown in the tables, overall pre-coverage gap medication adherence

was higher than medication adherence while in the coverage gap. Paired t-tests indicate

significant differences in the brand cohort for all years and the generic cohort for years

2010-2012.

Table 9. Univariate analysis comparing medication adherence pre-coverage gap and within the coverage gap for the brand cohort

\begin{tabular}{|l|l|l|l|l|l|l|l|l|l|l|}
\hline Brand & \multicolumn{3}{|l|}{$\begin{array}{l}\text { Pre-cov. gap } \\
\text { PDC }\end{array}$} & \multicolumn{2}{l|}{$\begin{array}{l}\text { Within cov. } \\
\text { gap PDC }\end{array}$} & \multicolumn{7}{l|}{ Paired T test } \\
\hline & N & Mean & SD & Mean & SD & Mean & SD & DF & t & p \\
\hline $\mathbf{2 0 0 9}$ & 260 & 0.901 & 0.097 & 0.861 & 0.184 & 0.040 & 0.207 & 259 & 3.15 & 0.0018 \\
\hline $\mathbf{2 0 1 0}$ & 387 & 0.909 & 0.080 & 0.868 & 0.168 & 0.041 & 0.185 & 296 & 4.33 & $<0.0001$ \\
\hline $\mathbf{2 0 1 1}$ & 943 & 0.909 & 0.078 & 0.857 & 0.159 & 0.051 & 0.178 & 942 & 8.84 & $<0.0001$ \\
\hline $\mathbf{2 0 1 2}$ & 1084 & 0.883 & 0.100 & 0.828 & 0.197 & 0.055 & 0.218 & 1083 & 8.32 & $<0.0001$ \\
\hline $\mathbf{2 0 1 3}$ & 1150 & 0.877 & 0.101 & 0.835 & 0.190 & 0.042 & 0.206 & 1149 & 6.96 & $<0.0001$ \\
\hline $\mathbf{2 0 1 4}$ & 2002 & 0.858 & 0.116 & 0.828 & 0.195 & 0.030 & 0.216 & 2001 & 6.30 & $<0.0001$ \\
\hline
\end{tabular}

Table 10. Univariate analysis comparing medication adherence pre-coverage gap and within the coverage gap for the generic cohort

\begin{tabular}{|l|l|l|l|l|l|l|l|l|l|l|}
\hline \multicolumn{2}{|l|}{ Generic } & \multicolumn{2}{l|}{$\begin{array}{l}\text { Pre-cov. gap } \\
\text { PDC }\end{array}$} & $\begin{array}{l}\text { Within cov. } \\
\text { gap PDC }\end{array}$ & \multicolumn{2}{l|}{ Paired T test } \\
\hline & N & Mean & SD & Mean & SD & Mean & SD & DF & t & p \\
\hline $\mathbf{2 0 0 9}$ & 170 & 0.870 & 0.111 & 0.845 & 0.211 & 0.025 & 0.194 & 169 & 1.68 & 0.0940 \\
\hline $\mathbf{2 0 1 0}$ & 281 & 0.883 & 0.127 & 0.822 & 0.237 & 0.061 & 0.225 & 280 & 4.52 & $<0.0001$ \\
\hline $\mathbf{2 0 1 1}$ & 677 & 0.882 & 0.119 & 0.847 & 0.211 & 0.035 & 0.209 & 676 & 4.30 & $<0.0001$ \\
\hline $\mathbf{2 0 1 2}$ & 916 & 0.873 & 0.117 & 0.829 & 0.231 & 0.043 & 0.236 & 915 & 5.55 & $<0.0001$ \\
\hline $\mathbf{2 0 1 3}$ & 1026 & 0.874 & 0.125 & 0.865 & 0.223 & 0.009 & 0.210 & 1025 & 1.38 & 0.1671 \\
\hline $\mathbf{2 0 1 4}$ & 1727 & 0.876 & 0.118 & 0.867 & 0.222 & 0.009 & 0.215 & 1726 & 1.74 & 0.0823 \\
\hline
\end{tabular}


As previously noted, PQA selected 0.8 (or 80 percent) as the threshold above which the patient can be considered to be adherent for most classes of chronic medications. The percent of health plan members in each cohort that were adherent with a PDC $>80 \%$ during the pre-coverage gap phase and during the coverage gap phase are presented in Figures 14 and 15. In each cohort, the percentage of adherent members was greater in the pre-coverage gap period versus the gap period (consistent $\mathrm{p}$-value $<0.05$ ).

The health plan member cost share amount for the index fill in January, as well as the days spent pre-gap and within the coverage gap are presented in Tables 11 and 12. In general, the findings reflect an increase in member cost share for brand diabetic medications year over year.

Figure 14. Percent of health plan members utilizing brand diabetic medications that were adherent with a $\mathrm{PDC}>80 \%$

\begin{tabular}{|c|c|c|c|c|c|c|}
\hline \multicolumn{7}{|l|}{$100.00 \%$} \\
\hline \multicolumn{7}{|l|}{$90.00 \%$} \\
\hline \multicolumn{7}{|l|}{$70.00 \%$} \\
\hline \multicolumn{7}{|l|}{$60.00 \%$} \\
\hline \multicolumn{7}{|l|}{$5000 \%$} \\
\hline \multicolumn{7}{|l|}{$50.00 \%$} \\
\hline \multicolumn{7}{|l|}{$\begin{array}{l}40.00 \% \\
30.00 \%\end{array}$} \\
\hline \multicolumn{7}{|l|}{00.0070} \\
\hline \multicolumn{7}{|l|}{$\begin{array}{l}20.00 \% \\
10.00 \%\end{array}$} \\
\hline \multirow{2}{*}{$0.00 \%$} & & & & & & \\
\hline & 2009 & 2010 & 2011 & 2012 & 2013 & 2014 \\
\hline$\therefore$ Pre-Cov. Gap & $88.10 \%$ & $93.00 \%$ & $91.50 \%$ & $84.00 \%$ & $82.80 \%$ & $75.30 \%$ \\
\hline Cov. Gap & $74.60 \%$ & $76.20 \%$ & $72.70 \%$ & $67.30 \%$ & $67.70 \%$ & $65.70 \%$ \\
\hline
\end{tabular}


Figure 15. Percent of health plan members utilizing generic diabetic medications that were adherent with a PDC $>80 \%$

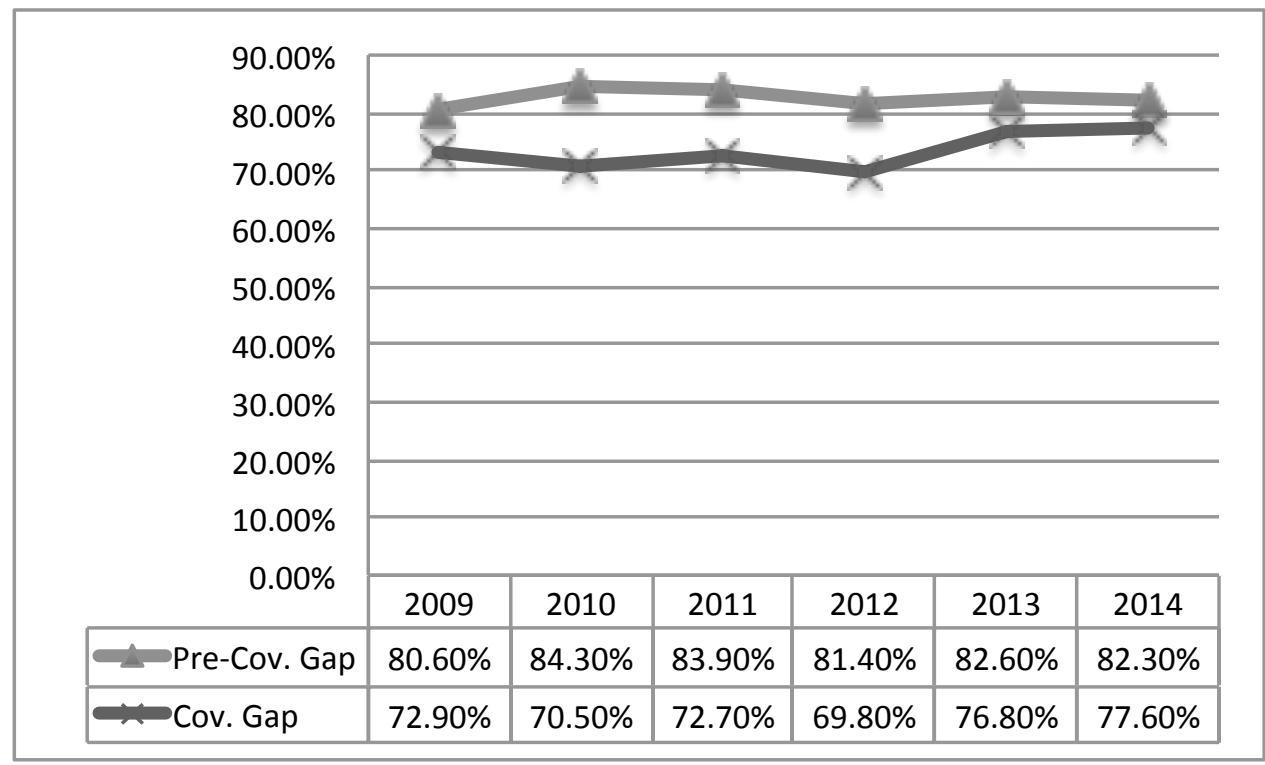

Table 11. Index fill cost share, days spent in pre-coverage gap and coverage gap for health plan members using brand diabetic medications

\begin{tabular}{|l|l|l|l|l|l|l|}
\hline & $\mathbf{2 0 0 9}$ & $\mathbf{2 0 1 0}$ & $\mathbf{2 0 1 1}$ & $\mathbf{2 0 1 2}$ & $\mathbf{2 0 1 3}$ & $\mathbf{2 0 1 4}$ \\
\hline $\mathbf{n}$ & 260 & 387 & 943 & 1084 & 1150 & 2002 \\
\hline $\left.\begin{array}{l}\text { Index Fill } \\
\text { Health Plan } \\
\begin{array}{l}\text { Member Cost } \\
\text { Share }\end{array}\end{array}\right)$ & 40.36 & 42.73 & 45.96 & 49.38 & 49.10 & 58.80 \\
\hline Days Pre-Gap & 211.7 & 214.4 & 219.2 & 210.5 & 224.9 & 213.8 \\
\hline Days Gap & 153.3 & 150.6 & 145.8 & 155.5 & 140.1 & 151.2 \\
\hline
\end{tabular}

Table 12. Index fill cost share, days spent in pre-coverage gap and coverage gap for health plan members using generic diabetic medications

\begin{tabular}{|l|l|l|l|l|l|l|}
\hline & $\mathbf{2 0 0 9}$ & $\mathbf{2 0 1 0}$ & $\mathbf{2 0 1 1}$ & $\mathbf{2 0 1 2}$ & $\mathbf{2 0 1 3}$ & $\mathbf{2 0 1 4}$ \\
\hline n & 170 & 281 & 677 & 916 & 1026 & 1727 \\
\hline $\begin{array}{l}\text { Index Fill } \\
\text { Health Plan } \\
\begin{array}{l}\text { Member Cost } \\
\text { Share }\end{array}\end{array} 4.25$ & 1.53 & 1.90 & 1.79 & 9.65 & 4.76 \\
\hline Days Pre-Gap & 216.7 & 217.8 & 222.0 & 207.4 & 218.1 & 214.3 \\
\hline Days Gap & 148.3 & 147.2 & 143.0 & 158.6 & 146.8 & 150.7 \\
\hline All numbers reported as mean
\end{tabular}




\section{Propensity score matching}

Objective 2 required the used of a control group. Medicare Part D health plan members eligible for a low-income subsidy (LIS) were chosen because they do not incur the full cost of medications in the Part D coverage gap. The following criteria were utilized to determine inclusion/exclusion of the control group:

1) At least one prescription claim for a medication of interest at Humana's mail order pharmacy during the month of January in plan years 2009, 2010, 2011, 2012, 2013 or 2014

2) Aged 18 to 89 years at the beginning of the plan year

3) 12 months continuous enrollment in a plan year

4) Reached the Medicare coverage gap spending limits between April 1st and September 30th during the respective plan year

The propensity score for matching was obtained utilizing a logistic regression analysis where the dependent variable was a LIS indicator. Excluded from the matched sample were untreated subjects that could not be matched to a treated subject with a propensity score within the caliper range of 0.001 . The caliper refers to the number of decimals allowed for a treatment to be matched to a control based on propensity score. Smaller calipers result in stricter matches. A "greedy", nearest-neighbor matching algorithm was utilized to form pairs of treated and untreated subjects. Austin advises "greedy, nearest neighbor matching within specified caliper widths may not result in all treated subjects being matched to an untreated subject, because for some treated subjects, there may not be any untreated subjects who are unmatched and whose propensity score lies within the specified caliper distance of that of the treated subject (Austin, 2014)." 
Prior to analyzing any results from a propensity- score matched model, it is necessary to evaluate the model's goodness of fit. Ho et al. suggest the propensity-score model is adequate when the distribution of measured baseline covariates is similar between treated and untreated subjects (D. Ho, Imai, King, \& Stuart, 2007). Therefore, the appropriateness of the model is assessed by examining the degree to which matching on the estimated propensity score has resulted in a matched sample where the distribution of measured baseline covariates is similar between treated and untreated subjects (Austin, 2014).

The method used to assess the model's fit in this study was standardized difference. The standardized difference compares the difference in means in units of the pooled standard deviation (Austin, 2014). The standardized difference is not influenced by sample size unlike t-tests and other statistical tests of hypothesis. Therefore, the standard difference can be useful to evaluate balance in measured variables between treated and untreated subjects in the matched sample with that in the unmatched sample. Rosenbaum and Rubin first published their use of the standardized difference to assess the comparability of treated and untreated subjects in matched samples (Rosenbaum \& Rubin, 1985). Since then, several authors have used this approach in the clinical literature (Austin, 2008a, 2008c; Normand et al., 2001)

Absolute standardized differences comparing baseline covariates between treated and untreated subjects in the unmatched and matched samples are reported in Tables 13 24. In the unmatched sample, the largest absolute standardized differences were observed in the age difference of the groups with the control group being younger than the treatment group $(0.200-0.759)$. In general, the propensity score resulted in a matched 
sample in which the means and percentages of baseline covariates were relatively similar between treated and untreated subjects. For example, the ability of PSM to equalize variables is illustrated in Table 13. The unmatched control group had a mean age of 64.7 years, a little over half were female and less than a third of the members were white. The matched sample equalized the variability so both samples were 69.1 years in mean age, a little over half were female and race exhibited a far less pronounced gap. While PSM attempts to reduce the difference among the groups, it cannot eliminate them completely. For example, as shown in Table 19, some marked differences remain in the matched groups for mean age (69.7 vs. 72.0$)$ and gender (53.5\% vs. $77.0 \%)$.

Table 13. Comparison of baseline statistics for unmatched and matched health plan members for brand diabetic medication cohort, 2009

\begin{tabular}{|l|l|l|l|l|l|l|}
\hline & \multicolumn{2}{|c|}{ Original Unmatched Sample } & \multicolumn{2}{l|}{ Propensity-score Matched Sample } \\
\hline Var. & $\begin{array}{l}\text { Control } \\
\text { LI: Yes } \\
(\boldsymbol{N}=\mathbf{4 5})\end{array}$ & $\begin{array}{l}\text { Treatment } \\
\text { LI: No } \\
(\boldsymbol{N}=\mathbf{2 6 0})\end{array}$ & $\begin{array}{l}\text { Std. } \\
\text { Diff. }\end{array}$ & $\begin{array}{l}\text { Control } \\
\text { LI: Yes } \\
(\boldsymbol{N = 2 7 )}\end{array}$ & $\begin{array}{l}\text { Treatment } \\
\text { LI: No } \\
(\boldsymbol{N}=\mathbf{2 7})\end{array}$ & $\begin{array}{l}\text { Std. } \\
\text { Diff. }\end{array}$ \\
\hline Age & $64.7 \pm 9.8$ & $70.7 \pm 6.1$ & 0.726 & $69.1 \pm 6.0$ & $69.1 \pm 5.9$ & 0.006 \\
\hline Female & $25(55.6 \%)$ & $91(35.0 \%)$ & 0.422 & $16(59.2 \%)$ & $16(59.2 \%)$ & 0.000 \\
\hline White & $70(26.9 \%)$ & $188(72.3 \%)$ & 0.027 & $22(81.5 \%)$ & $21(77.8 \%)$ & 0.092 \\
\hline $\begin{array}{l}\text { Continuous variables are reported as mean } \pm \text { standard deviation. } \\
\text { Dichotomous variables are reported as } N \text { (percent). }\end{array}$ \\
\hline
\end{tabular}

Table 14. Comparison of baseline statistics for unmatched and matched health plan members for generic diabetic medication cohort, 2009

\begin{tabular}{|c|c|c|c|c|c|c|}
\hline & \multicolumn{3}{|c|}{ Original Unmatched Sample } & \multicolumn{3}{|c|}{ Propensity-score Matched Sample } \\
\hline Var. & $\begin{array}{l}\text { Control } \\
\text { LI: Yes } \\
(N=29) \\
\end{array}$ & $\begin{array}{l}\text { Treatment } \\
\text { LI: No } \\
(N=170)\end{array}$ & $\begin{array}{l}\text { Std. } \\
\text { Diff. }\end{array}$ & $\begin{array}{l}\text { Control } \\
\text { LI: Yes } \\
(N=18) \\
\end{array}$ & $\begin{array}{l}\text { Treatment } \\
\text { LI: No } \\
(N=18)\end{array}$ & $\begin{array}{l}\text { Std. } \\
\text { Diff. }\end{array}$ \\
\hline Age & $65.4 \pm 10.3$ & $71.0 \pm 5.7$ & 0.681 & $70.5 \pm 5.3$ & $70.6 \pm 5.5$ & 0.010 \\
\hline Female & $12(41.4 \%)$ & $63(37.1 \%)$ & 0.089 & $9(50.0 \%)$ & $9(50.0 \%)$ & 0.000 \\
\hline White & $21(72.4 \%)$ & $125(73.5 \%)$ & 0.035 & $14(77.8 \%)$ & $16(88.9 \%)$ & 0.302 \\
\hline
\end{tabular}


Table 15. Comparison of baseline statistics for unmatched and matched health plan members for brand diabetic medication cohort, 2010

\begin{tabular}{|l|l|l|l|l|l|l|}
\hline & \multicolumn{3}{|c|}{ Original Unmatched Sample } & \multicolumn{2}{l|}{ Propensity-score Matched Sample } \\
\hline Var. & $\begin{array}{l}\text { Control } \\
\text { LI: Yes } \\
(\boldsymbol{N}=\mathbf{7 9})\end{array}$ & $\begin{array}{l}\text { Treatment } \\
\text { LI: No } \\
(\boldsymbol{N}=\mathbf{3 8 7})\end{array}$ & $\begin{array}{l}\text { Std. } \\
\text { Diff. }\end{array}$ & $\begin{array}{l}\text { Control } \\
\text { LI: Yes } \\
(\boldsymbol{N}=\mathbf{5 8})\end{array}$ & $\begin{array}{l}\text { Treatment } \\
\text { LI: No } \\
(\boldsymbol{N}=\mathbf{5 8})\end{array}$ & $\begin{array}{l}\text { Std. } \\
\text { Diff. }\end{array}$ \\
\hline Age & $68.9 \pm 9.7$ & $70.7 \pm 5.7$ & 0.238 & $70.6 \pm 7.9$ & $71.1 \pm 5.8$ & 0.074 \\
\hline Female & $47(59.5 \%)$ & $145(37.5 \%)$ & 0.452 & $33(56.9 \%)$ & $33(56.9 \%)$ & 0.000 \\
\hline White & $55(69.6 \%)$ & $312(80.6 \%)$ & 0.257 & $45(75.6 \%)$ & $42(72.4 \%)$ & 0.120 \\
\hline $\begin{array}{l}\text { Continuous variables are reported as mean } \pm \text { standard deviation. } \\
\text { Dichotomous variables are reported as } N \text { (percent). }\end{array}$ \\
\hline
\end{tabular}

Table 16. Comparison of baseline statistics for unmatched and matched health plan members for generic diabetic medication cohort, 2010

\begin{tabular}{|c|c|c|c|c|c|c|}
\hline & \multicolumn{3}{|c|}{ Original Unmatched Sample } & \multicolumn{3}{|c|}{ Propensity-score Matched Sample } \\
\hline Var. & $\begin{array}{l}\text { Control } \\
\text { LI: Yes } \\
(N=53)\end{array}$ & $\begin{array}{l}\text { Treatment } \\
\text { LI: No } \\
(N=\mathbf{2 8 1})\end{array}$ & $\begin{array}{l}\text { Std. } \\
\text { Diff. }\end{array}$ & $\begin{array}{l}\text { Control } \\
\text { LI: Yes } \\
(N=39)\end{array}$ & $\begin{array}{l}\text { Treatment } \\
\text { LI: No } \\
(N=39)\end{array}$ & $\begin{array}{l}\text { Std. } \\
\text { Diff. }\end{array}$ \\
\hline Age & $69.2 \pm 7.9$ & $70.5 \pm 5.4$ & 0.200 & $70.9 \pm 5.3$ & $70.7 \pm 5.4$ & 0.043 \\
\hline Female & $35(66.0 \%)$ & $105(37.3 \%)$ & 0.599 & $24(30.8 \%)$ & $24(30.8 \%)$ & 0.000 \\
\hline White & $41(77.4 \%)$ & $226(80.4 \%)$ & 0.075 & $31(79.5 \%)$ & $32(82.1 \%)$ & 0.065 \\
\hline
\end{tabular}

Table 17. Comparison of baseline statistics for unmatched and matched health plan members for brand diabetic medication cohort, 2011

\begin{tabular}{|c|c|c|c|c|c|c|}
\hline & \multicolumn{3}{|c|}{ Original Unmatched Sample } & \multicolumn{3}{|c|}{ Propensity-score Matched Sample } \\
\hline Var. & $\begin{array}{l}\text { Control } \\
\text { LI: Yes } \\
(N=136)\end{array}$ & $\begin{array}{l}\text { Treatment } \\
\text { LI: No } \\
(N=943)\end{array}$ & $\begin{array}{l}\text { Std. } \\
\text { Diff. }\end{array}$ & $\begin{array}{l}\text { Control } \\
\text { LI: Yes } \\
(N=101)\end{array}$ & $\begin{array}{l}\text { Treatment } \\
\text { LI: No } \\
(N=101)\end{array}$ & $\begin{array}{l}\text { Std. } \\
\text { Diff. }\end{array}$ \\
\hline Age & $66.8 \pm 9.4$ & $71.0 \pm 5.9$ & 0.540 & $69.4 \pm 7.4$ & $69.7 \pm 7.8$ & 0.040 \\
\hline Female & $81(59.6 \%)$ & $344(36.5 \%)$ & 0.475 & $61(60.4 \%)$ & $65(64.4 \%)$ & 0.082 \\
\hline White & $103(75.7 \%)$ & $844(89.5 \%)$ & 0.369 & $85(84.2 \%)$ & $85(84.2 \%)$ & 0.000 \\
\hline
\end{tabular}


Table 18. Comparison of baseline statistics for unmatched and matched health plan members for generic diabetic medication cohort, 2011

\begin{tabular}{|l|l|l|l|l|l|l|}
\hline & \multicolumn{2}{|c|}{ Original Unmatched Sample } & \multicolumn{2}{l|}{ Propensity-score Matched Sample } \\
\hline Var. & $\begin{array}{l}\text { Control } \\
\text { LI: Yes } \\
(\boldsymbol{N}=\mathbf{1 1 1})\end{array}$ & $\begin{array}{l}\text { Treatment } \\
\text { LI: No } \\
(\boldsymbol{N}=\mathbf{6 7 7})\end{array}$ & $\begin{array}{l}\text { Std. } \\
\text { Diff. }\end{array}$ & $\begin{array}{l}\text { Control } \\
\text { LI: Yes } \\
(\boldsymbol{N = 8 1 )}\end{array}$ & $\begin{array}{l}\text { Treatment } \\
\text { LI: No } \\
(\boldsymbol{N}=\mathbf{8 1})\end{array}$ & $\begin{array}{l}\text { Std. } \\
\text { Diff. }\end{array}$ \\
\hline Age & $66.2 \pm 9.9$ & $70.8 \pm 5.8$ & 0.565 & $69.3 \pm 7.5$ & $70.7 \pm 7.0$ & 0.186 \\
\hline Female & $64(57.7 \%)$ & $258(38.1 \%)$ & 0.399 & $46(56.8 \%)$ & $56(69.1 \%)$ & 0.258 \\
\hline White & $86(77.5 \%)$ & $603(89.1 \%)$ & 0.314 & $70(86.4 \%)$ & $60(74.1 \%)$ & 0.314 \\
\hline $\begin{array}{l}\text { Continuous variables are reported as mean } \pm \text { standard deviation. } \\
\text { Dichotomous variables are reported as } N \text { (percent). }\end{array}$ \\
\hline
\end{tabular}

Table 19. Comparison of baseline statistics for unmatched and matched health plan members for brand diabetic medication cohort, 2012

\begin{tabular}{|c|c|c|c|c|c|c|}
\hline & \multicolumn{3}{|c|}{ Original Unmatched Sample } & \multicolumn{3}{|c|}{ Propensity-score Matched Sample } \\
\hline Var. & $\begin{array}{l}\text { Control } \\
\text { LI: Yes } \\
(N=344)\end{array}$ & $\begin{array}{l}\text { Treatment } \\
\text { LI: No } \\
(N=\mathbf{1 0 8 4})\end{array}$ & $\begin{array}{l}\text { Std. } \\
\text { Diff. }\end{array}$ & $\begin{array}{l}\text { Control } \\
\text { LI: Yes } \\
(N=\mathbf{2 1 7})\end{array}$ & $\begin{array}{l}\text { Treatment } \\
\text { LI: No } \\
(N=\mathbf{2 1 7})\end{array}$ & $\begin{array}{l}\text { Std. } \\
\text { Diff. }\end{array}$ \\
\hline Age & $65.1 \pm 10.3$ & $71.1 \pm 5.8$ & 0.717 & $69.7 \pm 7.2$ & $72.0 \pm 7.9$ & 0.307 \\
\hline Female & $202(58.7 \%)$ & $360(33.2 \%)$ & 0.530 & $116(53.5 \%)$ & $167(77.0 \%)$ & 0.509 \\
\hline White & $274(79.7 \%)$ & $1016(93.7 \%)$ & 0.424 & $198(91.2 \%)$ & $200(92.2 \%)$ & 0.033 \\
\hline
\end{tabular}

Continuous variables are reported as mean \pm standard deviation.

Dichotomous variables are reported as $N$ (percent).

Table 20. Comparison of baseline statistics for unmatched and matched health plan members for generic diabetic medication cohort, 2012

\begin{tabular}{|c|c|c|c|c|c|c|}
\hline & \multicolumn{3}{|c|}{ Original Unmatched Sample } & \multicolumn{3}{|c|}{ Propensity-score Matched Sample } \\
\hline Var. & $\begin{array}{l}\text { Control } \\
\text { LI: Yes } \\
(N=\mathbf{2 9 1})\end{array}$ & $\begin{array}{l}\text { Treatment } \\
\text { LI: No } \\
(N=916)\end{array}$ & $\begin{array}{l}\text { Std. } \\
\text { Diff. }\end{array}$ & $\begin{array}{l}\text { Control } \\
\text { LI: Yes } \\
(N=196)\end{array}$ & $\begin{array}{l}\text { Treatment } \\
\text { LI: No } \\
(N=196)\end{array}$ & $\begin{array}{l}\text { Std. } \\
\text { Diff. }\end{array}$ \\
\hline Age & $64.9 \pm 10.3$ & $70.6 \pm 5.7$ & 0.680 & $68.6 \pm 7.5$ & $68.6 \pm 7.3$ & 0.002 \\
\hline Female & $176(60.5 \%)$ & $314(34.3 \%)$ & 0.544 & $115(58.7 \%)$ & $114(58.2 \%)$ & 0.010 \\
\hline White & $228(74.4 \%)$ & $846(92.4 \%)$ & 0.404 & $175(89.3 \%)$ & $174(88.8 \%)$ & 0.016 \\
\hline
\end{tabular}


Table 21. Comparison of baseline statistics for unmatched and matched health plan members for brand diabetic medication cohort, 2013

\begin{tabular}{|l|l|l|l|l|l|l|}
\hline & \multicolumn{3}{|c|}{ Original Unmatched Sample } & \multicolumn{2}{l|}{ Propensity-score Matched Sample } \\
\hline Var. & $\begin{array}{l}\text { Control } \\
\text { LI: Yes } \\
(\boldsymbol{N = 3 9 2 )}\end{array}$ & $\begin{array}{l}\text { Treatment } \\
\text { LI: No } \\
(\boldsymbol{N}=\mathbf{1 1 5 0})\end{array}$ & $\begin{array}{l}\text { Std. } \\
\text { Diff. }\end{array}$ & $\begin{array}{l}\text { Control } \\
\text { LI: Yes } \\
(\boldsymbol{N}=\mathbf{2 7 5})\end{array}$ & $\begin{array}{l}\text { Treatment } \\
\text { LI: No } \\
(\boldsymbol{N}=\mathbf{2 7 5})\end{array}$ & $\begin{array}{l}\text { Std. } \\
\text { Diff. }\end{array}$ \\
\hline Age & $69.2 \pm 10.6$ & $71.2 \pm 5.8$ & 0.702 & $68.8 \pm 8.3$ & $71.7 \pm 6.6$ & 0.385 \\
\hline Female & $269(68.6 \%)$ & $469(40.8 \%)$ & 0.583 & $169(61.5 \%)$ & $241(87.6 \%)$ & 0.630 \\
\hline White & $317(80.9 \%)$ & $1064(92.5 \%)$ & 0.348 & $244(88.7 \%)$ & $243(88.4 \%)$ & 0.011 \\
\hline $\begin{array}{l}\text { Continuous variables are reported as mean } \pm \text { standard deviation. } \\
\text { Dichotomous variables are reported as } N \text { (percent). }\end{array}$ \\
\hline
\end{tabular}

Table 22. Comparison of baseline statistics for unmatched and matched health plan members for generic diabetic medication cohort, 2013

\begin{tabular}{|c|c|c|c|c|c|c|}
\hline & \multicolumn{3}{|c|}{ Original Unmatched Sample } & \multicolumn{3}{|c|}{ Propensity-score Matched Sample } \\
\hline Var. & $\begin{array}{l}\text { Control } \\
\text { LI: Yes } \\
(N=357)\end{array}$ & $\begin{array}{l}\text { Treatment } \\
\text { LI: No } \\
(N=\mathbf{1 0 2 6})\end{array}$ & $\begin{array}{l}\text { Std. } \\
\text { Diff. }\end{array}$ & $\begin{array}{l}\text { Control } \\
\text { LI: Yes } \\
(N=\mathbf{2 2 1})\end{array}$ & $\begin{array}{l}\text { Treatment } \\
\text { LI: No } \\
(N=221)\end{array}$ & $\begin{array}{l}\text { Std. } \\
\text { Diff. }\end{array}$ \\
\hline Age & $64.6 \pm 10.2$ & $70.5 \pm 5.8$ & 0.712 & $69.1 \pm 6.8$ & $69.3 \pm 7.1$ & 0.029 \\
\hline Female & $248(69.5 \%)$ & $416(40.6 \%)$ & 0.608 & $151(68.3 \%)$ & $154(70.1 \%)$ & 0.039 \\
\hline White & $284(79.6 \%)$ & $939(91.5 \%)$ & 0.345 & $200(90.5 \%)$ & $200(90.5 \%)$ & 0.000 \\
\hline
\end{tabular}

Table 23. Comparison of baseline statistics for unmatched and matched health plan members for brand diabetic medication cohort, 2014

\begin{tabular}{|c|c|c|c|c|c|c|}
\hline & \multicolumn{3}{|c|}{ Original Unmatched Sample } & \multicolumn{3}{|c|}{ Propensity-score Matched Sample } \\
\hline Var. & $\begin{array}{l}\text { Control } \\
\text { LI: Yes } \\
(N=665)\end{array}$ & $\begin{array}{l}\text { Treatment } \\
\text { LI: No } \\
(N=\mathbf{2 0 0 2})\end{array}$ & $\begin{array}{l}\text { Std. } \\
\text { Diff. }\end{array}$ & $\begin{array}{l}\text { Control } \\
\text { LI: Yes } \\
(N=\mathbf{4 6 0})\end{array}$ & $\begin{array}{l}\text { Treatment } \\
\text { LI: No } \\
(N=\mathbf{4 6 0})\end{array}$ & $\begin{array}{l}\text { Std. } \\
\text { Diff. }\end{array}$ \\
\hline Age & $65.2 \pm 10.3$ & $71.2 \pm 6.2$ & 0.701 & $69.4 \pm 7.3$ & $69.5 \pm 7.6$ & 0.019 \\
\hline Female & $431(64.8 \%)$ & $839(41.9 \%)$ & 0.472 & $293(63.7 \%)$ & $307(66.7 \%)$ & 0.064 \\
\hline White & $505(75.9 \%)$ & $1836(91.7 \%)$ & 0.438 & $380(82.6 \%)$ & $378(82.2 \%)$ & 0.011 \\
\hline
\end{tabular}


Table 24. Comparison of baseline statistics for unmatched and matched health plan members for generic diabetic medication cohort, 2014

\begin{tabular}{|c|c|c|c|c|c|c|}
\hline & \multicolumn{3}{|c|}{ Original Unmatched Sample } & \multicolumn{3}{|c|}{ Propensity-score Matched Sample } \\
\hline Var. & $\begin{array}{l}\text { Control } \\
\text { LI: Yes } \\
(N=\mathbf{5 8 9})\end{array}$ & $\begin{array}{l}\text { Treatment } \\
\text { LI: No } \\
(N=1727)\end{array}$ & $\begin{array}{l}\text { Std. } \\
\text { Diff. }\end{array}$ & $\begin{array}{l}\text { Control } \\
\text { LI: Yes } \\
(N=\mathbf{4 0 8})\end{array}$ & $\begin{array}{l}\text { Treatment } \\
\text { LI: No } \\
(N=\mathbf{4 0 8})\end{array}$ & $\begin{array}{l}\text { Std. } \\
\text { Diff. }\end{array}$ \\
\hline Age & $64.6 \pm 10.1$ & $70.9 \pm 6.1$ & 0.759 & $68.3 \pm 7.5$ & $68.5 \pm 7.5$ & 0.029 \\
\hline Female & $380(64.5 \%)$ & $718(41.6 \%)$ & 0.472 & $264(64.7 \%)$ & $270(66.2 \%)$ & 0.030 \\
\hline White & $458(77.8 \%)$ & $1587(91.9 \%)$ & 0.402 & $348(85.3 \%)$ & $340(83.3 \%)$ & 0.054 \\
\hline
\end{tabular}

The C-statistic, which is an indicator for concordance, is also useful in evaluating the goodness of fit of logistic regression models. The C-Statistic offers values ranging from 0.5 to 1.0 . A value of 0.5 indicates that the model is no better than chance at making a prediction of membership in a group and a value of 1.0 indicates that the model perfectly identifies those within a group and those not. Models are typically considered reasonable when the $\mathrm{C}$-statistic is higher than 0.7 and strong when $\mathrm{C}$ exceeds 0.8 (Hosmer \& Lemeshow, 1989). All C-statistics were above 0.7 and are provided in Table 25.

Table 25. C-statistics for logistic regression models by year, medication cohort

\begin{tabular}{|l|c|c|}
\hline Year & $\begin{array}{c}\text { Brand diabetic } \\
\text { medication cohort }\end{array}$ & $\begin{array}{c}\text { Generic diabetic } \\
\text { medication cohort }\end{array}$ \\
\hline $\mathbf{2 0 0 9}$ & 0.773 & 0.700 \\
\hline $\mathbf{2 0 1 0}$ & 0.701 & 0.706 \\
\hline $\mathbf{2 0 1 1}$ & 0.713 & 0.705 \\
\hline $\mathbf{2 0 1 2}$ & 0.761 & 0.759 \\
\hline $\mathbf{2 0 1 3}$ & 0.761 & 0.761 \\
\hline $\mathbf{2 0 1 4}$ & 0.755 & 0.765 \\
\hline
\end{tabular}




\section{Descriptive analyses of propensity score matched control and treatment groups}

Mean medication adherence by cohort for propensity score matched health plan members is presented in Tables $26-27$. The control group represents those health plan members with no gap in coverage during the plan year and the treatment group represents those health plan members who reached the Part D coverage gap. As shown in the tables, the control group exhibited higher medication adherence. T-tests indicate significant differences in the brand cohort for years 2011-2014 and the generic cohort for years 2013-2014.

Table 26. Univariate analysis comparing medication adherence of the control and treatment groups for the brand cohort

\begin{tabular}{|l|l|l|l|l|l|l|l|l|l|l|}
\hline Brand & \multicolumn{2}{l|}{$\begin{array}{l}\text { Control } \\
\text { Group } \\
\text { Annual PDC }\end{array}$} & $\begin{array}{l}\text { Treatment } \\
\text { Group } \\
\text { Annual PDC }\end{array}$ & \multicolumn{7}{|c|}{ T test } \\
\hline & N & Mean & SD & Mean & SD & Mean & SD & DF & t & p \\
\hline $\mathbf{2 0 0 9}$ & 27 & 0.928 & 0.070 & 0.884 & 0.104 & 0.044 & 0.089 & 52 & 1.83 & 0.0730 \\
\hline $\mathbf{2 0 1 0}$ & 58 & 0.927 & 0.093 & 0.901 & 0.082 & 0.026 & 0.088 & 114 & 1.62 & 0.1091 \\
\hline $\mathbf{2 0 1 1}$ & 101 & 0.919 & 0.090 & 0.879 & 0.095 & 0.041 & 0.013 & 200 & 3.12 & 0.0021 \\
\hline $\mathbf{2 0 1 2}$ & 217 & 0.919 & 0.082 & 0.874 & 0.115 & 0.046 & 0.100 & 432 & 4.74 & $<0.0001$ \\
\hline $\mathbf{2 0 1 3}$ & 275 & 0.910 & 0.093 & 0.857 & 0.111 & 0.053 & 0.102 & 548 & 6.12 & $<0.0001$ \\
\hline $\mathbf{2 0 1 4}$ & 460 & 0.913 & 0.087 & 0.839 & 0.121 & 0.074 & 0.106 & 918 & 10.65 & $<0.0001$ \\
\hline
\end{tabular}

Table 27. Univariate analysis comparing medication adherence of the control and treatment groups for the generic cohort

\begin{tabular}{|l|l|l|l|l|l|l|l|l|l|l|}
\hline \multicolumn{2}{|l}{ Generic } & $\begin{array}{l}\text { Control } \\
\text { Group } \\
\text { Annual PDC }\end{array}$ & $\begin{array}{l}\text { Treatment } \\
\text { Group } \\
\text { Annual PDC }\end{array}$ & \multicolumn{7}{c|}{ T test } \\
\hline & N & Mean & SD & Mean & SD & Mean & SD & DF & t & p \\
\hline $\mathbf{2 0 0 9}$ & 18 & 0.899 & 0.121 & 0.899 & 0.084 & 0.000 & 0.106 & 30 & 0.01 & 0.9928 \\
\hline $\mathbf{2 0 1 0}$ & 39 & 0.882 & 0.170 & 0.849 & 0.181 & 0.034 & 0.175 & 76 & 0.85 & 0.4000 \\
\hline $\mathbf{2 0 1 1}$ & 81 & 0.876 & 0.165 & 0.883 & 0.108 & 0.007 & 0.140 & 138 & 0.34 & 0.7368 \\
\hline $\mathbf{2 0 1 2}$ & 196 & 0.889 & 0.146 & 0.867 & 0.140 & 0.022 & 0.143 & 390 & 1.51 & 0.1318 \\
\hline $\mathbf{2 0 1 3}$ & 221 & 0.899 & 0.138 & 0.871 & 0.135 & 0.028 & 0.137 & 435 & 2.16 & 0.0311 \\
\hline $\mathbf{2 0 1 4}$ & 408 & 0.903 & 0.136 & 0.874 & 0.127 & 0.029 & 0.132 & 808 & 3.17 & 0.0016 \\
\hline
\end{tabular}




\section{Diabetic medication adherence across plan years}

Medication adherence across plan years is presented in Figures 16-19. Plan year 2009 is used as a reference and statistical significance is denoted with an asterisk. The only statistically significant difference was seen in the decline in brand diabetic medication adherence for the treatment group from 2009 to 2014

Figure 16. Control group medication adherence across plan years for the brand cohort

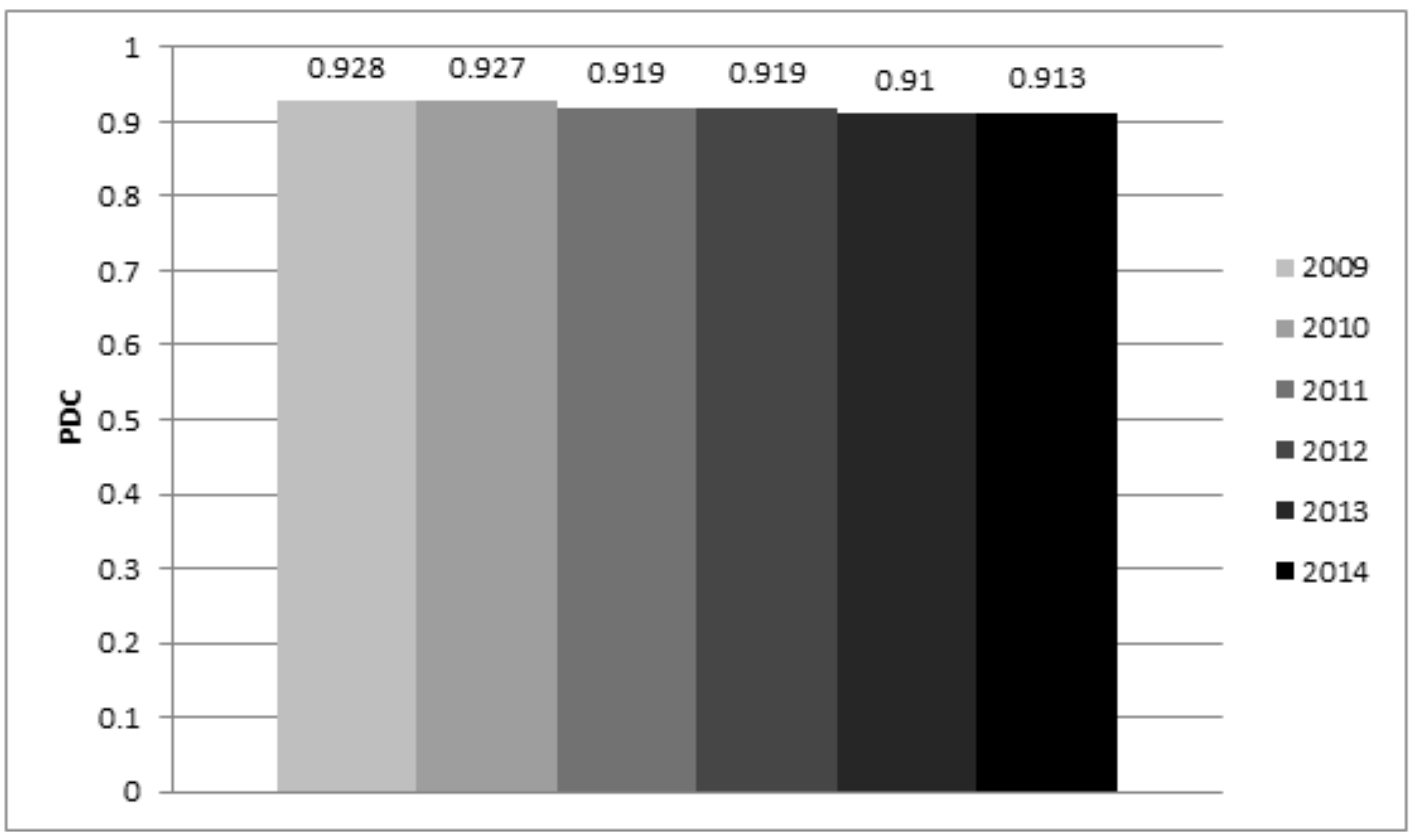

*Indicates $\mathrm{p}<0.05$ using a t-test to compare the mean PDC using plan year 2009 as a reference 
Figure 17. Control group medication adherence across plan years for the generic cohort

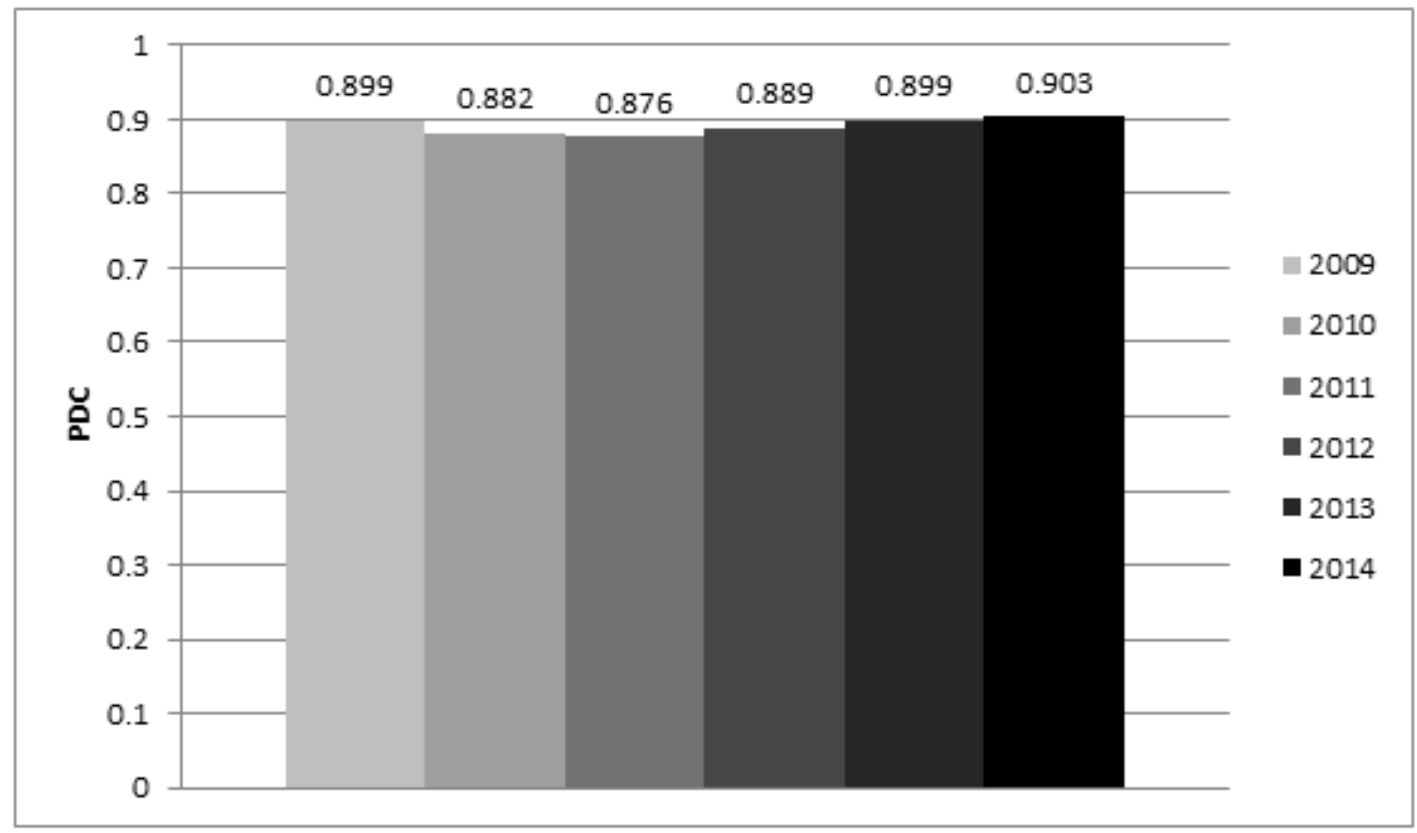

*Indicates $\mathrm{p}<0.05$ using a t-test to compare the mean PDC using plan year 2009 as a reference

Figure 18. Treatment group medication adherence across plan years for the brand cohort

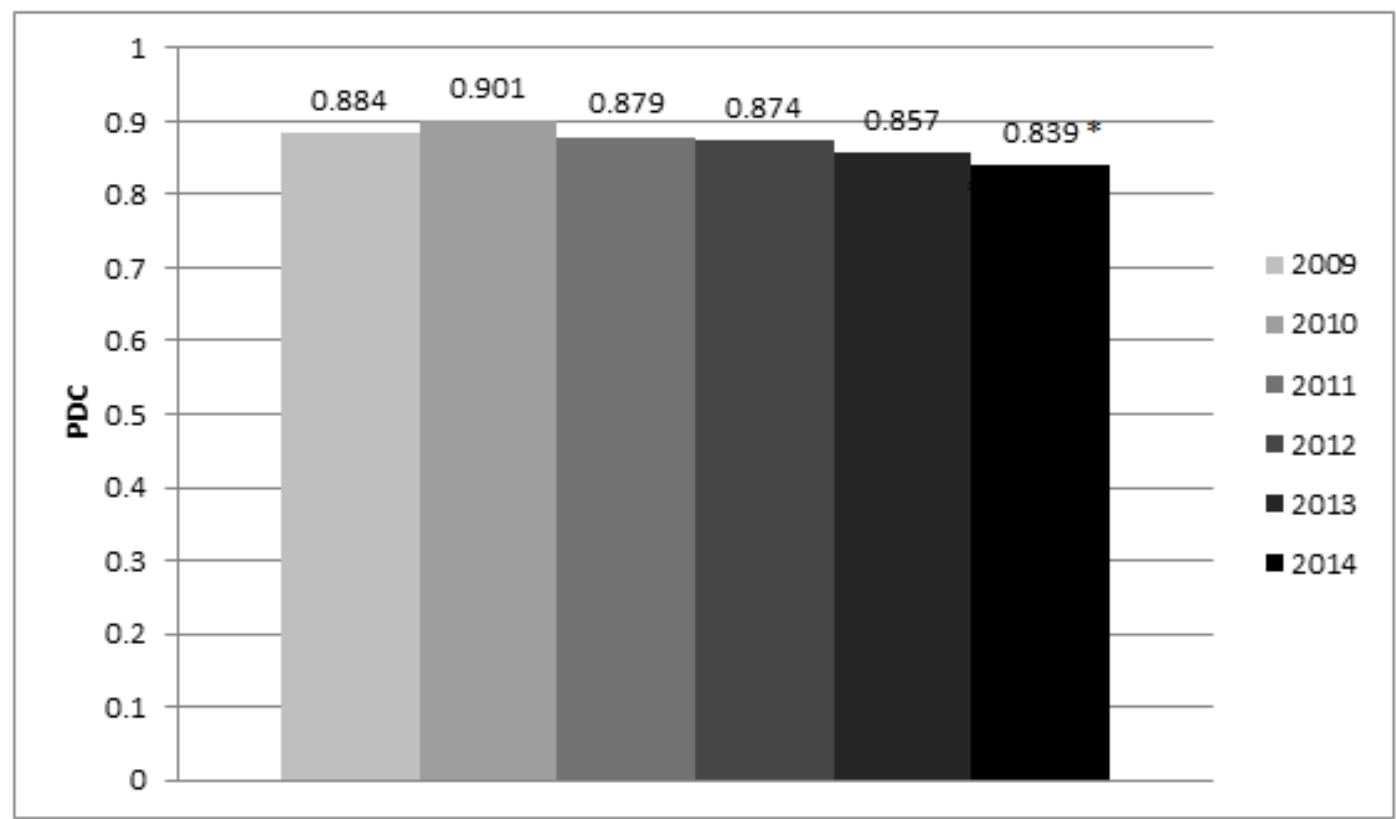

*Indicates $\mathrm{p}<0.05$ using a t-test to compare the mean PDC using plan year 2009 as a reference 
Figure 19. Treatment group medication adherence across plan years for the generic cohort

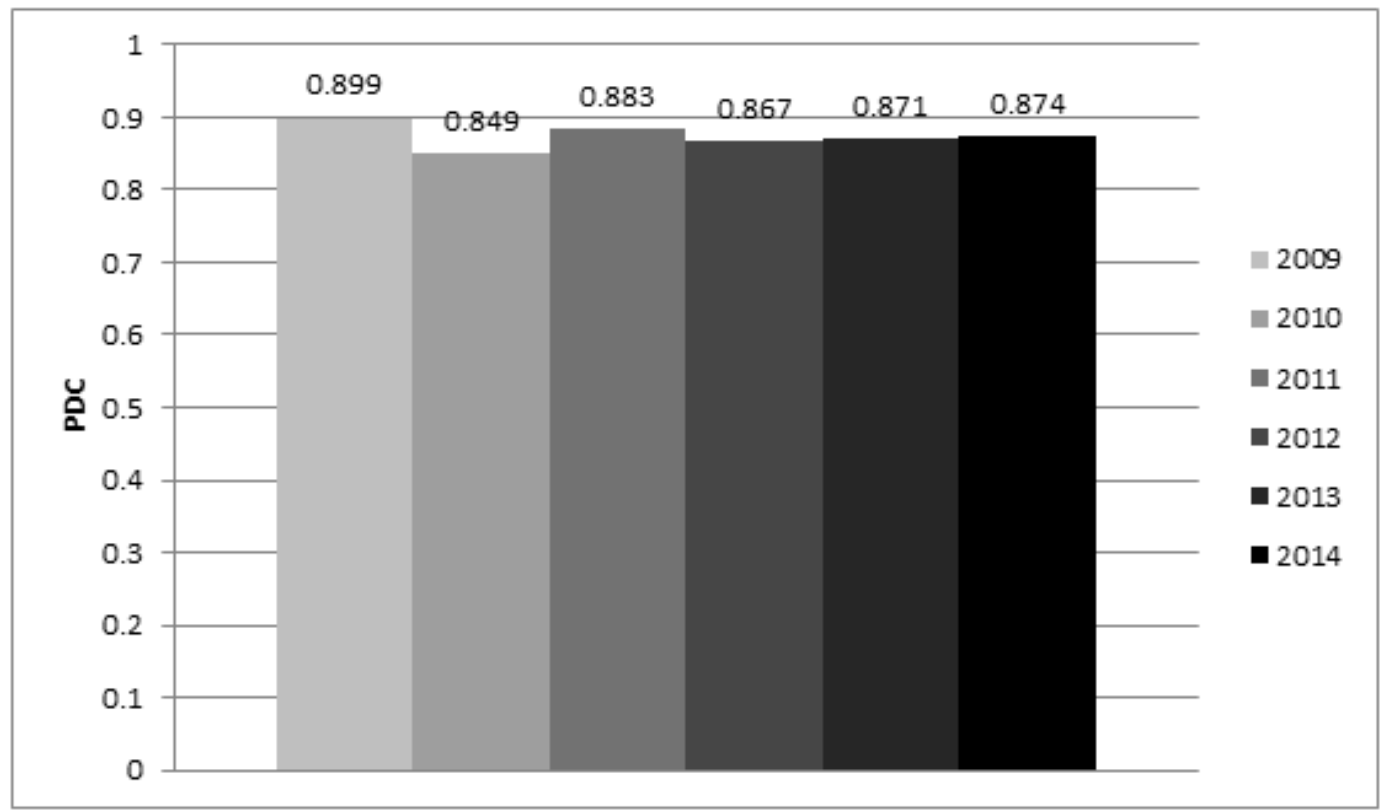

*Indicates $\mathrm{p}<0.05$ using a t-test to compare the mean PDC using plan year 2009 as a reference

\section{Summary}

The percent of eligible study participants who reached the coverage gap more than doubled between 2009 and 2014. Overall pre-coverage gap medication adherence was higher than medication adherence in the coverage gap. Significant differences were noted in the brand cohort for all years and the generic cohort for years 2010-2012. A comparison of medication adherence between the control and treatment group showed statistically significant differences for almost all years in the brand cohort and later year s in the generic cohort. However, medication adherence across plan years showed statistically significant differences for one year in the treatment brand cohort only. 


\section{CHAPTER 5}

\section{DISCUSSION}

This chapter begins with a discussion of the study results with regard to the research objectives. In addition to the results, a discussion of strengths, limitations, findings and recommendations for future research are offered.

\section{Coverage Gap}

As shown in Figure 8, the percent of eligible study participants in the brand cohort who entered the coverage gap ranged from 4.62 percent (2009) to 24.01 percent (2014). In the generic cohort, the percent of eligible study participants who entered the coverage gap ranged from 0.82 percent (2009) to 1.98 percent (2014). A study conducted by Kaiser Family Foundation reported that 26 percent of non-LIS Part D enrollees who filled one or more prescriptions in 2007 reached the coverage gap (Hoadley, Hargrave, Cubanski, \& Neuman, 2008). Each year the Medicare Payment Commission (MEDPAC) publishes the percent of Part D enrollees that reach the coverage gap in The Medicare Payment Policy Report to the Congress. Data available for non-LIS Part D enrollees from 2009 through 2012 is displayed in Figure 20. Since 2007, the proportion of Part D nonLIS enrollees reaching the gap has declined, likely due to the increased availability of generic medications for many chronic conditions (Hoadley et al., 2011). However, the 
absolute number of people reaching the gap has declined less than the proportion because of an increase in the number of Part D enrollees as shown in Table 28.

Figure 20. Percent of non-LIS Part D enrollees who entered the coverage gap, 2009-2012 (Medicare Payment Advisory Commission, 2012, 2013, 2014, 2015)

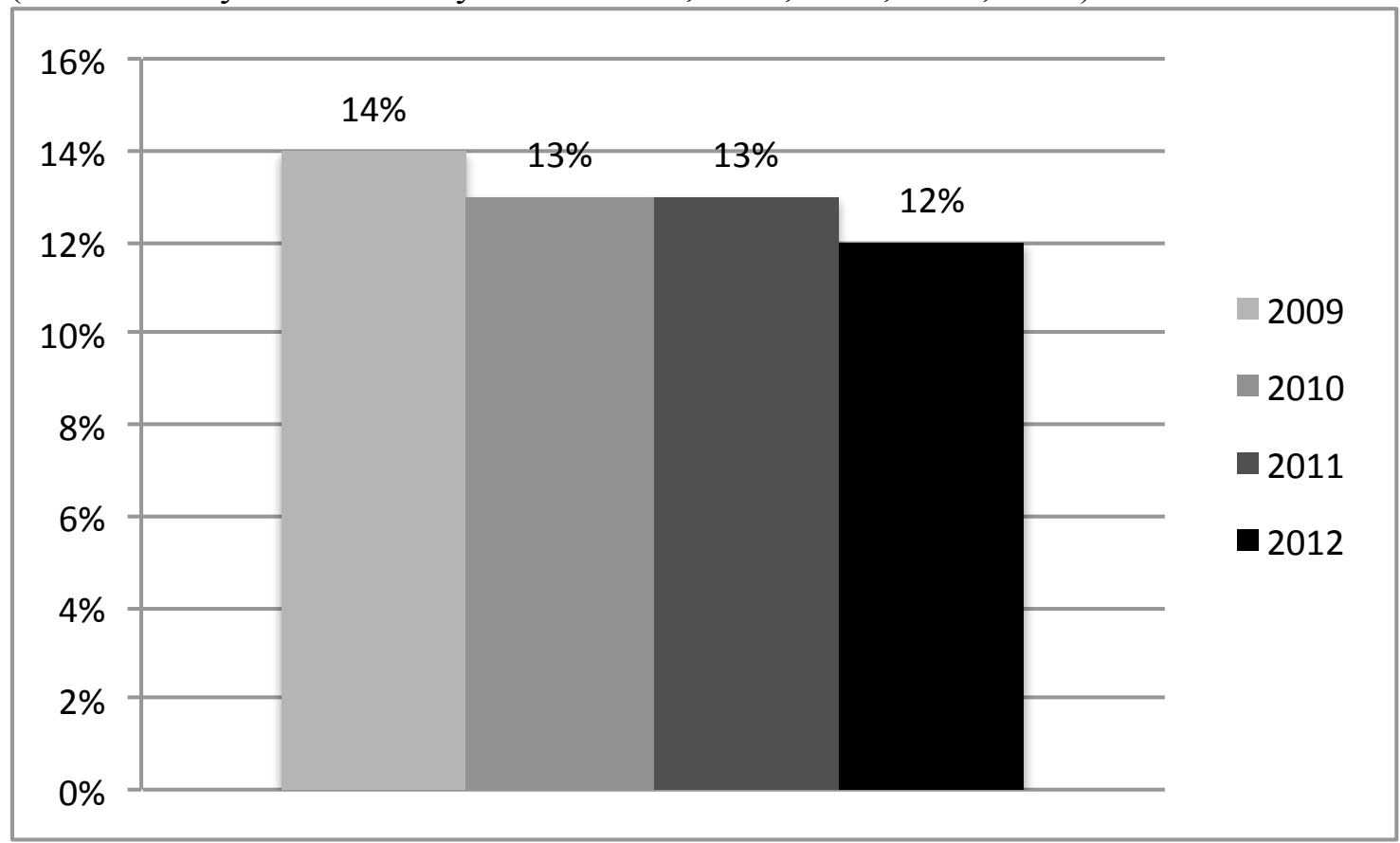

Table 28. Medicare Part D Plan Enrollment Trends, 2007 - 2014 (Medicare Payment Advisory Commission, 2015)

\begin{tabular}{|l|c|c|c|c|c|c|}
\hline & & & & & & $\begin{array}{c}\text { Average } \\
\text { Annual } \\
\text { Growth } \\
\text { Rate } \\
\text { 2007-2014 }\end{array}$ \\
\hline $\begin{array}{l}\text { Total Part D enrollment } \\
\text { (in millions) }\end{array}$ & $\mathbf{2 0 0 7}$ & $\mathbf{2 0 0 8}$ & $\mathbf{2 0 1 0}$ & $\mathbf{2 0 1 2}$ & $\mathbf{2 0 1 4}$ & \\
\hline $\begin{array}{l}\text { Percent of Medicare } \\
\text { enrollees }\end{array}$ & 24.2 & 25.6 & 27.6 & 31.5 & 37.4 & $6 \%$ \\
\hline LIS (in millions) & 9.4 & $56 \%$ & $58 \%$ & $60 \%$ & $69 \%$ & \\
\hline Non-LIS (in millions) & 14.8 & 16.0 & 17.1 & 10.7 & 26.0 & $8 \%$ \\
\hline $\begin{array}{l}\text { Percent receiving the } \\
\text { LIS }\end{array}$ & $39 \%$ & $38 \%$ & $36 \%$ & $34 \%$ & $30 \%$ & \\
\hline
\end{tabular}


The percent of health plan members who reached the gap in this study fell within a broad range, likely due to the strict limitations for inclusion (i.e., fill in January, fill at mail order, diabetic medications only). In this study, the increase in the percentage of health plan members reaching the gap year over year may be due in part to the rising cost and increased availability of branded medications in the diabetic class. During the study period, there were a total of six branded medications that lost their patent and had generic medications launch, which increases competition and drives down the medication price. However, there were thirteen FDA approvals and brand medications that launched during this period. Brand medications are expensive and could increase spending to move people into the coverage gap. Figure 21 shows the movement of brand medications and patent losses in the market over the study period along with the percent of health plan members who reached the gap.

Figure 21. Percent of health plan members who reached the gap with brand launches and patent losses

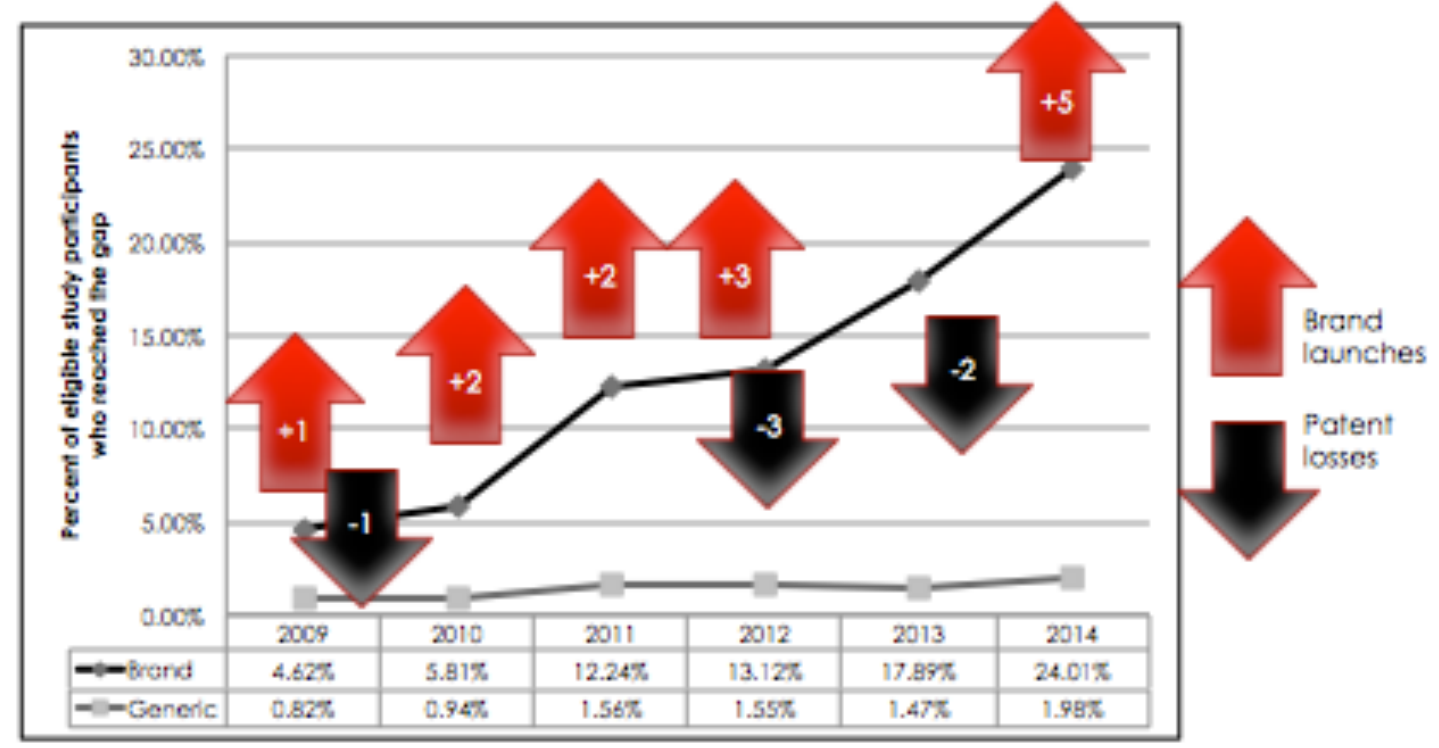


The 2014 Drug Trend Report produced by The Express Scripts Lab stated that the diabetes medication category experienced a higher per-member-per-year (PMPY) spend (\$358.93) than any other traditional therapy class among Medicare enrollees (The Express Scripts Lab, 2015). This represented a 26.4\% increase in trend over 2013, mainly due to unit cost (21.5\%). While popular branded drugs like nateglinide (brand name Starlix), pioglitazone (brand name Actos), pioglitazone hydrochloride/metformin hydrochloride (brand name Actosplus MET), glimepiride/pioglitazone (brand name Duetact), rosiglitazone (brand name Avandia) and repaglinide (brand name Prandin) lost patent and became available in a generic form during the study period, they were replaced by new branded medications. Table 29 contains the specific diabetic medications approved by the U.S. Food and Drug Administration during the study period.

Table 29. Insulin and diabetic medications approved between 2009 - 2014 (U.S. Food and Drug Administration, 2015)

\begin{tabular}{|l|l|l|l|}
\hline Drug Class & Brand Name & Generic Name & Approval Date \\
\hline DPP-4 & Onglyza & saxagliptin & July 2009 \\
\hline GLP-1 & Victoza & liraglutide & January 2010 \\
\hline DPP-4 & Kombiglyze XR & saxagliptin/metformin & November 2010 \\
\hline DPP-4 & Tradjenta & linagliptin & May 2011 \\
\hline DPP-4 & Juvisync & sitagliptin/simvistatin & October 2011 \\
\hline GLP-1 & Bydureon & exenatide synthetic & January 2012 \\
\hline DPP-4 & Jentadueto & linagliptin/metformin & February 2012 \\
\hline DPP-4 & Janumet XR & sitagliptin/metformin & February 2012 \\
\hline SGLT-2 & Farxiga & dapagliflozin & January 2014 \\
\hline GLP-1 & Tanzeum & abilglutide & May 2014 \\
\hline Insulin & $\begin{array}{l}\text { Afrezza } \\
\text { Inhalation }\end{array}$ & insulin human & June 2014 \\
& Powder & & \\
\hline SGLT-2 & Jardiance & empagliflozin & August 2014 \\
\hline GLP-1 & Trulicity & duglaglutide & September 2014 \\
\hline
\end{tabular}


In addition to the market entry of new branded products, highly utilized medications saw double-digit increases in unit-cost trend, including insulin glargine [rDNA origin] (brand name Lantus) and sitagliptin (brand name Januvia) (The Express Scripts Lab, 2015). Although insulin was excluded from adherence calculations in this study, the cost did contribute to a member reaching the coverage gap. As presented in Table 11, the average member cost of the brand diabetic medication index fill increased from $\$ 40.38$ in 2009 to $\$ 58.80$ in 2014 .

The graph in Figure 22 depicts the prescription price index of brand and generic medications utilizing 2008 dollars as a baseline. As stated in the 2014 Drug Trend Report, "from the base price of $\$ 100.00$ set in January 2008, in December 2014 prices for the most commonly used generic medications decreased to $\$ 37.13$ (in 2008 dollars) and prices for the most commonly used brand medications increased to $\$ 227.39$ (in 2008 dollars). In contrast, a market basket of commonly used household goods costing $\$ 100.00$ in 2008, as measured by the Bureau of Labor Statistics (BLS) Consumer Price Index, grew to only \$111.24 (in 2008 dollars) by December 2014 (The Express Scripts Lab, 2015). “ 
Figure 22. The Express Scripts Prescription Price Index (The Express Scripts Lab, 2015)

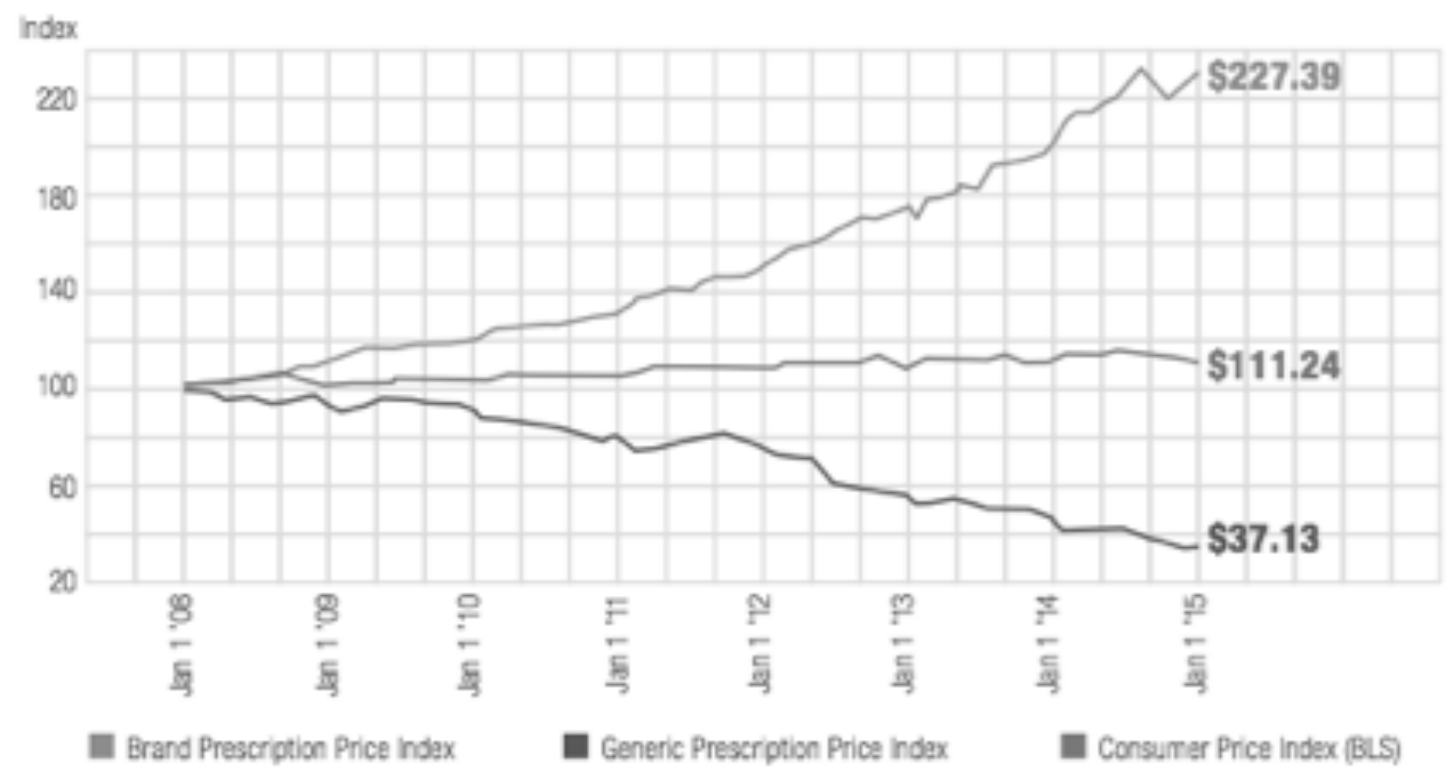

\section{Pre-coverage gap and within coverage gap medication adherence}

The first objective of the study was to evaluate diabetes medication adherence of health plan members before they reach the coverage gap and then while they are in the coverage gap. The study participants were separated into two cohorts by brand and generic medication utilization. The results of this study indicate that health plan members using brand medications decreased medication adherence once they entered the coverage gap for all years. The brand cohort also had a decrease in medication adherence year over year both before the health plan members entered the coverage gap and while in the coverage gap as presented in Figure 23. As shown in Table 9, the difference in the mean between the pre-gap adherence and within-gap adherence decreased from $2009(0.040)$ to 
2014 (0.030). In other words, although adherence was decreasing once health plan members entered the gap, the decline was less in 2014.

Figure 23. Medication adherence pre-coverage gap and while in the coverage gap for the brand cohort

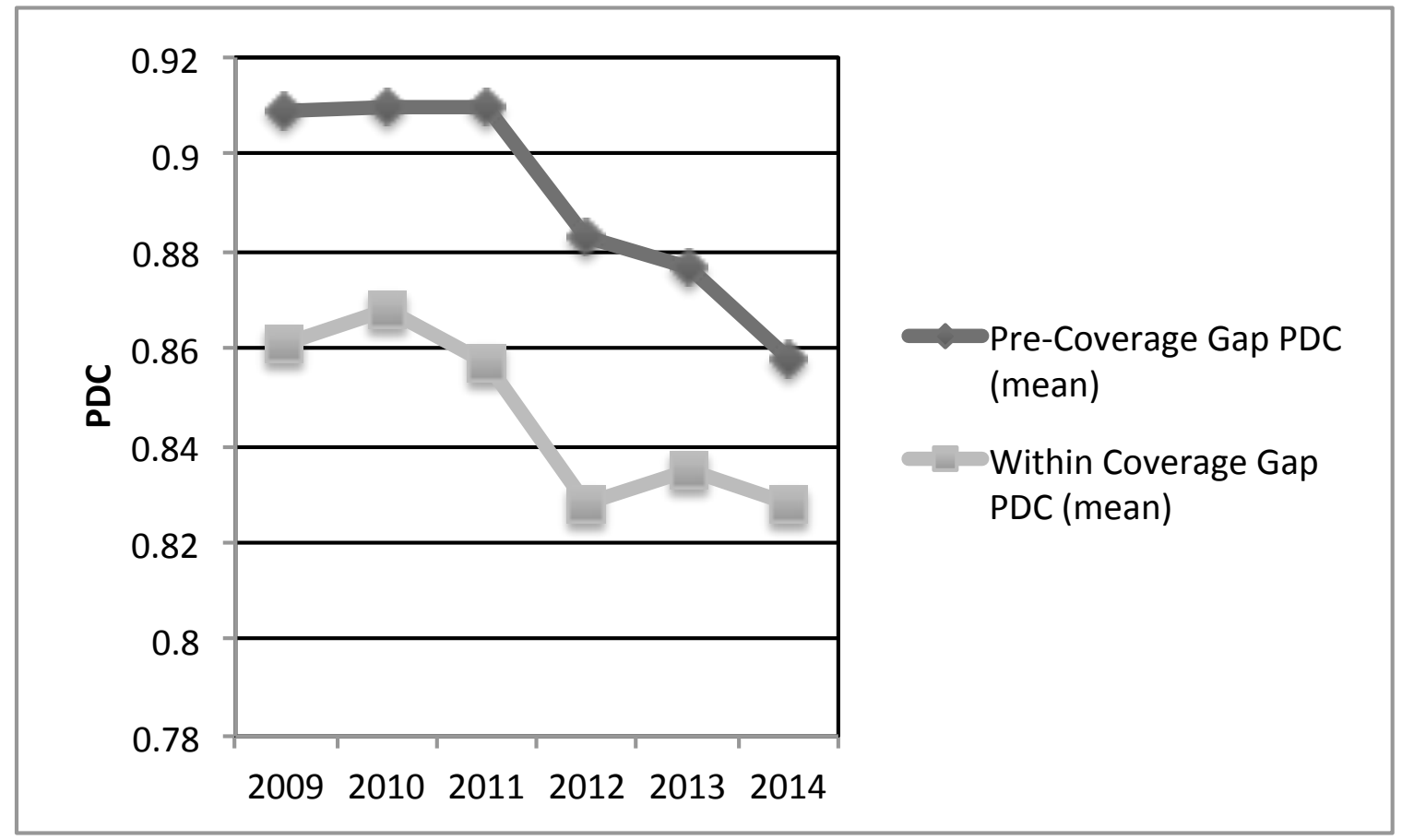

In the generic cohort, there was observed a decline in medication adherence once health plan members entered the coverage gap. Medication adherence prior to entering the coverage gap remained relatively flat year over year while adherence in the coverage gap fluctuated as shown in Figure 24. They also exhibited a decrease in the difference in the mean between the pre-gap adherence and within-gap adherence over the study period. As shown in Table 10, the mean for 2009 was 0.025 and decreased to 0.009 in 2014. 
Figure 24. Medication adherence pre-coverage gap and while in the coverage gap for the generic cohort

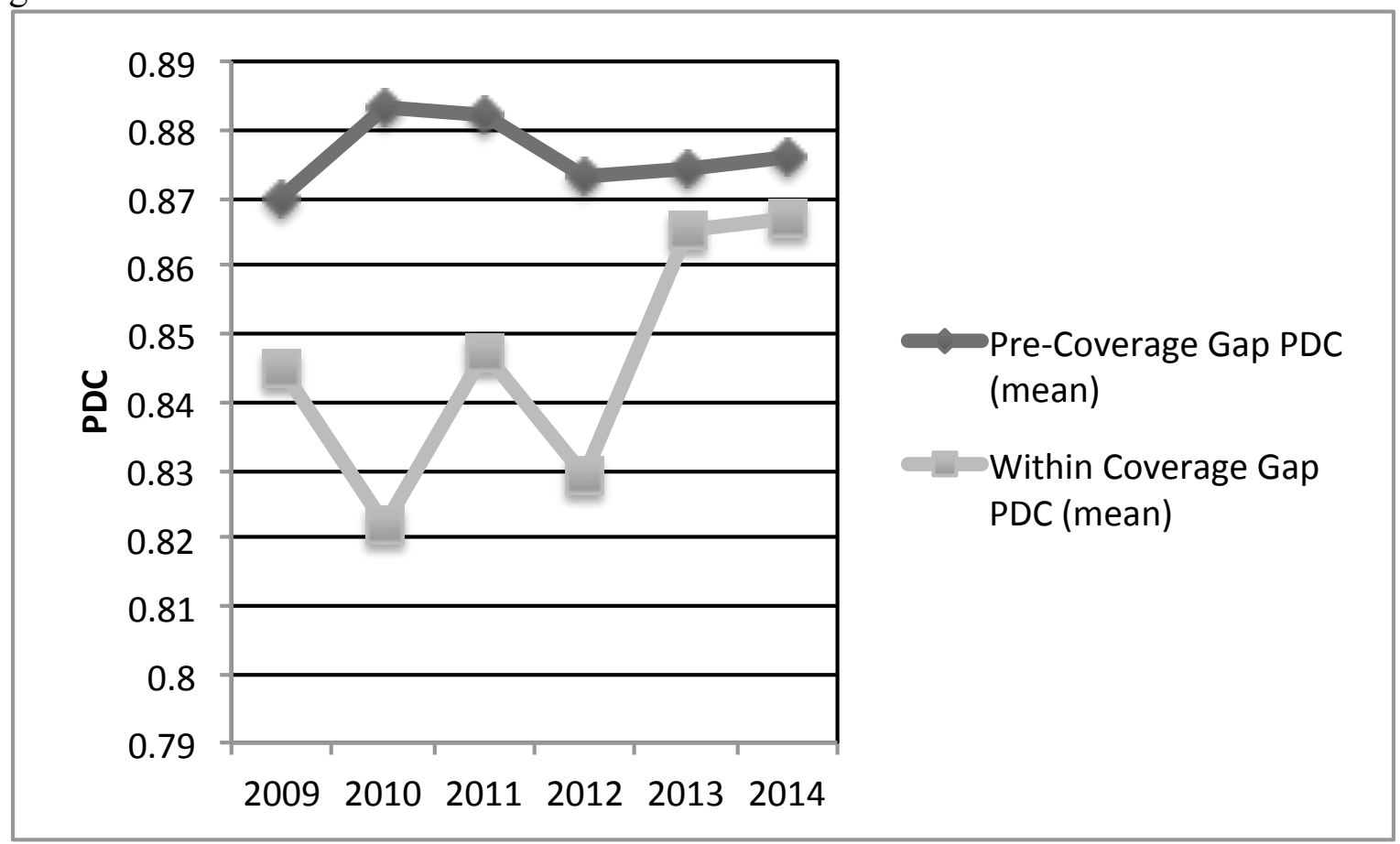

These findings are consistent with other published studies. A decrease in adherence to medications in the coverage gap was reported in studies conducted by $\mathrm{Gu}$, et al., Li, et al., Sacks, et al. and Zhang, et al (Gu, Zeng, Patel, \& Tripoli, 2010; Li et al., 2012; Sacks et al., 2013; Zhang et al., 2013). Researchers in Zhang's study also found that health plan members with generic coverage in the coverage gap decreased brand utilization significantly and generic utilization slightly, even though generic medications were covered under their prescription drug benefit. The Kaiser Family Foundation published a study finding that among Part D health plan members using medications for diabetes who reached the coverage gap in 2007,10 percent stopped taking their diabetes medication and 5 percent reduced their medication use (Hoadley, Hargrave, et al., 2008). 


\section{Demographics for propensity score matched groups}

The second objective was to compare diabetes medication adherence between two similar groups with differing benefit structures, one group with a gap in coverage as opposed to a group with no benefit changes within the year. Health plan members eligible for a low-income subsidy (LIS) were used as the control group. Health plan members with no benefit once reaching the coverage gap were used as the treatment group. The unmatched groups exhibited a great degree of variation. As a result, propensity score matching was conducted using age, race and sex as covariates. Both groups filled a diabetic medication at Humana's mail order pharmacy in January of the respective plan year. In addition, both groups had total drug costs that would qualify them to reach the Medicare Part D coverage gap in the respective plan years albeit the control group did not incur the actual costs associated with reaching the coverage gap. The control and treatment groups were equalized but some variability remained across years. Treatment group demographics across plan years are displayed in Tables 30-31.

Table 30. Demographics across plan years for treatment group using brand medications

\begin{tabular}{|l|l|l|l|l|l|l|}
\hline & $\mathbf{2 0 0 9}$ & $\mathbf{2 0 1 0}$ & $\mathbf{2 0 1 1}$ & $\mathbf{2 0 1 2}$ & $\mathbf{2 0 1 3}$ & $\mathbf{2 0 1 4}$ \\
\hline $\begin{array}{l}\text { Age } \\
\text { (mean) }\end{array}$ & 69.1 & 71.1 & 69.1 & 72.0 & 71.7 & 69.5 \\
\hline Female & $59.3 \%$ & $56.9 \%$ & $64.4 \%$ & $77.0 \%$ & $87.6 \%$ & $66.7 \%$ \\
\hline White & $77.8 \%$ & $72.4 \%$ & $84.2 \%$ & $92.2 \%$ & $88.4 \%$ & $82.2 \%$ \\
\hline
\end{tabular}

Table 31. Demographics across plan years for treatment group using generic medications

\begin{tabular}{|l|l|l|l|l|l|l|}
\hline & $\mathbf{2 0 0 9}$ & $\mathbf{2 0 1 0}$ & $\mathbf{2 0 1 1}$ & $\mathbf{2 0 1 2}$ & $\mathbf{2 0 1 3}$ & $\mathbf{2 0 1 4}$ \\
\hline $\begin{array}{l}\text { Age } \\
\text { (mean) }\end{array}$ & 70.6 & 70.7 & 70.7 & 68.6 & 69.3 & 68.5 \\
\hline Female & $50.0 \%$ & $61.5 \%$ & $69.1 \%$ & $58.2 \%$ & $70.1 \%$ & $66.2 \%$ \\
\hline White & $88.9 \%$ & $82.1 \%$ & $74.1 \%$ & $88.8 \%$ & $90.5 \%$ & $83.3 \%$ \\
\hline
\end{tabular}




\section{Medication adherence in control and treatment groups}

In general, the control group exhibited better medication adherence than the treatment group as displayed in Figures 25-26. These results align with other published studies. Researchers of a cross-sectional, retrospective analysis using claims from 20052006 showed LIS health plan members had better diabetic medication adherence $(62.5 \%)$ than non-LIS health plan members with no coverage gap benefit (57.7\%) (Yala et al., 2014). In a retrospective cohort study using data from the U.S. Renal Data System (USRDS), researchers examined medication adherence for Medicare-eligible dialysis patients (Park et al., 2014). The health plan members were separated into four groups: Cohort 1 consisted of those that did not reach the coverage gap, Cohort 2 entered the coverage gap, Cohort 3 had spending to qualify catastrophic coverage and Cohort 4 were LIS members. Health plan members in cohort 2 on diabetic medications had a significant decrease in medication adherence once they entered the coverage gap ( $72.4 \%$ vs. $57.9 \%)$. In addition, LIS members had statistically significant better diabetic medication adherence than non-LIS members who reached the coverage gap (67.8\% vs. $65.7 \%)$. 
Figure 25. Medication adherence of the control and treatment groups for the brand cohort

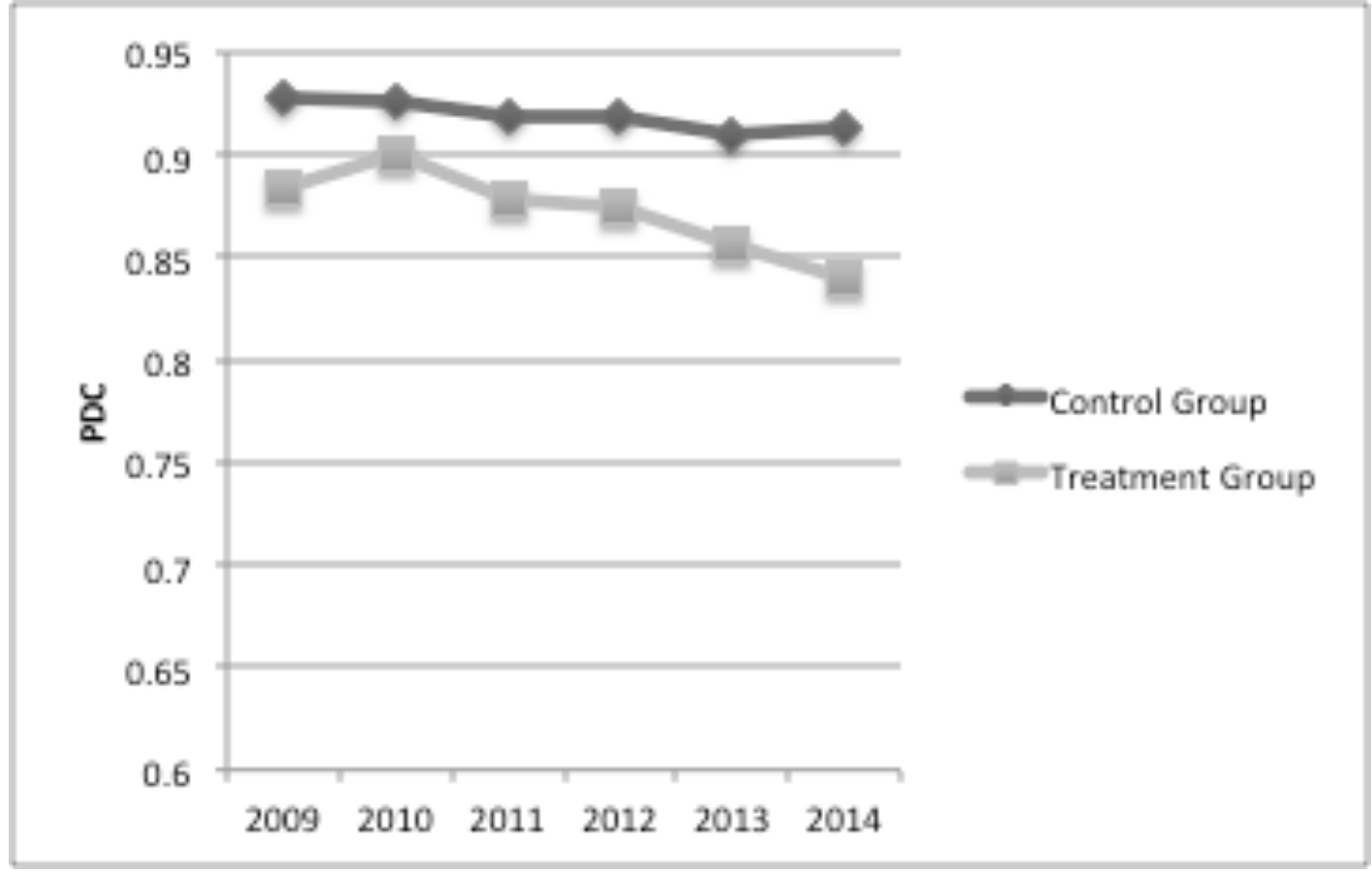

Figure 26. Medication adherence of the control and treatment groups for the generic cohort

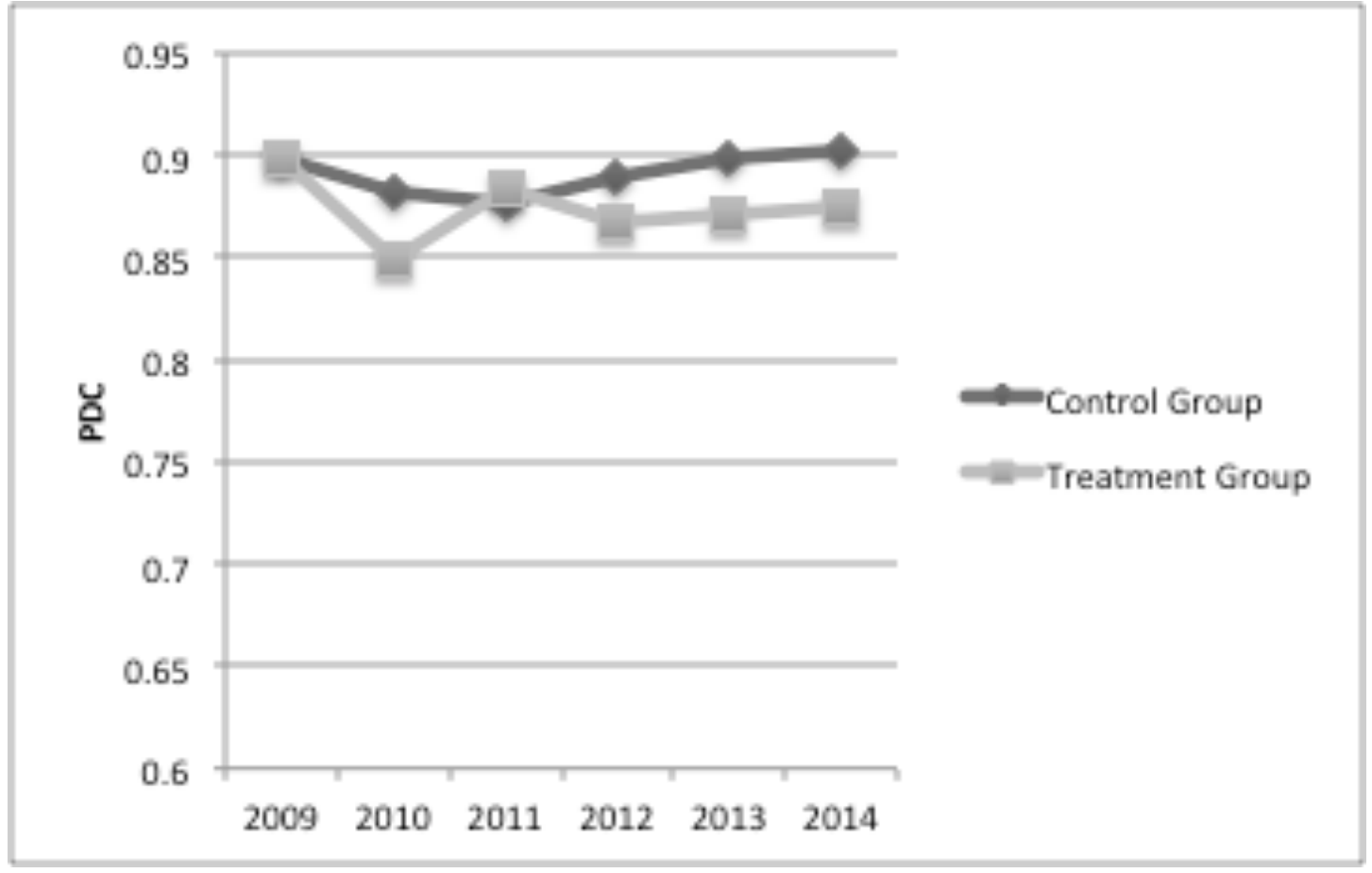




\section{Medication adherence across plan years}

The third objective was to examine the diabetes medication adherence trend over multiple years as the coverage gap is closed. As Table 3 outlined, the member cost share in the coverage gap began to decrease starting in 2010 but at the same time for most years the initial deducible, the threshold to enter the coverage gap and the catastrophic phase entry threshold all increased. This means health plan members faced the possibility of higher out of pocket costs before reaching the coverage gap.

The adherence for the control group, both brand and generic cohorts contained very little fluctuation year over year. Treatment group adherence for brand medications increased in year 2010 but then showed a decline each additional year. Treatment group adherence for generic medications fluctuated but showed an overall decrease from year 2009.

Although multiple studies have been conducted on the effect of the Part D coverage gap on medication adherence, few studies exist that examine the effect of closing the coverage gap. In a study conducted by Zeng, et al., researchers found adherence of health plan members in a national Pharmacy Benefit Manager (PBM) increased from 2010 to 2011 as the coverage gap initially began to close (Zeng et al., 2013). Additionally, in a study conducted by Brown, et al. initial data from another national PBM indicated adherence was modestly improving across plan years from 2009 to 2011 for brand medications (Brown et al., 2012).

A possible explanation for the finding that adherence is decreasing as the coverage gap is closing could be the limitation of the study population to mail order utilizers. In a literature search conducted by Cramer on findings from 1966 - 2003, 
overall oral diabetic medication adherence was found to range from $36-93$ percent (Cramer, 2004). In another literature review conducted by DiMatteo, mean diabetic medication adherence from 23 studies was found to be 67.5 percent (DiMatteo, 2004). Finally, Express Scripts reports average diabetic therapy adherence at 79.1 percent (2009) and 79.2 percent (2010) (The Express Scripts Lab, 2010, 2011). However, studies have shown when segregated, mail order utilizers have higher adherence than health plan members who fill at retail pharmacies. In 2011, Khandelwal, et al. noted no significant adherence difference in 90-day at retail verses mail order utilization except in the diabetic medication class (80.2 vs. 83.1 percent) (Khandelwal et al., 2011). Researches using diabetic patient data from Kaiser Permanente Northern California reported similar results, mail order (84.7 percent) versus retail pharmacy (76.9 percent) (Duru et al., 2010). Finally, in 2014 researchers presented data showing a significant difference in diabetic medication adherence in mail order (90.9 percent) versus retail (66.8 percent) (Iyengar \& Lefrancois, 2014). By limiting the study population to mail order utilizers who already exhibit a high medication adherence, the opportunity to identify significant changes in adherence may have been hindered.

However, the study findings indicate a decrease in adherence rather than the expected increase associated with reducing the coverage gap cost barrier. Although the coverage gap amount was decreasing during the study period, there were additional cost pressures from medication price inflation, increases in benefit caps and a downturn in the economy. As noted in the 2011 Drug Trend Report, "intensity, changes in adherence to medication, has suffered during the recent economic downturn as some patients have reacted to financial stress by foregoing their medications or taking them less frequently 
than prescribed to save money. We anticipate that intensity will increase as the economy improves." (The Express Scripts Lab, 2012)

Finally, cost is only one determinant of patient adherence. Piette, et al. described the cost-adherence relationship as "modified by contextual factors, including patients' characteristics (e.g., age, ethnicity, and attitudes toward medications), the type of medications they are using (e.g., the complexity of dosing and the drug's clinical target), clinician factors (e.g., choice of first-line agent and communication about medication costs), and health system factors (e.g., efforts to influence clinicians' prescribing and to help patients apply for financial assistance programs) (Piette, Heisler, Horne, \& Caleb, 2006)."

\section{Strengths and Limitations}

Evidence from the literature suggests that health plan members reduce the use of medications while in the coverage gap. This study is one of only a few to examine health plan data while the coverage gap is closing due to the ACA and the only one to cover six years.

The study design accounts for different types of effects that can introduce biases in our estimates. First, in assessing objective 1 (medication adherence rates during the gap), eligible health plan members were used as their own controls. Since the same cohort of patients is observed before and after the intervention, this reduces potential bias introduced due to differences in beneficiary characteristics between the study periods.

Second, this study used the pre-post-with-a-comparison-group design to assess objectives 2 and 3 , the strongest quasi-experiment observational study design. The benefit to this 
approach was that the drug coverage in the control group did not change in the pre-gap and within-gap periods, while treatment groups were exposed to a sudden increase in medication price. Even though the control group was different in socioeconomic status from the treatment groups, all groups had similar baseline trends in diabetic medication use.

The study is not without limitations. The use of retrospective claims data implies that the study is affected by limitations related to secondary data sources. One significant limitation is the assumption that filled prescriptions were taken as prescribed. Another limitation of claims data is the lack of visibility into physician dispensed samples or cash

prescriptions. This study was limited to only one health plan, although the health plan had the second largest national share of Medicare Part D membership during the study period. This study was also limited to health plan members using diabetic medications at Humana's mail order facility and therefore may not generalize to the broader population.

\section{Findings and recommendations for future research}

The results of this study indicate that being in the coverage gap was a significant indicator of a decrease in adherence for health plan members on brand diabetic medications. This was apparent when evaluating pre-gap versus within-gap adherence and when the cohort was compared to a control group. Although the generic cohort did not show significant differences for all years, the cohort did show a decrease in adherence while in the coverage gap. Both cohorts also exhibited a decrease in the difference between pre-gap verses within-gap adherence from 2009 to 2014, which could indicate the closing of the coverage gap is beginning to have an effect on within-gap behavior. In 
other words, in later years health plan members had a less significant drop in adherence rates once they entered the coverage gap and this could be due to the ACA lessening the impact of the coverage gap.

While the study findings showed a decrease rather than an increase in the treatment group medication adherence year over year, the results did indicate no significant changes in the control group. The expectation would be that once the coverage gap is fully closed in 2020, the treatment group would exhibit similar behavior. Both groups exhibited high adherence overall suggesting the mail order dispensing channel could have an effect on adherence.

Limiting the population to mail order utilizers was an unintended potentially important variable in this study. Studies have shown that mail order utilizers have considerably higher adherence than health plan members who utilize retail pharmacies. One reason for higher adherence at mail order could be the automatic refill option available at many mail order pharmacies where refills are shipped without the health plan member requesting it. This could result in an inflated adherence rate because the medication is shipped whether the member needs it or not. It should be noted that Humana's mail order pharmacy does not offer automatic refills for Medicare Part D members. They do have reminder calls but the health plan member must take some action on their part and opt in to order a refill.

Because dispensing channel was an unintended variable, it was not included in the theoretical model discussion, specifically Andersen's Behavioral Model. In the model, enabling resources are factors that support or impede the use of health services. For example, the type of health insurance is considered an enabling resource. Dispensing 
channel would be classified as an enabling resource in the model considering it affects the method by which a health plan member accesses their medication. It would be considered a highly mutable factor because it can be changed from a retail pharmacy to mail order or even to a physician office or hospital.

Future research should examine the effect of the coverage gap once it is fully closed in 2020 and it is possible to take an even broader view of the coverage gap impact. As evidence from the literature suggests, decreases in medication adherence can result in poor clinical outcomes, which can increase the total cost of care. Therefore, in addition to adherence, future research should be directed at studying the impact of the Medicare Part D coverage gap on utilization of other health care services like diagnostic tests, physician office utilization, emergency room visits and hospitalizations. Finally, more attention should be given to the dispensing channel and it's possible effect on medication adherence. Future research should focus on whether mail order utilization promotes better medication adherence or if better adherers choose mail order.

\section{Summary}

This study is important and relevant because it is one of the only studies identified that utilized 6 years of data related to the closing of the coverage gap. While the results failed to show the closing of the coverage gap as having an impact on improving adherence in this group over multiple years, it was determined that entering the coverage gap decreased adherence and the additional cost pressures in the form of increasing coverage limits and price inflation may have offset any good closing the coverage gap is doing in these diabetic patients. This study also 
highlights the complexity of medication adherence and the need for additional research in this area. 


\section{REFERENCES}

American Diabetes Association. (2015). Standards of Medicare Care in Diabetes- 2015. Glycemic targets. Section 6. Diabetes Care, 38(1), S33-S40.

Andersen, R. M. (1995). Revisiting the Behavioral Model and Access to Medical Care: Does it Matter? Journal of Health and Social Behavior, 36(1), 1-10.

Austin, P. C. (2008a). A critical appraisal of propensity score matching in the medical literature from 1996 to 2003. Statistics in Medicine, 27, 2037-2049.

Austin, P. C. (2008c). A report card on propensity-scre matching in the cardiology literature from 2004 to 2006: results of a systematic review. Circulation: Cardiovascular Quality and Outcomes, 1, 62-67.

Austin, P. C. (2014). A comparison of 12 algorithms for matching on the propensity score. Statistics in Medicine, 33, 1057-1069.

Bailey, C. J., \& Kodack, M. (2011). Patient adherence to medication requirements for therapy of type 2 diabetes. Int J Clin Pract, 65(3), 314-322. doi: 10.1111/j.17421241.2010.02544.x

Brown, C., Ward, M., \& Yihua, X. (2012). Impact of the Affordable Care Act on Medication Adherence in a Population of Medicare Part D Beneficiaries. Academy of Managed Care Pharmacy.

Burns, T., \& Shaw, J. (2007). Is It Acceptable For People to Be Paid to Adhere to Medication? British Medical Journal, 335(7613), 233-234.

Case Management Society of America. (2006). CASE MANAGEMENT ADHERENCE GUIDELINES VERSION 2.0: Guidelines from the Case Management Society of America for improving patient adherence to medication therapies. Retrieved from: http://www.cmsa.org/portals/0/pdf/cmag2.pdf

Center for Medicaid and Medicare Services. (2014). Understanding True Out-Of-Pocket (TrOOP) Costs. from https://www.cms.gov/Outreach-andEducation/Outreach/Partnerships/downloads/11223-P.pdf

Cramer, J. A. (2004). A systematic review of adherence with medications for diabetes. Diabetes Care, 27(5), 1218-1224.

D'Agostino , R. (1998). Propensity Score Methods for Bias Reduction in the Comparison of a Treatment to a Non-randomized Control Group. Statistics in Medicine(17), $2265-2281$.

DiMatteo, M. R. (2004). Variations in patients' adherence to medical recommendations: a quantitative review of 50 years of research. Med Care, 42(3), 200-209.

Duru, O. K., Schmittdiel, J. A., Dyer, W. T., Parker, M. M., Uratsu, C. S., Chan, J., \& Karter, A. J. (2010). Mail-order pharmacy use and adherence to diabetes-related medications. Am J Manag Care, 16(1), 33-40.

Elixhauser, A., Steiner, C., Harris, D., \& Coffey, R. (1998). Comorbidity measures for use with administrative data. Med Care, 36, 8-27. 
Gibson, T. B., Ozminkowski, R. J., \& Goetzel, R. Z. (2005). The effects of prescription drug cost sharing: a review of the evidence. American Journal of Managed Care, 11(11), 730-740.

Giuffrida, A., \& Torgerson, D. J. (1997). Should we pay the patient? Review of financial incentives to enhance patient compliance. $B M J, 315(7110), 703-707$.

Goldman, D. P. (2004). Pharmacy Benefits and the Use of Drugs by the Chronically Ill. JAMA, 19(291), 2344-2350.

Green, J. (2013). Executive Update on Medication Quality Measures in Medicare Part D Plan Ratings 2013: Pharmacy Quality Alliance.

Gu, Q., Zeng, F., Patel, B. V., \& Tripoli, L. C. (2010). Part D coverage gap and adherence to diabetes medications. Am J Manag Care, 16(12), 911-918.

Ho, D., Imai, K., King, G., \& Stuart, E. (2007). Matching as nonparametric preprocessing for reducing model dependence in parametric causal inference. Political Analysis, $15,199-236$.

Ho, P., Bryson, C., \& Rumsfeld, J. (2009). Medication Adherence: its importance in cardiovascular outcomes. Circulation: Cardiovascular Quality and Outcomes, 119(23), 3028-3035. doi: 10.1161/CIRCULATIONAHA.108.768986

Hoadley, J., Hargrave, E., Cubanski, J., \& Neuman, T. (2008). The Medicare Part D Coverage Gap: Costs and Consequences in 2007. Kaiser Family Foundation.

Hoadley, J., Summer, L., Hargrave, E., \& Cubanski, J. (2011). Understanding the effects of the Medicare Part D Coverage Gap in 2008 and 2009. Kaiser Family Foundation.

Hoadley, J., Summer, L., Hargrave, E., \& Cubanski, J. (2013). Medicare Part D Prescription Drug Plans: The Marketplace in 2013 and Key Trends, 2006-2013. Kaiser Family Foundation.

Hoadley, J., Thompson, J., Hargrave, E., Cubanski, J., \& Neuman, T. (2008). The Coverage Gap. Kaiser Family Foundation.

Hosmer, D., \& Lemeshow, S. (1989). Applied Logistic Regression. New York, NY: John Wiley \& Sons.

Iyengar, R., \& Lefrancois, A. (2014). Association of Pharmacy Dispensing Channel with Medication Adherence among Medicare Part D Patients having Comorbid Conditions. Paper presented at the Academy of Managed Care Pharmacy 26th Annual Meeting.

Khandelwal, N., Duncan, I., Rubinstein, E., Ahmed, T., Pegus, C., Murphy, P., \& Kudrak, K. E. (2011). Medication adherence for 90-day quantities of medication dispensed through retail and mail order pharmacies. Am J Manag Care, 17(11), e427-434.

Lau, D. T., \& Nau, D. P. (2004). Oral Antihyperglycemic Medication Nonadherence and Subsequent Hospitalization Among Individuals with Type 2 diabetes. Diabetes Care, 27(9), 2149-2153.

Li, P., McElligott, S., Bergquist, H., Schwartz, J. S., \& Doshi, J. A. (2012). Effect of the Medicare Part D coverage gap on medication use among patients with hypertension and hyperlipidemia. Ann Intern Med, 156(11), 776-784, W-263, W264, W-265, W-266, W-267, W-268, W-269. doi: 10.7326/0003-4819-156-11201206050-00004 
Martin, B. C., Wiley-Exley, E. K., Richards, S., Domino, M. E., Carey, T. S., \& Sleath, B. L. (2009). Contrasting Measures of Adherence with Simple Drug Use, Medication Switching, and Therapeutic Duplication. Ann Pharmacother, 43(1), 36-44.

McCarthy, R. (1998). The price you pay for the drug not taken. Business and Health, 16(10), 27-32.

McKenzie, M. C., Lenz, T. L., Gillespie, N. D., \& Skradski, J. J. (2012). Medication Adherence Improvements in Employees Participating in a Pharmacist-Run Risk Reduction Program. Innovations in Pharmacy, 3(4).

Medicare Payment Advisory Commission. (2012). Report to the Congress: Medicare Payment Policy (pp. 352). Washington, D.C.

Medicare Payment Advisory Commission. (2013). Report to the Congress: Medicare Payment Policy (pp. 343). Washington, D.C.

Medicare Payment Advisory Commission. (2014). Report to the Congress: Medicare Payment Policy (pp. 365). Washington, D.C.

Medicare Payment Advisory Commission. (2015). Report to the Congress: Medicare Payment Policy (pp. 374). Washington, D.C.

. The Medicare Prescription Drug Benefit Fact Sheet. (2014) (September 14, 2014 ed.): The Henry J. Kaiser Family Foundation.

Mehta, S. N., Nansel, T. R., Volkening, L. K., Butler, D. A., Haynie, D. L., \& Laffel, L. M. (2015). Validation of a contemporary adherence measure for children with Type 1 diabetes: the Diabetes Management Questionnaire. Diabetic Medicine, 32(9), 1232-1238.

Nau, D. Proportion of Days Covered (PDC) as a Preferred Method of Measuring Medication Adherence.

New England Healthcare Institute. (2009). Thinking Outside the Pillbox: A System-wide Approach to Improving Patient Medication Adherence for Chronic Disease.

Normand, S., Landrum, M., Guadagnoli, E., Ayanian, J., Ryan, T., Cleary, P., \& McNeil, B. (2001). Validating recommendations for coronary angiography following an acute myocardial infarction in the elderly: a matched analysis using propensity scores. Journal of Clinical Epidemiology, 54, 387-398.

Osterberg, L., \& Blaschke, T. (2005). Adherence to medication. N Engl J Med, 353(5), 487-497. doi: 10.1056/NEJMra050100

Park, H., Rascati, K., Lawson, K., Barner, J., Richards, K., \& Malone, D. (2014). Therapy Among Medicare Part D Beneficiaries on Dialysis: Comparisons of Benefit Type and Benefit Phase. Journal of Managed Care Pharmacy, 20(8), 862876.

Patterson, M. E., Blalock, S. J., Smith, A. J., \& Murray, M. D. (2011). Associations between prescription copayment levels and beta-blocker medication adherence in commercially insured heart failure patients 50 years and older. Clin Ther, 33(5), 608-616. doi: 10.1016/j.clinthera.2011.04.022

Pharmacist's Letter/Prescriber's Letter. (June 2015). PL Detail-Document, Drugs for Type 2 Diabetes.

Piette, J., Heisler, M., Horne, R., \& Caleb, A. (2006). A conceptually based approach to understanding chronically ill patients' responses to medication cost pressures. Social Science Medicine, 62(4), 846-857. 
Priebe, S., Sinclair, J., Burton, A., Marougka, S., Larsen, J., Firn, M., \& Ashcroft, R. (2010). Acceptability of offering financial incentives to achieve medication adherence in patients with severe mental illness: a focus group study. $J$ Med Ethics, 36(8), 463-468. doi: 10.1136/jme.2009.035071

Q1Group. 2016-2006 Medicare Part D Standard Benefit Model Plan Parameters. from http://www.q1medicare.com/PartD-TheMedicarePartDOutlookAllYears.php

Rosenbaum, P. R., \& Rubin, D. B. (1983). The Central Role of the Propensity Score in Observational Studies for Casual Effects. Biometrika, 70(1), 41-55.

Rosenbaum, P. R., \& Rubin, D. B. (1985). Constructing a control group using multivariate matched sampling methods that incorporate the propensity score. The American Statistician, 39, 33-38.

Sacks, N. C., Burgess, J. F., Jr., Cabral, H. J., Pizer, S. D., \& McDonnell, M. E. (2013). Cost sharing and decreased branded oral anti-diabetic medication adherence among elderly Part D Medicare beneficiaries. J Gen Intern Med, 28(7), 876-885. doi: 10.1007/s11606-013-2342-3

Sundar, H. (2015). The High Price of Low Adherence to Medication: The Express Scripts Lab.

The Express Scripts Lab. (2010). 2009 Drug Trend Report.

The Express Scripts Lab. (2011). 2010 Drug Trend Report.

The Express Scripts Lab. (2012). 2011 Drug Trend Report.

The Express Scripts Lab. (2015). 2014 Drug Trend Report.

Touchette, D., \& Shapiro, N. (2008). Medication Compliance, Adherence, and Persistence: Current Status of Behavioral and Educational Interventions to Improve Outcomes. Journal of Managed Care Pharmacy, 14(6), S2-10.

U.S. Food and Drug Administration. (2015). FDA-Approved Diabetes Medicines. from http://www.fda.gov/ForPatients/Illness/Diabetes/ucm408682.htm

Yala, S., Obidiugwu, K., Ettner, S., Turk, N., Mangione, C., \& Brown, A. (2014). Patterns of prescription drug expenditures and medication adherence among medicare part D beneficiaries with and without the low-income supplement. $B M C$ Health Services Research, 14(664). doi: doi:10.1186/s12913-014-0665-3

Zeng, F., Patel, B. V., \& Brunetti, L. (2013). Effects of coverage gap reform on adherence to diabetes medications. Am J Manag Care, 19(4), 308-316.

Zhang, Y., Baik, S. H., \& Lave, J. R. (2013). Effects of Medicare Part D coverage gap on medication adherence. Am J Manag Care, 19(6), e214-224. 


\section{APPENDIX I}

\section{GLOSSARY}

Coverage gap: A benefit phase in Medicare Part D where the enrollee incurs all or most of the drug cost until they hit a certain coverage limit

Low-income subsidy (LIS): Medicare beneficiaries who qualify for assistance in paying for their Part D monthly premium, annual deductible, coinsurance, and copayments

Medicare Advantage prescription drug plan (MAPD): a drug benefit offered as part of a Medicare replacement plan

Medicare Modernization Act (MMA): Legislation passed in 2003 allowing Medicare expansion in 2006 to offer voluntary outpatient prescription drug coverage

Pharmacy Quality Alliance (PQA): A consensus-based, multi-stakeholder membership organization committed to improving health care quality and patient safety with a focus on the appropriate use of medications

Prescription drug plan (PDP): A drug benefit offered as a supplement to standard Medicare 
Propensity score matching (PSM): A statistical matching technique that attempts to estimate the effect of a treatment, policy or other intervention by accounting for the covariates that predict receiving the treatment

Proportion of days covered (PDC): A measurement period covered by prescription claims for the same medication or another in its therapeutic category

True-out-of-pocket-spending (TrOOP): Only costs incurred and paid by the health plan member, those prescription drug costs that count toward the annual out- of-pocket threshold that health plan members must reach before the catastrophic drug benefit phase begins 


\section{APPENDIX II}

\section{UNIVERSITY OF LOUISVILLE INSTITUTIONAL REVIEW BOARD DETERMINATION}

\section{UNIVERSIYY OF LOUISVILLE}

Human Subjects Protection Program Office

MedCenter One - Suite 200

501 E. Broadway

Louisville, KY 40202-1798

Office: 502.852.5188 Fax: 502.852.2164

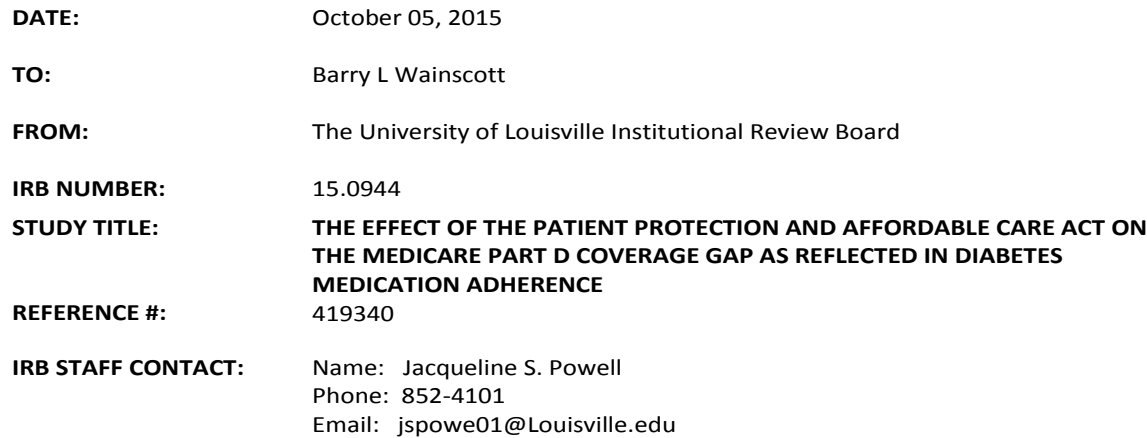

This study was reviewed on 10/02/2015 by the Chair of the Institutional Review Board and approved through the Expedited Review Procedure, according to 45 CFR 46.110(b), since this study falls under Category 5: Research involving materials (data, documents, records, or specimens) that have been collected, or will be collected solely for non-research purposes (such as medical treatment or diagnosis)

This study was also approved through 45 CFR 46.116 (D), which means that it has been granted a waiver of informed consent because it meets the following criteria:

- $\quad$ The research involves no more than minimal risk to the subjects.

- $\quad$ The waiver or alteration will not adversely affect the rights and welfare of the subjects.

- The research could not practicably be carried out without the waiver or alteration.

- Whenever appropriate, the subjects will be provided with the additional pertinent information after participation.

The following items have been approved:

\begin{tabular}{|l|l|l|l|}
\hline \multicolumn{5}{|l|}{ Submission Components } \\
\hline Extracted Fields & Version 1.0 & $09 / 25 / 2015$ & Approved \\
\hline Protocol Methods & Version 1.0 & $09 / 23 / 2015$ & Approved \\
\hline HIPAA Complete Waiver & Version 1.2 & $09 / 30 / 2015$ & Approved \\
\hline
\end{tabular}

This study now has final IRB approval from 10/02/2015 through 10/01/2016. 


\section{Site Approval}

If this study will take place at an affiliated research institution, such as KentuckyOne Health, Norton Healthcare or University of Louisville Hospital, permission to use the site of the affiliated institution may be necessary before the research may begin. If this study will take place outside of the University of Louisville Campuses, permission from the organization should be obtained before the research may begin. Failure to obtain this permission may result in a delay in the start of your research.

\section{Privacy \& Encryption Statement}

The University of Louisville's Privacy and Encryption Policy requires such information as identifiable medical and health records: credit card, bank account and other personal financial information; social security numbers; proprietary research data; dates of birth (when combined with name, address and/or phone numbers) to be encrypted. For additional information: http://security.louisville.edu/PolStds/ISO/PS018.htm.

\section{Implementation of Changes to Previously Approved Research}

Prior to the implementation of any changes in the approved research, the investigator will submit any modifications to the IRB and await approval before implementing the changes, unless the change is being made to ensure the safety and welfare of the subjects enrolled in the research. If such occurs, a Protocol Deviation/Violation should be submitted within five days of the occurrence indicating what safety measures were taken, along with an amendment to revise the protocol.

\section{Unanticipated Problems Involving Risks to Subjects or Others (UPIRTSOs)}

In general, these may include any incident, experience, or outcome, which has been associated with an unexpected event(s), related or possibly related to participation in the research, and suggests that the research places subjects or others at a greater risk of harm than was previously known or suspected. UPIRTSOs may or may not require suspension of the research. Each incident is evaluated on a case by case basis to make this determination. The IRB may require remedial action or education as deemed necessary for the investigator or any other key personnel. The investigator is responsible for reporting UPIRTSOs to the IRB within 5 working days. Use the UPIRTSO form located within the iRIS system to report any UPIRTSOs.

\section{Continuation Review Requirements}

You are responsible for submitting a continuation review 30 days prior to the expiration date of your research study. Investigators who allow their study approval to expire have committed significant non-compliance with federal regulations. Such lapses may require reporting to federal agencies, a program audit by compliance auditors to ensure that subjects were not enrolled during the expired period, and may lead to findings of serious and continuing noncompliance if expiration were to occur a second time.

The committee will be advised of this action at a regularly scheduled meeting.

If you have any questions, please contact the HSPPO at (502) 852-5188 or hsppofc@louisville.edu

Thank you for your submission.

Full Accreditation since June 2005 by the Association for the Accreditation of Human Research Protection Programs, Inc.

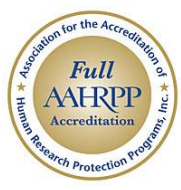


Sincerely,

Pite $m$ Lusadn

Peter M. Quesada, Ph.D., Chair

Social/Behavioral/Educational Institutional Review Board

PMQ/jsp

Full Accreditation since June 2005 by the Association for the Accreditation of

Human Research Protection Programs, Inc.

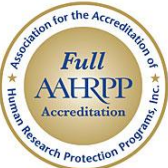




\section{CURRICULUM VITAE}

NAME: Jennifer Forristal

ADDRESS: School of Public Health and Information Sciences

485 Gray Street

Louisville, KY 40202

DOB: $\quad$ Pittsburgh, PA - September 8, 1977

\section{EDUCATION\&TRAINING}

B.A., Chemistry

University of Louisville

Graduated 2003

M.P.H., Public Health

University of Louisville

Graduated 2012

Ph.D., Public Health Sciences, Health Management \& Systems Science University of Louisville

Anticipated 2015

PROFESSIONAL EXPERIENCE

2006 - Present Humana, Inc.

Program Manager, Innovative Contracting

Pharmacy Business Development Consultant, HPS Analytics

Procurement Supply Chain Consultant, RightSource

Pharmacy Rebates Consultant, Finance

Medical/Pharmacy Commodity Analyst, Procurement

$2005-2006 \quad$ Solectron Global Services

$2004-2005 \quad$ Kindred Pharmacy Services

$2001-2004 \quad$ Flint Ink 